\title{
EVALUATION OF SOME PROCEDURES RELEVANT TO THE DETERMINATION OF TRACE ELEMENTAL COMPONENTS IN BIOLOGICAL MATERIALS BY DESTRUCTIVE NEUTRON ACTIVATION ANALYSIS
}

Donald Louis Berry

Based on a Ph.D. thesis submitted to Iowa State University

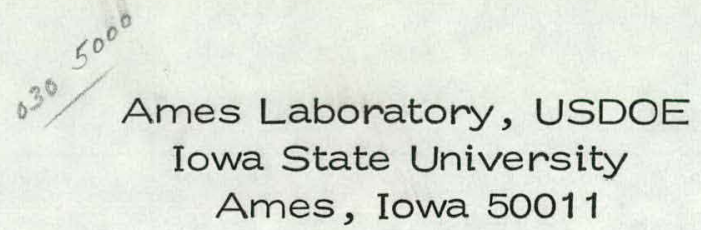

Date Transmitted: January 1979

PREPARED FOR THE U.S. DEPARTMENT OF ENERGY UNDER CONTRACT NO. W-7405-eng-82

This report was prepared as an account of work This repod by the United States Government. Neither the United States nor the United States Department of Energy, nor any of their employees, nor any of their contractors, subcontractors, or their employees, makes any warranty, express or implied, or assumes any legat liability or responsibility for the accuracy, completeness or usefulness of any information, apparatus, product or process disclosed, or represents that its use would not infringe privately owned rights. 


\section{DISCLAIMER}

This report was prepared as an account of work sponsored by an agency of the United States Government. Neither the United States Government nor any agency Thereof, nor any of their employees, makes any warranty, express or implied, or assumes any legal liability or responsibility for the accuracy, completeness, or usefulness of any information, apparatus, product, or process disclosed, or represents that its use would not infringe privately owned rights. Reference herein to any specific commercial product, process, or service by trade name, trademark, manufacturer, or otherwise does not necessarily constitute or imply its endorsement, recommendation, or favoring by the United States Government or any agency thereof. The views and opinions of authors expressed herein do not necessarily state or reflect those of the United States Government or any agency thereof. 


\section{DISCLAIMER}

Portions of this document may be illegible in electronic image products. Images are produced from the best available original document. 


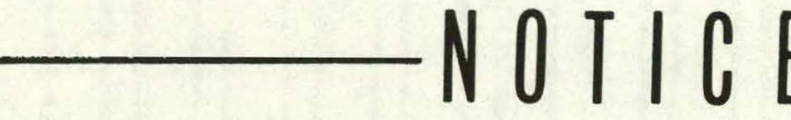

This report was prepared as an account of work sponsored by the United States Government. Neither the United States nor the United States Department of Energy, nor any of their employees, nor any of their contractors, subcontractors, or their employees, makes any warranty, express or implied, or assumes any legal liability or responsibility for the accuracy, completeness, or usefulness of any information, apparatus, product or process disclosed, or represents that its use would not infringe privately owned rights.

Available from: National Technical Information Service

U. S. Department of Commerce

P.O. Box 1553

Springfield, VA 22161

Price: Microfiche $\$ 3.00$ 
Evaluation of some procedures relevant to the determination of trace elemental components in biological materials by destructive neutron activation analysis

\author{
by \\ Donald Louis Berry \\ A Dissertation Submitted to the \\ Graduate Faculty in Partial Fulfillment of \\ The Requirements for the Degree of \\ DOCTOR OF PHILOSOPHY \\ Department: Chemistry \\ Major: Analytical Chemistry
}

Approved:

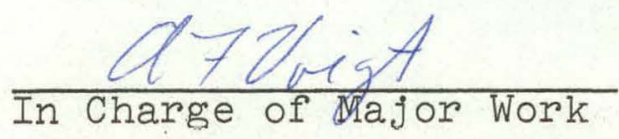

For the Major Department

For the Graduate College

Iowa State University

Ames, Iowa

1978 
TABLE OF CONTENTS

Page

Abstract

I. INTRODUCTION

$\stackrel{x}{I}$

A. Trace Elements in Biological Systems i

II. LITERATURE REVIEW

A. Destructive Neutron Activation Analysis

B. Pre-Irradiation Treatment

C. Destruction of Organic Matter

D. Decontamination and Concentration

III. EXPERIMENTAL

A. Physical Facilities and Equipment

B. Counting and Data Processing Equipment

C. Experimental Procedures

D. DNAA Procedure

IV. RESULTS AND DISCUSSION

A. Objectives 143

B. OutIine of Proposed DNAA Scheme 143

C. Freeze-Drying

D. Capsulation $14 \dot{5}$

E. Sample Containers 150

F. Wet Ashing 1.55

G. Decontamination and Separation $\quad 165$

H. Compatibility Tests 183

I. Analyses of Biological Materials 190 
J. Conclusions

202

K. Future Work

204

V. BIBLIOGRAPHY

206

VI. ACKNOWLEDGEMENTS

218 


\section{LIST OF TABLES}

Page

Table 1. Trace element content of reference man

Table 2. Experimentally determined elements in human blood serum

Table 3. Diseases and conditions in which analysis of trace elements may be of aid in diagnosis, or disclose abnormalities

Table 4. Elements for which AA has a detection Ilmit lower than $\mathrm{AE}$ by at least a factor of 5

Table 5. Elements for which $A E$ has a detection limit lower than $\mathrm{AA}$ by at least $a$ factor of 5

Table 6. Elements for which $A E$ and $A A$ have comparable detection limits

Table 7. Detection limits for nonflame spectrophotometric methods

Table 8. Approximate detection limits for elements detectable by DC arc sources

Table 9. Colorimetric lower detection limits 25

Table 10. Fluorimetric lower detection limits . 27

Table 11. X-ray fluorescence detection limits 29

Table 12. SSMS calculated limits of detection for some elements in an iron matrix

Table 13. Estimated detection limits for SSMS with photographic plates as detectors

Table 14. Sensitivities for elements by chelation coupled with CIMS

Table 15. Detection limits with anodic stripping voltammetry and differential pulse polarography

Table 16. Metal chelates separated by GC 
Table 17. NAA detection limits $\cdots \quad 40$

Table 18. Elemental detection limits in blood with instrumental NAA 43

Table 19. Criteria for an ideal analytical method . 45

Table 20. Bolling points of halides which could form during wet ashing

Table 21. Stock solutions used in the production of carriers and standards

Table 22. Elements comprising tracer solution used in capsulation experiments

Table 23. Composition of typical carrier solutions used throughout the project

Table 24. Elements tested for sorption on various HAP materials

Table 25. Elements 1dentified in digest remaining after "wet ashing" CFQ T21 quartz

Table 26. Ratio of specific activities of nuclides common to Amercil Quartz and Biological Samples

Table 27. Quantitative results for elements common to $\mathrm{CFQ} T 21$ quartz, bovine liver, and U.K. master mix blood

Table 28. Masses of elements contained in $4.81 \mathrm{~g}$ of two kinds of synthetic silica glass

Table 29. Summary of ampoule test results. The "pre-sealed" recoveries indicated that the same amount of each nuclide was in the test and reference vials. The remaining recoveries indicated that relative to the reference vials no material was lost from the test vials during sealing, heating and decanting

Table 30. Recovery of tracer nuclides following a $\mathrm{HNO}_{3} / \mathrm{HClO}_{4}$ wet ashing procedure 
Table 31. Recovery of tracer nuclides following a $\mathrm{H}_{2} \mathrm{SO}_{4} / \mathrm{H}_{2} \mathrm{O}_{2}$ wet ashing procedure as a temperature between $70^{\circ} \mathrm{C}$ and $90^{\circ} \mathrm{C}$

Table 32. Recovery of tracers from a $\mathrm{H}_{2} \mathrm{SO}_{4} / \mathrm{H}_{2} \mathrm{O}_{2}$ wet ashing medium and the modified Gorsuch device

Table 33. Characteristics of HAP materials . 167

Table 34. Recovery of nuclides from three HAP materials

Table 35. Elution characteristics of AG2-X8 bromide form with various solvents

Table 36. Elution characteristics of AG2-X8 chloride form with varlous solvents

Table 37. Percent removal of interfering activities from solutions of irradiated standard biological materials

Table 38. Ashing and HAP recoveries from a medium containing $\mathrm{H}_{2} \mathrm{O}_{2}$

Table 39. Summary of analyses of United Kingdom Master Mix Blood

Table 40. Summary of analyses of NBS Bovine Liver SRM 1577 
Figure 2. System for the capsulation of heat sensitive biological materials

Figure 3. Bethge apparatus as modified by Gorsuch for the controlled destruction of organic materials

Figure 4. Gorsuch apparatus as modified to enhance the retention of trace components and to facilitate the introduction of reagents during the "wet-ashing" of organic matrices

Figure 5. Chromatographic support column

Figure 6. Integral sodium elution curve for HAP materials using hydrochloric and nitric acids

Figure 7. Spectrum of digested bovine liver sample without decontamination processing: sample decay time $=2.84$ days; sample counting time $=0.50 \operatorname{hour}(\mathrm{s})$

Figure 8. Spectrum of digested bovine liver decontaminated by elution through AG2-X8, in the bromide form, with concentrated hydrobromic acid eluent: sample decay time $=1.49$ days; sample counting time $=1.85$ hours

Figure 9. Spectrum of digested bovine liver sample without decontamination processing: sample decay time $=5.91$ days; sample counting time $=2.00$ hours

Figure 10. Spectrum of digested bovine liver decontaminated by elution through Af2-X8, in the bromine form, with concentrated hydrobromic acid eluent: sample decay time $=5.30$ days; sample counting time $=3.06$ hours 
Evaluation of some procedures relevant to the determination of trace elemental components in blological materials by destructive neutron activation analysis ${ }^{1}$

\title{
Donald Louls Berry
}

\section{Under the supervision of Adolf F. Voigt \\ From the Department of Chemistry Iowa State University}

\begin{abstract}
This work details the development of a simplified procedure for the analysis of blological materials by destructive neutron activation analysis (DNAA). The sample manipulations preceding gamma ray assay were investigated as five specific stages of processing: 1) pre-irradiation treatment; 2) sample irradiation; 3) removal of the organic matrix; 4) removal of interfering radioactivities; and 5) concentration and separation of analyte activities. Each stage was evaluated with respect to susceptibility to sample. contamination, loss of trace elemental components, and compatibility with other operations in the overall DNAA procedures.
\end{abstract}

$I_{\text {Work performed for the U.S. Department of Energy }}$ under. Contract No. IS-T-82I. 
A system was designed and tested for capsulation, irradiation, and decantation of heat sensitive biological materials. Experimental results verified the quantitative retention of trace elemental components and the lack of gross contamination of the sample by the container material.

Several acid/oxidant "wet-ashing" systems were evaluated for inclusion in a DNAA procedure. A vessel for the controlled destruction of biological materials was designed and evaluated in conjunction with a sulfuric acid/hydrogen peroxide $(90 \%)$ ashing medium. The ashing system effectively destroyed the matrices of bovine liver and blood without the loss of trace elemental components.

Hydrated antimony pentaoxide (HAP) and alumina were evaluated for the removal of radio-nuclides of sodium and potassium, respectively, from solutions of irradiated biological materials. Due to incompatibilities between ashing media and the optimum conditions for the employment of HAP, the sodium separation was generally not as effective as typically reported in the literature. Relationships between HAP synthesis parameters and properties of the final material were considered. Alumina was found to be marginaliy acceptable as part of a DNAA procedure:

The bromide, chloride and acetate forms of the ion exchanger $A G 2-X 8$ were investigated w1th respect to concentrating analyte ionic species and removing interfering 
radio-nuclides. The bromide form was most effective both for concentrating analyte species and removing interferences.

A complete DNAA procedure was proposed and evaluated for the analysis of standard bovine liver and blood samples. The DNAA system was effective for the determination of As, Cu, $\mathrm{Fe}, \mathrm{Hg}, \mathrm{Mo}, \mathrm{Rb}, \mathrm{Sb}, \mathrm{Se}$, and $\mathrm{Zn}$ without yield determinations and with a minimum turn-around time of approximately 3 days. 


\section{INTRODUCTION}

\section{A. Trace Elements in Blological Systems}

Advances in medical technology have demonstrated that the proper biological functioning of an organism is critically dependent on the presence of elements other than the basic organic building blocks: carbon, hydrogen, oxygen, nitrogen, and phosphorus (1-3). If methods of the proper sensitivity are employed, most elements in the geochemical environment can be detected in plant and animal tissue (4). In biological systems, these elements are present at either bulk or trace concentration levels. The definition of what constitutes a trace amount varies somewhat throughout the ilterature. From a biological or physiological perspective, Schroeder and Nason specify that an element exists at the trace level in the human body if that element comprises less than .01\% of the body's total mass (1). More generally, Varcoe (5) states that it is commonly accepted that 100 parts-per-million (ppm) in any sample is the upper limit of a trace amount. Whichever definition is used, to date, approximately fifty elements have been detected and identified as "trace elements" in the human body.

Trace elements are in turn divided into two classes, essential and nonessential. Essential elements are those 
which are required for the normal functioning of the body: Nonessential elements are, conversely, those trace elements detected in the human body which have not been found to serve in any physiological capacity. It should be noted that in 1971 there were roughly twelve trace elements recognized as essential (I), and presently some sixteen trace elements are so classified (5). With the development of more sensitive analytical techniques, the number of essential trace elements is expected to increase.

The body regulates the levels of the various elements, both essential and nonessential, within specific limits. Abnormalities associated with the essential trace elements may be caused by a specific deficiency (from dietary inadequacies, imbalances, or the result of other diseases) or accumulation of innately toxic concentrations of trace elements from the environment. While disease states due to the deficiency, as opposed to the excess of an essential trace element, are more prevalent, practically all concern with nonessential trace elements is with respect to the physiological effects of accumulating excesses. Since excursions in the concentrations of trace elements outside of normal ranges are theoretically detectable by an appropriately sensitive technique, the diagnosis and treatment of human disorders based on changes in the levels of trace elements in the body is feasible. 


\section{Trace elements identifled}

Table 1 lists the relative amounts of essential and nonessential trace elements in the body and blood of "Reference Man" (6). A listing of the concentrations of essential and nonessential elements which have been found In the serum of normal human subjects is provided in Table 2. The values listed in Table 2 can be accepted only as an indication of the levels of traces elements which can be found in the human body $(1,7-9)$. In reality, the actual bodily concentrations of trace components will certainly be a function of the subject's environment. Sophisticated techniques are needed which can accurately distinguish these environmental differences, thus enabling one to establish a basis for the "normal" concentration.

\section{Function of trace elements}

Trace elements are involved in many biological

functions. Evidence supports the role of trace elements as active components in enzyme systems, transport mechanics, tissue synthesis, and bone formation (10). Trace elements are probably significant with respect to longevity (11). Correlation of trace elemental variations with diseases began as soon as their importance in metabolism was recognized.

Most trace elements are not found in the body as free lons, but exist as complexes with various stabilities. 
Table I. Trace element content of reference man ${ }^{a}$

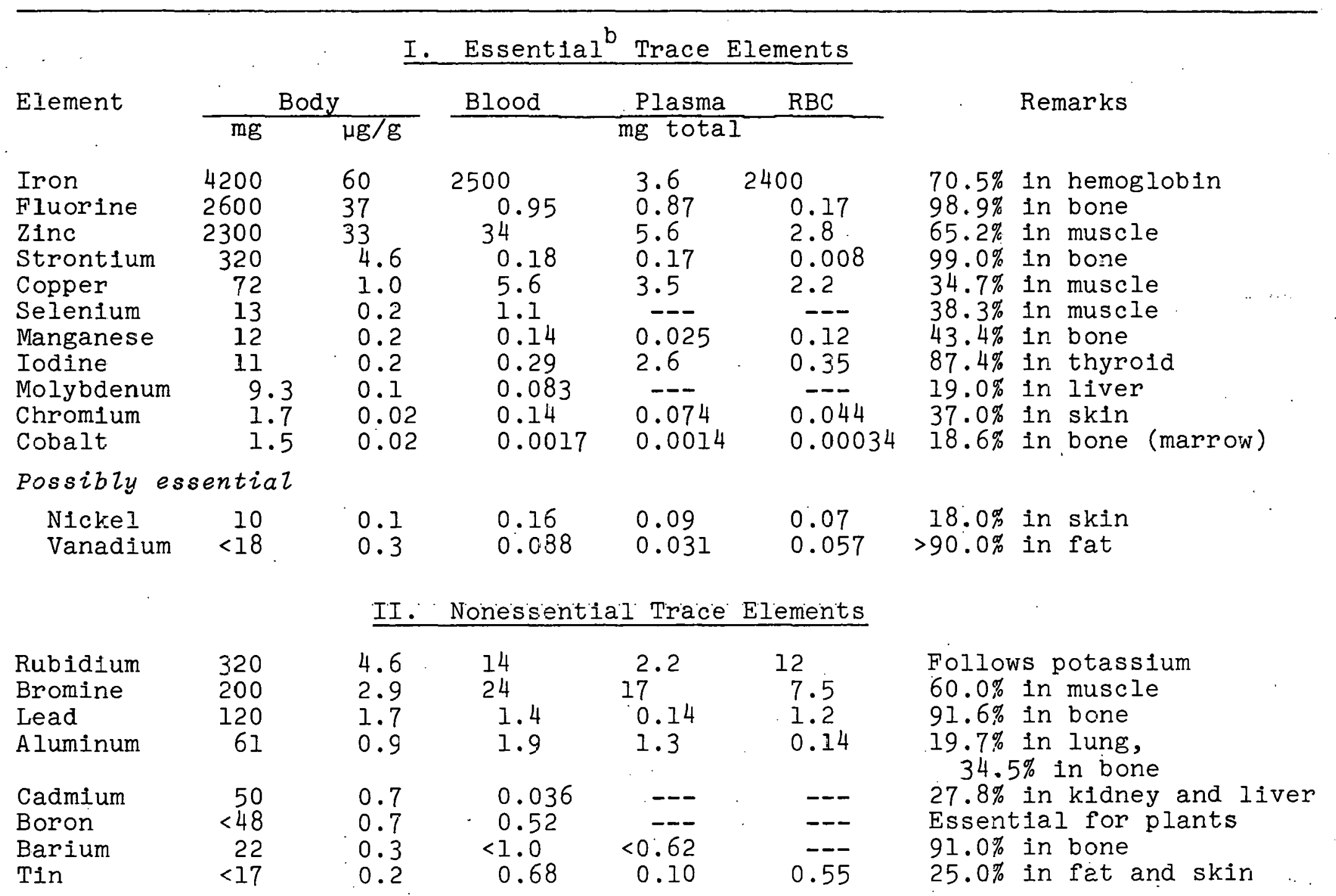




\begin{tabular}{|c|c|c|c|c|c|c|}
\hline $\begin{array}{l}\text { Mercury } \\
\text { Titanium }\end{array}$ & $\begin{array}{r}13 \\
9\end{array}$ & $\begin{array}{l}0.2 \\
0.1\end{array}$ & $\begin{array}{l}0.026 \\
0.14\end{array}$ & $\begin{array}{l}0.009 \\
0.12\end{array}$ & $\begin{array}{l}0.017 \\
0.08\end{array}$ & $\begin{array}{l}69.2 \% \text { in fat and muscle } \\
49.1 \% \text { in lung and lymph } \\
\text { nodes }\end{array}$ \\
\hline Gold & $<10$ & 0.1 & 0.00021 & --- & -- & $52.0 \%$ in bone \\
\hline Antimony & $? 7.9$ & 0.1 & 2.024 & 0.16 & --- & $25.0 \%$ in bone \\
\hline Cesium & 1.5 & 0.02 & 0.015 & -- & -- & Follows potassium \\
\hline Uranium & 0.09 & 0.001 & 0.0046 & --- & --- & $65.5 \%$ in bone \\
\hline Beryllium & 0.036 & --- & $<0.00052$ & -- & -- & $75.0 \%$ in bone \\
\hline Arsentc & $? 18$ & 0.3 & 2.5 & $<0.093$ & 0.59 & Follows phosphorus \\
\hline Lithium & 2.2 & 0.03 & 0.10 & 0.093 & 0.061 & $50.0 \%$ in muscle \\
\hline Z1rcontum & 420 & 6.0 & 13 & 1.2 & 12 & $67.0 \%$ in fat \\
\hline Niobium & $? 110$ & 1.6 & 13 & $<0.25$ & 13 & $26.0 \%$ in fat \\
\hline Tellurium & $? \quad 8.2$ & 0.1 & 0.18 & 0.09 & 0.078 & Probably in bone \\
\hline
\end{tabular}

${ }^{a}$ Data of Bowen (3) ard Tipton (6).

$\mathrm{b}_{\text {As }}$ of 1971. 
Table 2. Experimentally determined elements in human blood s.erum

\section{Element}

Serum Concentration $\mu \mathrm{g} / \mathrm{ml}$

Reference

Essential

Bulk

$\begin{array}{lc}\mathrm{Ca} & 2.8 \\ \mathrm{Cl} & 1,000 \\ \mathrm{~K} & 1,700 \\ \mathrm{Mg} & 13 \\ \mathrm{Na} & 3,250 \\ \mathrm{P} & 0.50 \\ \mathrm{~S} & 5,400\end{array}$

Essential

Trace

$\begin{array}{lc}\mathrm{Co} & 0.00018 \\ \mathrm{Cr} & 0.02-0.05 \\ \mathrm{Cu} & 1.16 \\ \mathrm{~F} & 0.028 \\ \mathrm{Fe} & 1.14 \\ \mathrm{I} & 0.0029-0.11 \\ \mathrm{Mn} & 0.0083 \\ \mathrm{Mo} & 0.4 \\ \mathrm{~N} 1 & 0.0042 \\ \mathrm{Se} & 1.1 \\ \mathrm{~S} 1 & 7.0 \\ \mathrm{Sn} & 0.033 \\ \mathrm{~V} & 1.0 \\ \mathrm{Zn} & 0.98\end{array}$


Table 2. (Continued.)

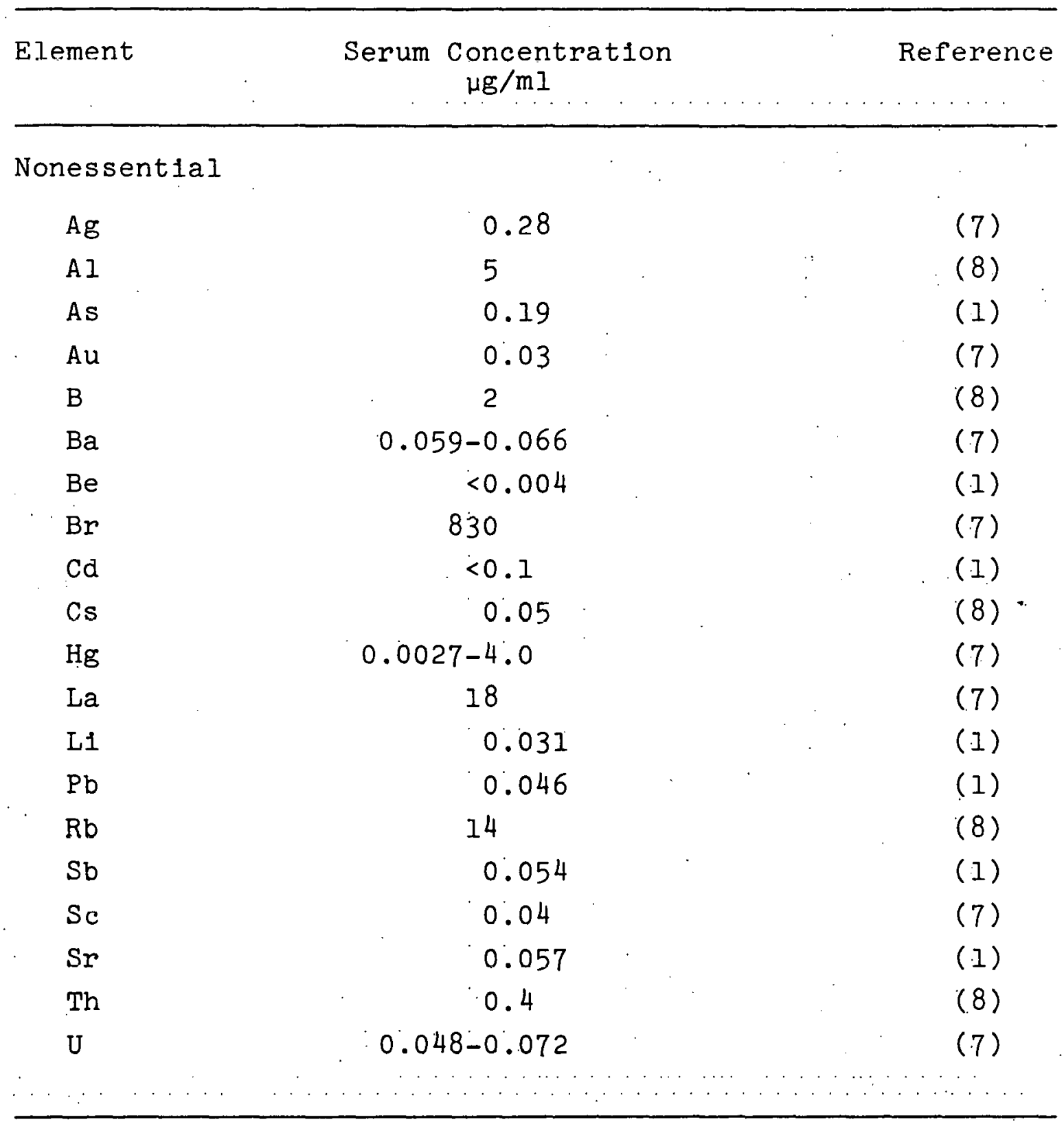


Through these stability constants, control is maintained over the concentrations of the trace elemental components in the fluids circulating throughout the body. Analyses for diagnostic purposes have been performed on both whole blood and serum - coagulated blood plasma. For elements which are largely contained within the cell (e..g., potassium, magnesium, iron, zinc, copper, manganese), the serum concentrations will not necessarily reflect the body content of those elements (1). For these elements, the concentrations in the red blood cells are a more reliable index. On the other hand, for elements which accumulate in bone (e.g., fluorine, strontium, lead, barium, beryllium) or in fat (e..g., vanadium, mercury, zirconium), both blood and plasma may be unreliable indicators of total body burden. For these elements, the analysis of a pathological specimen from the site of concentration would be optimum for the determination of total body load.

To determine general availabllity of trace elements to the body, analytical studies of the urine may be sufficient. If the amount of a trace element in the urine is normal, it may be presumed that the amount of that trace element ava1lable to the body is sufficlent (1). In the search for a spectfic disorder, the use of a more specialized fluid may be indicated (e. of the nervous system). Of the materials available for 
diagnostic analysis, blood, which contacts all tissues and organs, is the most pervasive and would most frequently yield values of trace components reflective of total body load.

3. Disease relationships

Correlations between abnormal concentrations of trace elements and various disease states have been extensively enumerated $(1,5)$. Usually, the trace element abnormality is a secondary effect of a disorder which may be effectively treated by correcting the concentration abnormality ( 5 ). In this particular situation, the analysis for a trace component can be of significant diagnostic value as an Indicator of a disorder.

Studies implicating trace elements in cardiovascular diseases and cancer, two of the leading causes of death each year in the United States, are numerous (10-26). Whether. the trace elements actually influence the course of the disease has not yet been definitely established. However, It has been shown that knowledge of trace element concentrations can be significant in understanding and diagnosing a. disease. In practice, it has also been shown that the examination of the concentrations of some trace elements can be useful in evaluating the course of treatment of some cancers (10). Specifically, changes in the concentration of copper in patients under treatment for tumors may precede 
by an appreciable amount of time any apparent clinical changes in the tumor. Other diseases for which trace element concentration relationships have been studied include: abnormal thyroid activity (27-34), rheumatoid arthritis $(35,36)$, hepatitis $(11,15-24)$, and diabetes mellitus $(I I, 37)$. A listing of disorders and conditions for which trace element analysis may aid in diagnosis is presented in Table 3 .

4. Analysis methods

The literature abounds with reports on the analysis of blood and serum for trace elements. Most of these analyses are limited to elements which are present at relatively high concentrations or are particularly sensitive to a specific analysis technique (5, p..2, 38-54). Lately, multielemental techniques have become more prevalent (54-57). AlI of these studies have illustrated that if a method is to be of value as a diagnostic tool, it must be capable of multi-elemental analysis, reproducible, relatively rapid, highly sensitive, specific, and suitable for automation.

The nature of a biological material presents a particularly troublesome problem which an analysis technique must be able to surmount: matrix interference is severe. The chosen method must be capable of multi-elemental determinations at the trace and subtrace level in the presence of several elements at macro-levels (See Table 2). 
Table 3. Diseases and condltions in which analysis of trace elements may be of ald in diagnosis, or disclose abnormalitie.s.

\begin{tabular}{|c|c|c|c|}
\hline Disease or Condition & $\begin{array}{l}\text { Deficlency } \\
\text { Present. }\end{array}$ & $\begin{array}{l}\text { Excess } \\
\text { Present }\end{array}$ & Reference \\
\hline $\begin{array}{l}\text { Acute Myocardial } \\
\text { Infarction } \\
\text { (Heart tissue) }\end{array}$ & $\begin{array}{l}\text { Co, } \mathrm{Cs}, \mathrm{K}, \\
\mathrm{Io}, \mathrm{P}, \\
\mathrm{lb}, \mathrm{Zn}\end{array}$ & $\begin{array}{l}\mathrm{Br}, \mathrm{Cu}, \mathrm{Ce}, \\
\mathrm{La}, \mathrm{Na}, \mathrm{Sb} \\
\mathrm{S}\end{array}$ & (12) \\
\hline $\begin{array}{l}\text { Myocardial Infarction } \\
\text { (Serum) }\end{array}$ & $\mathrm{Zn}$ & $\begin{array}{l}\mathrm{Cu}, \mathrm{Mn}, \mathrm{Ni} \\
\text { Mo, }\end{array}$ & $\begin{array}{l}(13,14 \\
11,15)\end{array}$ \\
\hline Allergic States & Co? & & (1) \\
\hline Arterial Hypertension & $\mathrm{Zn} ?$ & $\underline{\mathrm{Cd}}^{\mathrm{a}}$ & (1) \\
\hline $\begin{array}{l}\text { Atherosclorosis } \\
\text { Ischemic symptoms } \\
\text { Indolent ulcers }\end{array}$ & $\begin{array}{l}\frac{\mathrm{Cr}}{\mathrm{Zn}} \\
\mathrm{Zn}\end{array}$ & & (1) \\
\hline Alcoholism (Chronic) & $\mathrm{Zn}, \mathrm{Mn}$ & & (I) \\
\hline $\begin{array}{l}\text { Cancer } \\
\text { Leukemia } \\
\text { Lung } \\
\text { Prostate } \\
\text { Breast } \\
\text { Hodgkins }\end{array}$ & & $\begin{array}{l}\mathrm{BI} \\
\underline{\mathrm{Fe}}, \frac{\mathrm{Ni}}{\mathrm{Cu}}, \underline{\mathrm{Cr}(\mathrm{VI})} \\
\mathrm{Cu} \\
\mathrm{Cu}\end{array}$ & $\begin{array}{r}(16,23, \\
24)^{2} \\
\quad(11) \\
(25) \\
(10)\end{array}$ \\
\hline Cartilaginous Malformations & Mn? & & (1) \\
\hline Chronic Infections & $\mathrm{Zn}$ & & (I) \\
\hline $\begin{array}{l}\text { Cirrhosis of Liver, Adult } \\
\text { Juvenile }\end{array}$ & $\mathrm{Zn}$ & $\mathrm{Cu}, \mathrm{Ag}$ & (1) \\
\hline $\begin{array}{l}\text { Collagen Diseases } \\
\text { Disseminated lupus } \\
\text { Rheumatoid arthritis } \\
\text { Hydralazine disease }\end{array}$ & $\begin{array}{l}\mathrm{Mn} ? \\
\mathrm{Mn}\end{array}$ & $\mathrm{Cu}$ & (1) \\
\hline $\begin{array}{l}\text { Diabetes Mellitus, juvenile } \\
\text { Mild, adult }\end{array}$ & $\begin{array}{l}\mathrm{Cr} \\
\mathrm{Cr}\end{array}$ & & ( 1 ). \\
\hline
\end{tabular}

anderlined elements are considered causal factors in the diseases. 
Table 3. (Continued)

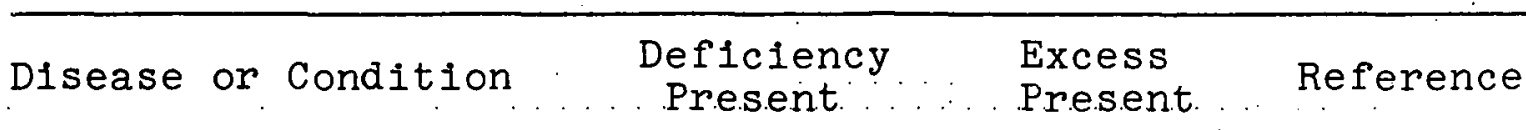

Dietary (Bantu) Siderosis

Fe, $\mathrm{Pb}$

Dental Caries

Sr, Mo?, F

Excessive Proteinuria

$\mathrm{Zn}$

Hepatolenticular

Degeneration

$\mathrm{Cu}, \mathrm{Ag}$

Hypoproteinemia

$\mathrm{Cu}$

Idiopathic Hemochromatosis

Fe, $\mathrm{Pb}$

Ill-defined Asthenia

$\mathrm{Pb}$

Ill-defined Neurosis

$\mathrm{Pb}$

Kwashiorkor

$\mathrm{Cr}, \mathrm{Mn}, \mathrm{Cu}$,
$\mathrm{Zn}, \mathrm{Mo}$ ?

Malnutrition

$$
\underset{\mathrm{Zn}, \mathrm{Mn}, \mathrm{Cu},}{\mathrm{Cu}}
$$

Milkman's Syndrome (ital itai disease)

$\underline{\mathrm{Cd}}$

Oral Contraceptives

$\mathrm{Zn}$

Parkinsonism

Mn?

Postoperative Convalescence $\mathrm{Zn}$

Pregnancy Toxemia

$\mathrm{Zn}, \mathrm{Mn}$ ?, Cr, Cu? $\underline{\mathrm{Zn}}$

Prolonged Intravenous Feeding

$\mathrm{Zn}, \mathrm{Mn}, \mathrm{Cu}$

Psoriasis

$\mathrm{Zn}$

Renal (Xanthine)

Calcul1

Mo 
Table 3.: (Continued)

Disease or Condition . Deficiency Present..... Present. Reference

Renal Insufficlency

$\mathrm{Zn}$

(I)

Rheumatold Arthritis

$$
\mathrm{Zn}, \mathrm{Fe}, \mathrm{Pb} \mathrm{Cu}, \mathrm{Ba}, \mathrm{Cs} \text {, }
$$

Sen1le Osteoporosis

$\underline{\mathrm{Sr}}$

Tuberculos1s, Active

$\mathrm{Zn}$

Wilson's Disease

$\mathrm{Cu}$

Wound Healing (Slow)

$\underline{\mathrm{zn}}$

Cholesterol Synthesis (Decreased)

$\mathrm{V}, \mathrm{Fe}$

Cholesterol Synthesis (Increased)

$\mathrm{Cr}, \mathrm{Mn}$

Hepatitis

$\mathrm{Zn}, \mathrm{Mn}$

Mental Retardation

(Juvenile)

$\mathrm{Pb}$ 
A discussion of some of the trace: elemental techniques most frequently cited in the literature for the analysis of biological materials follows.

a. Atomic emission, atomic absorption, atomic

fluorescence Atomic emission ( $A E$ ), atomic absorption $(\mathrm{AA})$, and atomic fluorescence (AF) are complimentary spectroscopic methods of analysis capable of determining elements at the trace level. Of the three techniques, only. AE has a practical simultaneous multi-elemental capability. Intrinsicaliy, the sensitivity of $\mathrm{AF}$ measurements are greater than those of AA because of the benefits gained from signal amplification and increased source intensity (58). Table 4 contains a listing of elements for which AA has a lower limit of detection than $A E$ by at least a factor of five. Those elements for which $A E$ has a lower limit of detection than $A A$ by at least a factor of five are listed in Table 5. Elements for which $\mathrm{AA}$ and $\mathrm{AE}$ have comparable limits of detection are listed in Table 6 . Reference to Table 2 indicates that for those trace elements in the human body which can be determined spectroscopically, the AA detection limits are equal to or lower than corresponding AE limits. This accounts for the early popularity of AA for the analysis of trace components in blological materials. 
Table 4. Elements for which AA has a detection limit lower than $\mathrm{AE}$ by a.t least a factor of $5^{\mathrm{a}}$

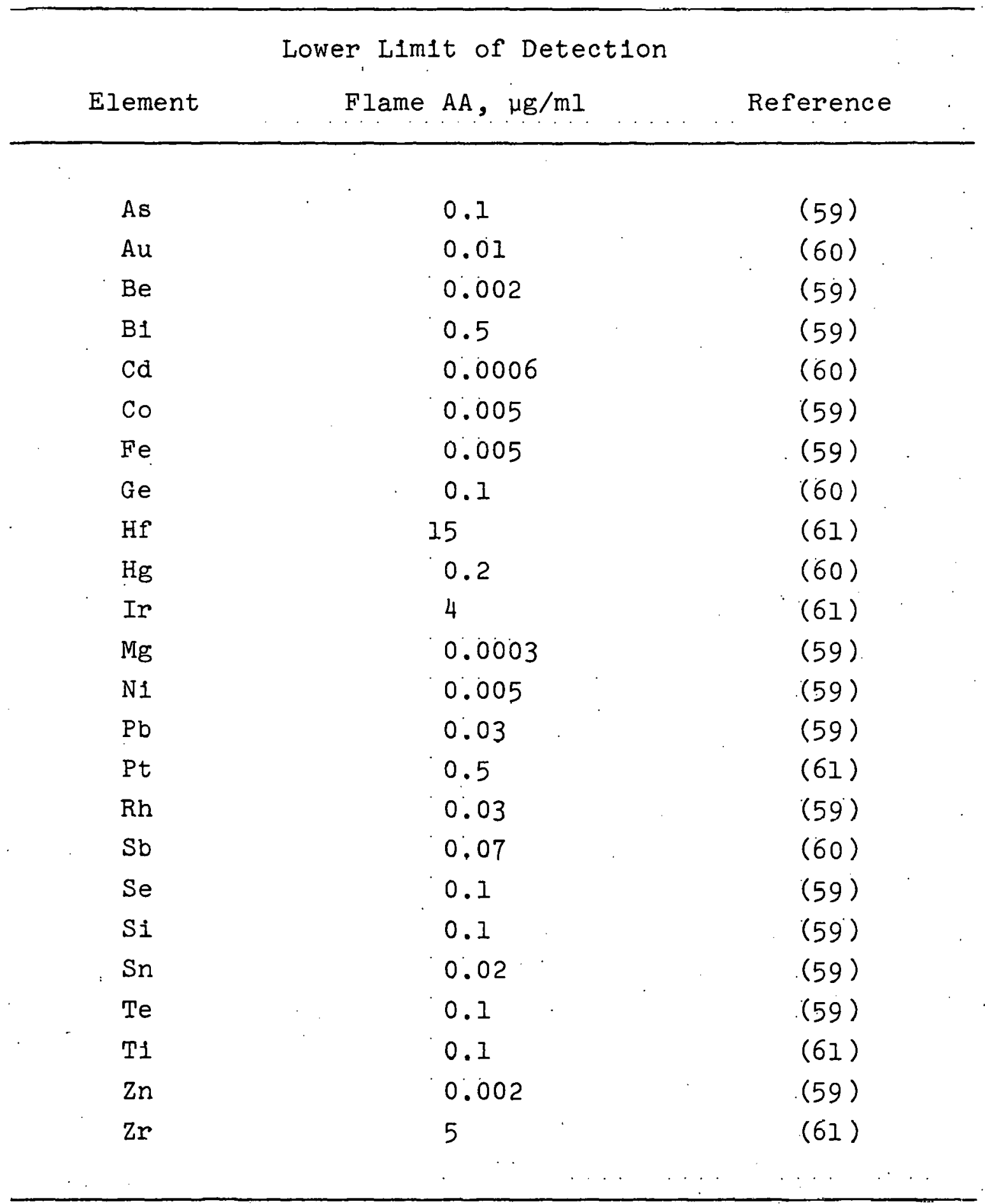

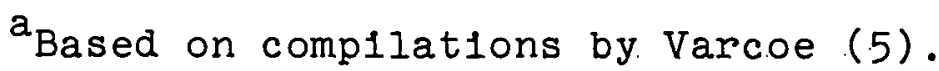


Table 5. Elements for which AE has a detection limit lower than AA by. at. I.east. a factor of. $5^{\mathrm{a}}$

\begin{tabular}{|c|c|c|c|c|c|}
\hline Element & $\mathrm{AE}$ & Detection Limit, & $\mu \mathrm{g} / \mathrm{ml}$ & $\therefore$ & Reference \\
\hline $\mathrm{AI}$ & & 0.005 & & & $(62)$ \\
\hline $\mathrm{Ca}$ & & 0.0001 & & & $(63)$ \\
\hline $\mathrm{Ce}$ & & 10 & & & $(61)$ \\
\hline $\mathrm{Cs}$ & & 0.008 & & . & $(61)$ \\
\hline $\mathrm{Eu}$ & & 0.003 & & & $(61)$ \\
\hline $\mathrm{Ga}$ & & 0.01 & & & $(63)$ \\
\hline In & & 0.002 & & & $(61)$ \\
\hline $\mathrm{La}$ & & 1 & & & $(61)$ \\
\hline Li & & 0.000003 & & & $(61)$ \\
\hline $\mathrm{Lu}$ & & 0.2 & & $\therefore$ & $(61)$ \\
\hline $\mathrm{Na}$ & & 0.0001 & & & $(61)$ \\
\hline $\mathrm{Nb}$ & & 1 & & & $\therefore(61)$ \\
\hline Os & & 10 & & & (6i) \\
\hline $\mathrm{Sm}$ & & 0.6 & & & $(61)$ \\
\hline $\mathrm{Sr}$ & & 0.0002 & & & $(63)$ \\
\hline $\mathrm{Th}$ & & 150 & & & $(61)$ \\
\hline$\cdots$ & $\cdots$ & $\therefore \ldots$ & & & $\cdots$ \\
\hline
\end{tabular}

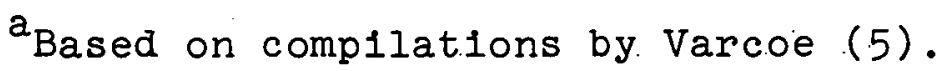


Table 6. Elements for which $\mathrm{AE}$ and $\mathrm{AA}$ have comparable detection Iimit.s ${ }^{2}$.

\begin{tabular}{|c|c|c|c|}
\hline \multirow{2}{*}{$\frac{\text { Element }}{\mathrm{Ag}}$} & \multicolumn{2}{|c|}{$\begin{array}{c}\text { Lower Limit of Detection, } \\
\mu \mu \mathrm{g} / \mathrm{ml} \text {. Technique. }\end{array}$} & \multirow{2}{*}{$\frac{\text { Reference }}{(59)}$} \\
\hline & 0.005 & $\mathrm{AA}$ & \\
\hline $\mathrm{Ba}$ & 0.03 & $\mathrm{AE}$ & (6I) \\
\hline $\mathrm{Cr}$ & 0.005 & $A A-A E$ & $(59,61)$ \\
\hline $\mathrm{Cu}$ & 0.003 & $\mathrm{AA}$ & $(60)$ \\
\hline Dy & 0.1 & $\mathrm{AE}$ & $(61)$ \\
\hline Er & 0.2 & $\mathrm{AA}$ & (6I) \\
\hline Gd & 2 & $\mathrm{AE}$ & $(61)$ \\
\hline Ho & 0.1 & $\mathrm{AE}$ & $(61)$ \\
\hline $\mathrm{K}$ & 0.003 & $\mathrm{AE}$ & $(6 I)$ \\
\hline $\mathrm{Mn}$ & 0.002 & $\mathrm{AA}$ & (59) \\
\hline Mo & 0.03 & $\mathrm{AA}$. & (59) \\
\hline $\mathrm{Nd}$ & 1 & $A E$ & $(6 I)$ \\
\hline $\mathrm{Pd}$ & 0.02 & $\mathrm{AA}$ & $(60)$ \\
\hline $\operatorname{Pr}$ & 2 & $\mathrm{AE}$ & (6I) \\
\hline $\mathrm{Rb}$ & 0.002 & $\mathrm{AE}$ & (6I) \\
\hline $\operatorname{Re}$ & 1 & $\mathrm{AE}$ & $(61)$ \\
\hline $\mathrm{Ru}$ & 0.3 & $A A-A E$ & $(61)$ \\
\hline $\mathrm{Sc}$ & 0.07 & $\mathrm{AE}$ & $(61)$ \\
\hline $\mathrm{Ta}$ & 6 & $\mathrm{AA}$ & (6I) \\
\hline $\mathrm{Tb}$ & 1 & $\mathrm{AE}$ & (61) \\
\hline $\mathrm{TI}$ & 0.02 & $A A-A E$ & $(64,65)$ \\
\hline $\operatorname{Tm}$ & 0.1 & $\mathrm{AA}$ & $(6 I)$ \\
\hline U & 10 & $\mathrm{AE}$ & $(61)$ \\
\hline V & 0.01 & $\mathrm{AE}$ & $(63)$ \\
\hline W & $3:$ & $\mathrm{AA}$ & $(61)$ \\
\hline$Y$. & 0.3 & $A A-A E$ & $(61)$ \\
\hline$Y b$ & 0.04 & $\mathrm{AA}$ & $(G I)$ \\
\hline
\end{tabular}


The absolute detection limits of $A E, A A$, and $A F$ are dependent upon the method of excitation of the analyte atoms. The avallable methods of excitation may be categorized as either flame or nonflame. Flames, the earliest source of excitation energy, were inexpensive and easy to operate. Compared with the other trace techniques available at the time (e.g., colorimetry, fluorimetry, etc.), flame spectroscopy was least likely to be affected by interferences. The principal interferences of flame spectroscopy are either chemical (those which prevent the atoms from reaching the free, dissociated, unionized state necessary for measurement in the flame) or spectral (bands emitted by the $\mathrm{OH}$ and $\mathrm{CN}$ radicals, which obscure atomic excitation lines). Chemical interferences are generally circumvented by the use of various masking and releasing agents. The proper choice of fuel and oxidizer, fuel/oxidizer ratios, and the position of the analytical zone in the flame could contribute to lower spectral interference.

The primary disadvantage of the flame methods is the need to keep the total salt concentration of the analyte fluid below $1 \%$. The required sample dilutions or sample extraction procedures adversely affect trace determinations due to contamination and sample losses (66, p. 127). Recent developments in nonflame atomization and excltation sources have lowered the absolute detection limits of $A A$, 
$A E$ and $A F$ considerably. The advantages of nonflame methods (e..g., Inductively Coupled Plasma Atomic Emission (ICPAE), Non-Flame Atomic Absorption (NFAA), and Non-Flame Atomic Fluorescence (NFAF)) over the corresponding flame techniques are illustrated by comparing the limits of detection listed in Table 7 with the previously given flame detection limits. (Compare Tables 4, 5 and 6).

Inductively coupled plasmas (a special type of plasma that derives its sustaining power by induction from a high frequency magnetic field) as compared to flames, provide cleaner background spectra, higher temperatures, and longer residence times in an inert environment for the analyte species. These factors lead to reduced solute vaporization interferences, nearly 100\% atomization, and reduction of inter-element and matrix effects $(67)$. Disadvantages in the use of the plasma system include: 1) the fraction of the atomized sample which enters the plasma is small; 2) the total salt concentration in most samples must be controlled - usually via dilution of the sample - to ensure efficient nebulization; and 3 ) the method is subject to contamination errors because most samples must be chemically processed prior to analysis (68, p. 236).

Nonflame AA and AF usually employ a form of electrically heated graphite furnace as atomizer. The principal reasons for the superior sensitivity and lower detection 
Table 7. Detection limits for nonflame spectrophotometric, methods.

\begin{tabular}{|c|c|c|c|}
\hline Element & ICPAES $\mathrm{a}^{\mathrm{a}} \mu \mathrm{g} / \mathrm{ml}$ & NFAAS $\quad \mu g / m I$ & NFAFS ${ }^{C} \mu g / m l$ \\
\hline $\mathrm{Ag}$ & 0.004 & $1 \times 10^{-7}$ & 0.007 \\
\hline Al & 0.002 & $1 \times 10^{-6}$ & \\
\hline As & 0.04 & $1 \times 10^{-6}$ & \\
\hline $\mathrm{Au}$ & 0.04 & $1 \times 10^{-6}$ & \\
\hline $\mathrm{B}$ & 0.005 & $2 \times 10^{-4}$ & \\
\hline $\mathrm{Ba}$ & 0.001 & $6 \times 10^{-6}$ & \\
\hline $\mathrm{Be}$ & 0.0005 & $3 \times 10^{-8}$ & \\
\hline $\mathrm{Bi}$ & 0.05 & $4 \times 10^{-6}$ & 0.01 \\
\hline $\mathrm{Ca}$ & 0.00007 & $4 \times 10^{-7}$ & \\
\hline $\mathrm{Cd}$ & 0.002 & $8 \times 10^{-8}$ & 0.001 \\
\hline $\mathrm{Ca}$ & 0.007 & & \\
\hline Co & 0.003 & $2 \times 10^{-6}$ & \\
\hline $\mathrm{Cr}$ & 0.001 & $2 \times 10^{-6}$ & 0.04 \\
\hline $\mathrm{Cu}$ & 0.001 & $6 \times 10^{-7}$ & 0.002 \\
\hline Dy & 0.004 & $2.2 \times 10^{-10} \mathrm{~g}$ & \\
\hline Er & 0.001 & $3.7 \times 10^{-1} \mathrm{~g}$ & \\
\hline $\mathrm{Cu}$ & 0.001 & $3 \times 10^{-1} \cdot 8$ & \\
\hline $\mathrm{Fe}$ & 0.005 & $I \times 10^{-5}$ & 0.02 \\
\hline Ga & 0.014 & $1 \times 10^{-12} \mathrm{~g}$ & \\
\hline $\mathrm{Hg}$ & 0.2 & $2 \times 10^{-5}$ & \\
\hline Ho & 0.01 & $3.3 \times 10^{-10} \mathrm{~g}$ & \\
\hline In & 0.03 & $4 \times 10^{-7}$ & 0.01 \\
\hline $\mathrm{La}$ & 0.003 & $0.1 \mu \mathrm{g} / \mathrm{ml}$ & \\
\hline $\mathrm{Mg}$ & 0.0007 & $4 \times 10^{-8}$ & 0.003 \\
\hline
\end{tabular}

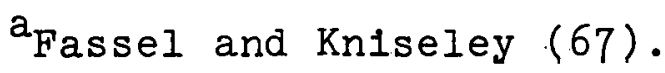

buIka and Risby (2) and L'vov (69).

${ }^{c}$ Clyburn, Bartschmid and Veilion (70). 
Table 7. (Continued)

\begin{tabular}{|c|c|c|c|}
\hline Element. & ICPAES $^{a} \mu \mathrm{g} / \mathrm{mI}$ & NFAAS ${ }^{b} \mu g / m 1$ & NFAFS $^{\mathrm{C}} \mu \mathrm{g} / \mathrm{ml}$ \\
\hline Mn & 0.0007 & $2 \times 10^{-7}$ & 0.005 \\
\hline Mo & 0.005 & $3 \times 10^{-6}$ & \\
\hline $\mathrm{Na}$ & 0.0002 & $1 \times 10^{-12} \mathrm{~g}$ & \\
\hline $\mathrm{Nb}$ & 0.01 & $12.0 \mu \mathrm{g} / \mathrm{ml}$ & \\
\hline $\mathrm{N} 1$ & 0.006 & $9 \times 10^{-6}$ & 0.03 \\
\hline $\mathrm{Pb}$ & 0.008 & $2 \times 10^{-6}$ & $0.0]$. \\
\hline$P d$ & 0.007 & $4 \times 10^{-6}$ & \\
\hline Pt & 0.08 & $1 \times 10^{-5}$ & \\
\hline $\mathrm{Rh}$ & 0.003 & $8 \times 10^{-6}$ & \\
\hline $\mathrm{Sb}$ & 0.2 & $5 \times 10^{-6}$ & \\
\hline $\mathrm{Sc}$ & 0.003 & & \\
\hline $\mathrm{Se}$ & 0.03 & $9 \times 10^{-6}$ & \\
\hline Si & 0.01 & $5 \times 10^{-8}$ & \\
\hline $\mathrm{Sn}$ & 0.3 & $2 \times 10^{-6}$ & 0.02 \\
\hline $\mathrm{Sr}$ & 0.00002 & $1 \times 10^{-6}$ & \\
\hline $\mathrm{Ta}$ & 0.07 & $7.0 \mu \mathrm{g} / \mathrm{mI}$ & \\
\hline $\mathrm{Te}$ & 0.08 & $1 \times 10^{-6}$ & \\
\hline $\mathrm{T} 1$ & 0.003 & $4 \times 10^{-5}$ & \\
\hline $\mathrm{TI}$ & 0.2 & $I \times 10^{-6}$ & \\
\hline $\mathrm{V}$ & 0.006 & $3 \times 10^{-6}$ & \\
\hline W & 0.002 & 1.0 & \\
\hline$Y$ & 0.0002 & 10.0 & \\
\hline $\mathrm{Zn}$ & 0.002 & $3 \times 10^{-8}$ & 0.005 \\
\hline $\mathrm{Zr}$ & 0.005 & 5.0 & \\
\hline
\end{tabular}


limits achieved by the graphite tube atomizers are: 1) a nonreactive atmosphere 1 s used; 2) the carbon provides a strongly reducing medium; 3) the analyte atoms are confined to a relatively small space for a relatively long time; and 4) the furnace gases have a low background emission (71, p. 256). The primary disadvantages of the graphite furnace are: 1) sample sizes are usually limited to between 1 and 100 microliters; 2) reproducibility is strongly dependent on sample placement in the furnace and the surface condition of the graphite; and 3) matrix effects are more troublesome (71, p. 256).

Combination atomization and excitation sources assoclated with $A E$ are the electrical arcs and sparks. With the high temperature arc, the analytical sensitivity is high, and low limits of detection result. The wandering nature of the arc on the electrode surface during the discharge is such that the amount of radiation reaching the detector is not reproducible from sample to sample. Reproducibilities better than about $\pm 10 \%$ are difficult to achleve (71, p. 136). Because limits of detection in arc spectroscopy depend on so many variables, only approximate ranges are glven in Table 8 . The usefulness of the DC arc source in qualitative and semiquantitative work is evident: virtually every metal in the periodic table can be detected at or below concentration levels of $100 \mathrm{ppm}$ $(0.01 \%)$. 
Table 8. Approximate detection limits for elements detectable by DC arc sources ${ }^{a}$.

Approximate Detection

Elements

Limit $^{b}$

Below $10^{-4} \%$

$10^{-4}-10^{-3} \%$

$10^{-3}-10^{-2} \%$

$10^{-2}-10^{-1} \%$
$\mathrm{L1}, \mathrm{Na}, \mathrm{Cu}, \mathrm{Ag}$

$\mathrm{K}, \mathrm{Rb}, \mathrm{Cs}, \mathrm{Be}, \mathrm{Mg}, \mathrm{Ca}, \mathrm{Sr}, \mathrm{Ba}$, $\mathrm{Sc}, \mathrm{Y}, \mathrm{La}, \mathrm{Ti}, \mathrm{Zr}, \mathrm{V}, \mathrm{Cr}, \mathrm{Mo}$, $\mathrm{Mn}, \mathrm{Fe}, \mathrm{Ru}, \mathrm{Co}, \mathrm{Rh}, \mathrm{Ni}, \mathrm{Pd}, \mathrm{Au}$, $\mathrm{Zn}, \mathrm{Cd}, \mathrm{B}, \mathrm{Al}, \mathrm{Ga}$, In, $\mathrm{Tl}, \mathrm{Ge}$, $\mathrm{Sn}, \mathrm{Pb}, \mathrm{Pr}, \mathrm{Nd}, \mathrm{Eu}, \mathrm{Tb}, \mathrm{Dy}, \mathrm{Ho}$, Er, Tm, Yb, Lu $\mathrm{Hf}, \mathrm{Nb}, \mathrm{Ta}, \mathrm{W}, \mathrm{Re}, \mathrm{Os}$, Ir, Pt, $\mathrm{Hg}, \mathrm{S} 1, \mathrm{P}, \mathrm{As}, \mathrm{Sb}, \mathrm{B} 1, \mathrm{~F}, \mathrm{Th}, \mathrm{U}$ $\mathrm{Se}, \mathrm{Te}, \mathrm{Ce}, \mathrm{Sm}, \mathrm{Gd}$

${ }^{a}$ Data of Veilion (71, p. 137).

$\mathrm{b}_{10^{-4} \%}=1$ microgram analyte per 1 gram solid. sample. 
The DC spark has an effective excitation temperature in the discharge many times that in the $D C$ arc, which means that virtually any element can be ionized, resulting in more complicated spectra. Detection limits are poorer than the DC arc, primarily because of the small amount of sample consumed. For the fifty or so elements most frequently analyzed by spark source spectroscopy, detection limits ranging from $10^{-7}$ to $10^{-2} \%$ (by weight) with most in the $10^{-4}$ to $10^{-2} \%$ range are typical ( $\left.71, \mathrm{p} .139\right)$.

b. Colorimetry and fluorimetry Colorimetry. and fluorimetry are two of the least expensive methods capable of determining elements at the trace level. However, the use of either method is severely limited by inter-element interferences. The organic reagents, with which the analyte element must form complexes in order to achieve the appropriate colored or fluorescent species, are generally not specific for one element which consequently leads to interference problems. For complex samples, such as blood, extensive separations are needed to 1solate the desired element. As suggested by the need for separation schemes, neither technique has a practical multi-elemental capacity. Included in Table 9 are some of the lower limits of colorimetric detection for several elements in clinical samples (1). Where specified in micrograms rather than micrograms per gram, the limit of detection represents the 
Table 9. Colorimetric lower detection limit.s ${ }^{2}$

\begin{tabular}{lllll}
\hline Element & $\therefore \ldots \ldots$ & $\ldots \ldots \ldots$ & Limit $(\mu \mathrm{g} / \mathrm{g})$ \\
\hline
\end{tabular}

Essential

$\begin{array}{ll}\mathrm{Cr} & 0.006 \\ \mathrm{Mn} & 0.01 \mu \mathrm{g} \\ \text { Mo } & 1.0 \mu \mathrm{g} \\ \mathrm{Ni} & 0.05 \\ \mathrm{Sn} & 5.0 \mu \mathrm{g} \\ \mathrm{V} & 0.5 \mu \mathrm{g}\end{array}$

Nonessential

As

B

$0.5 \mu \mathrm{g}$

$\mathrm{Ge}$

0.5

$\mathrm{Nb}$

0.1

$\mathrm{Pb}$

0.04

$0.05 \mu \mathrm{g}$

T1

0.25

$\mathrm{Zr}$

0.8

${ }^{a}$ Compiled by Schroeder and Nason (1). 
smallest amount detectable by differences in two solutions, both with known amounts of the element added.

The enhanced signal-to-noise ratio resulting from the optical geometry used in fluorimetric measurements results in lower detection limits than inorganic absorption spectrophotometry (72). The detection limits of several elements as noted by Winefordner et al. for an interference free media (Table 10) illustrate that under ideal conditions, fluorimetry can be comparable to the modern, sophisticated methods of trace analysis.

c. X-ray methods Recent developments in excitation sources, energy dispersive detectors and associated electronics have significantly increased the sensitivity and efficiency of X-ray fluorescence measurements. Under vacuum conditions, X-ray fluorescence is capable of determining all elements with atomic number 9 or greater at the ppm level (73, p. 352). However, the quantification of complex samples is complicated by the necessity to empirically correct for inter-element and matrix absorption effects. Even though these corrections, involving relatively large systems of simultaneous equations, have become routine with the introduction of mini-computers into fluorescence analysis systems, the precision and accuracy of the results are still significantly dependent on the nature of the sample. Methods for 
Table 10. Fluorimetric lower detection limits ${ }^{a}$

\begin{tabular}{|c|c|c|c|}
\hline Element & Limit, $\mu \mathrm{g} / \mathrm{ml}$ & Element & Limit, $\mu \mathrm{g} / \mathrm{ml}$ \\
\hline $\mathrm{Ag}$ & 0.004 & $\mathrm{Lu}$ & 100 \\
\hline Al & 0.0008 & $\mathrm{Mg}$ & 0.00001. \\
\hline As & 7 & $\mathrm{Mn}$ & 0.002 \\
\hline $\mathrm{Au}$ & 0.5 & Mo & 0.1 \\
\hline B & 0.0005 & $\mathrm{Nb}$ & 0.1 \\
\hline $\mathrm{Be}$ & 0.0004 & $\mathrm{Nd}$ & 5 \\
\hline $\mathrm{Bi}$ & 0.5 & $\mathrm{Ni}$ & 0.00006 \\
\hline $\mathrm{Ca}$ & 0.01 & Os & 0.05 \\
\hline $\mathrm{Cd}$ & 0.02 & $P$ & 0.0000006 \\
\hline $\mathrm{Ce}$ & 0.05 & $\mathrm{~Pb}$ & 5 \\
\hline $\mathrm{Cl}$ & 0.05 & $\operatorname{Pr}$ & 0.5 \\
\hline $\mathrm{Co}$ & 0.0001 & $\mathrm{Ru}$ & 1 \\
\hline $\mathrm{Cu}$ & 0.0002 & $\mathrm{Sb}$ & 0.05 \\
\hline Dy & 0.01 & Sc & 0.01 \\
\hline Er & 10 & $\mathrm{Se}$ & 0.005 \\
\hline $\mathrm{Eu}$ & 0.005 & Si & 0.08 \\
\hline$F$ & 0.001 & $\mathrm{Sm}$ & 0.5 \\
\hline $\mathrm{Fe}$ & 0.0008 & $\mathrm{Sn}$ & 0.1 \\
\hline $\mathrm{Ga}$ & 0.001 & $\mathrm{~Tb}$ & 0.1. \\
\hline Gd & 10 & $\mathrm{Te}$ & 0.2 \\
\hline $\mathrm{Ge}$ & 0.004 & Th & 0.02 \\
\hline $\mathrm{Hf}$ & 0.1 & $\mathrm{TI}$ & 0.02 \\
\hline $\mathrm{Hg}$ & 0.002 & $\mathrm{Tm}$ & 10 \\
\hline Ho & 100 & $\mathrm{U}$ & 0.01 \\
\hline I & 0.6 & V & 2 \\
\hline In & 0.04 & W & 0.04 \\
\hline Ir & 2.0 & $Y$ & 0.02 \\
\hline \multirow[t]{2}{*}{ L1 } & 0.2 & $\mathrm{Zn}$ & 0.002 \\
\hline & & $\mathrm{Zr}$ & 0.02 \\
\hline
\end{tabular}

${ }^{a}$ Compiled by Winefordner, et al. (72). 
the separation and concentration of the analyte species have been employed, but all are complicated by the necessity of carrying out the procedures without contaminating the sample. The tediousness and expense of using clean room facilities and ultra-pure reagents will be encountered if the full sensitivity of $X$-ray fluorescence is to be exploited.

The limit of detection of X-ray fluorescence for a given element is a function of the intensity of the fluorescence reaching the detector. Therefore, the limits are greatly affected by the form and type of matrix. In general, analyses of samples from about 1 microgram of analyte per gram $(0.0001 \%$ by weight) to essentially $100 \%$ analyte are possible (73, p. 363). Limits of detection have been reported in the range of 1 to 50 micrograms per gram and from 0.1 to 1 microgram for all elements with atomic number greater than 15 (phosphorus) (73, p. 363). A Ilsting of some reported detection limits for $\mathrm{X}$-ray fluorescence is provided in Table 1l. Despite the high sensitivities, the multi-elemental capacity, and the versatility with respect to the types of samples acceptable for analysis, the uncertainty of the corrections for interelement and absorption effects have limited the use of $\mathrm{X}$-ray fluorescence primarily to the analysis for components present at or greater than $1 \%$ by weight $(73, p .363)$. 
Table 11. X-ray fluorescence detection limits ${ }^{a}$

\begin{tabular}{lllc}
\hline Element & Limit $(\mu \mathrm{g})$ & Element & Limit $(\mu \mathrm{g})$ \\
\hline $\mathrm{Ag}$ & 1.2 & $\mathrm{Nd}$ & 0.30 \\
$\mathrm{Al}$ & 5.0 & $\mathrm{Ni}$ & 0.06 \\
$\mathrm{As}$ & 0.11 & $\mathrm{P}$ & 0.001 \\
$\mathrm{Au}$ & $0.001 / \mathrm{cm}^{2}$ & $\mathrm{~Pb}$ & 0.0003 \\
$\mathrm{Ba}$ & 0.12 & $\mathrm{Rb}$ & 0.0075 \\
$\mathrm{Bi}$ & 0.61 & $\mathrm{Rh}$ & $103 / \mathrm{ml}$ \\
$\mathrm{Ca}$ & 0.100 & $\mathrm{Sc}$ & 0.38 \\
$\mathrm{Cd}$ & 0.40 & $\mathrm{Se}$ & $0.020 / \mathrm{cm}^{2}$ \\
$\mathrm{Ce}$ & 0.17 & $\mathrm{Si}$ & $170 \mathrm{ppm}$ \\
$\mathrm{Co}$ & 0.15 & $\mathrm{Sm}$ & $4.1 / \mathrm{ml}$ \\
$\mathrm{Cr}$ & 0.00006 & $\mathrm{Sn}$ & $3.9 \mathrm{ppm}$ \\
$\mathrm{Cs}$ & 0.15 & $\mathrm{Sr}$ & 0.00007 \\
$\mathrm{Cu}$ & 0.00002 & $\mathrm{~Tb}$ & $159 / \mathrm{ml}$ \\
$\mathrm{Eu}$ & 0.66 & $\mathrm{Te}$ & 0.12 \\
$\mathrm{Fe}$ & 0.0085 & $\mathrm{Th}$ & $6.5 / \mathrm{ml}$ \\
$\mathrm{Ga}$ & 0.01 & $\mathrm{Ti}$ & 0.001 \\
$\mathrm{Hg}$ & 0.24 & $\mathrm{U}\left(\mathrm{as} \mathrm{UO}_{2}\right)$ & 0.72 \\
$\mathrm{In}$ & 1.1 & $\mathrm{U}$ & 0.00002 \\
$\mathrm{~K}$ & 0.52 & $\mathrm{Y}$ & 0.22 \\
$\mathrm{La}$ & 0.12 & $\mathrm{Yb}$ & $6.8 / \mathrm{ml}$ \\
$\mathrm{Mn}$ & 0.00015 & $\mathrm{Zn}$ & 0.00004 \\
$\mathrm{Mo}$ & 0.072 & $\mathrm{Zr}$ & 0.00002 \\
& & & $:$ \\
\hline
\end{tabular}

${ }^{a}$ Data from Dulka and Risby (2, p. 44). 
Electron Microprobe and Laser Probe X-Ray Microanalysis are two additional X-ray methods which have been applied to the analysis of blood samples. However, these methods allow only small areas of excitation and shallow penetration of the excitation radiation resulting in lower sensitivities than the X-ray fluorescence method. Only in special situations can analyses in the parts-per-million range be accomplished (73, p. 381).

d. Mass spectroscopy Mass spectroscopy offers the capability of determining the greatest number of elements with some of the lowest attainable limits of detection. The utility of mass spectroscopy is dependent upon the type of Ionization and detection systems employed. Spark source Mass Spectroscopy (SSMS) offers the greatest versatility with respect to the usable matrices and overall sensitivity. Consideration of equipment and maintenance costs, sensitivity of operation, and overall difficulty in obtaining quantitative results, explains why SSMS has not found widespread use as an analytical tool.

The detection limits of elements by SSMS are highly dependent upon the matrix and the detection systems. The infeasibility of spectrum scanning, due to the instability of the spark in the 1onization system, and, the resultant time variation in the ion currents at the detector, limits the technique to using photographic plates as detectors (5). 
Precision is thus limited to the homogeneity of the photographic emulsion of a single plate. Inhomogeneity in emulsions between plates and between emulsion lots are of significant magnitude and result in generally poor precision. The overall precision, according to de Galan, is limited to approximately $25 \%(66, p .127)$.

A theoretical approach to limits of detection based on signal levels has been described by Werner (74). A listing of detection limits as calculated by Werner for some elements in an iron matrix is given in Table 12. Morrison has determined limits of detection for elements based on the photographic plate as detector (75) (See Table 13).

Some elements after chelation with the proper organic reagents are susceptible to analysis by Chemical Ionization Mass Spectroscopy (CIMS). As indicated by the limits of detection listed in Table 14, CIMS offers an advantage over SSMS for some of the elements for which the technique is viable.

Better quantitative agreement can be obtained in SSMS if isotope dilution techniques are employed. Isotope dilution allows precise quantitative determinations because only isotopic ratios for analyte lines recorded under Identical matrix, exposure, development, and emulsion conditions are measured. Though blood analysis by Isotope 
Table 12. SSMS calculated limits of detection for some elements in an iron matrixa

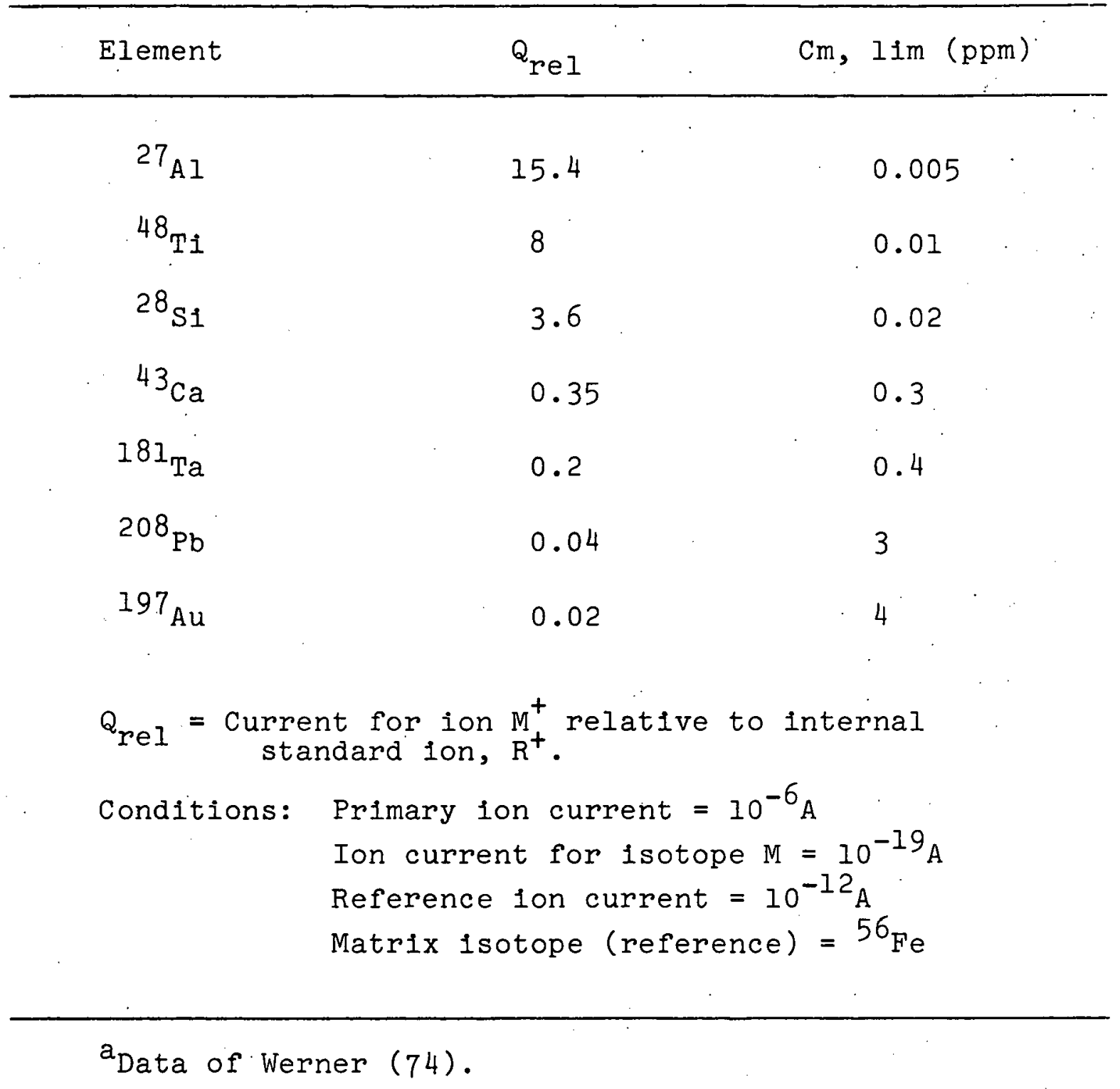


Table 13. Estimated detection limits for SSMS with photographic plates as detectors ${ }^{a}$

\begin{tabular}{|c|c|c|c|c|}
\hline Element & Absolute (ng) & Element & Absolute & $(n g)$ \\
\hline Ar & 0.03 & $\mathrm{Mn}$ & 0.05 & . \\
\hline $\mathrm{Ag}$ & 0.2 & Mo & 0.3 & \\
\hline AI & 0.02 & $\mathrm{~N}$ & 0.01 & \\
\hline As & 0.06 & $\mathrm{Na}$ & 0.02 & \\
\hline $\mathrm{Au}$ & 0.2 & $\mathrm{Ne}$ & 0.02 & \\
\hline $\mathrm{B}$ & 0.01 & $\mathrm{Nb}$ & 0.08 & \\
\hline $\mathrm{Ba}$ & 0.2 & $\mathrm{Nd}$ & 0.4 & \\
\hline $\mathrm{Be}$ & 0.008 & $\mathrm{NI}$ & 0.07 & \\
\hline $\mathrm{Bi}$ & 0.2 & 0 & 0.01 & \\
\hline $\mathrm{Br}$ & 0.1 & Os & 0.4 & \\
\hline $\mathrm{C}$ & 0.01 & $\mathrm{P}$ & 0.03 & \\
\hline $\mathrm{Ca}$ & 0.03 & $\mathrm{~Pb}$ & 0.3 & \\
\hline $\mathrm{Cd}$ & 0.3 & $P d$ & 0.3 & \\
\hline $\mathrm{Ce}$ & 0.1 & $\operatorname{Pr}$ & 0.1 & \\
\hline $\mathrm{Cl}$ & 0.04 & Pt & 0.5 & \\
\hline $\mathrm{Co}$ & 0.05 & $\mathrm{Rb}$ & $0 . \overline{1}$ & \\
\hline $\mathrm{Cr}$ & 0.05 & $\mathrm{Re}$ & 0.2 & . \\
\hline $\mathrm{Cs}$ & 0.1 & $\mathrm{Rh}$ & 0.09 & \\
\hline $\mathrm{Cu}$ & 0.08 & $\mathrm{Ru}$ & 0.03 & \\
\hline Dy & 0.5 & $S$ & 0.03 & \\
\hline Er & 0.5 & $\mathrm{Sb}$ & 0.2 & \\
\hline Eu & 0.2 & $\mathrm{Sc}$ & 0.04 & \\
\hline$F$ & 0.02 & $\mathrm{Se}$ & 0.1 & \\
\hline $\mathrm{Fe}$ & 0.05 & Si & 0.03 & \\
\hline $\mathrm{Ga}$ & 0.09 & $\mathrm{Sm}$ & 0.5 & \\
\hline Gd & 0.5 & $\mathrm{Sn}$ & 0.3 & \\
\hline $\mathrm{Ge}$ & 0.2 & $\mathrm{Sr}$ & 0.09 & \\
\hline $\mathrm{H}$ & 0.0008 & $\mathrm{Ta}$ & 0.2 & \\
\hline Ho & 0.003 & $\mathrm{~Tb}$ & 0.1 & \\
\hline $\mathrm{Hf}$ & 0.4 & $\mathrm{Te}$ & 0.2 & \\
\hline $\mathrm{Hg}$ & 0.6 & $\mathrm{~T} 1$ & 0.2 & \\
\hline $\mathrm{He}$ & 0.1 & Tl & 0.1 & \\
\hline$I$ & 0.1 & $\mathrm{Tm}$ & 0.2 & \\
\hline Ir. & 0.3 & $\mathrm{~V}$ & 0.04 & \\
\hline $\mathrm{K}$ & 0.03 & W & 0.5 & \\
\hline $\mathrm{Kr}$ & 0.1 & $\mathrm{Xe}$ & 0.4 & \\
\hline Là & 0.1 & $Y$ & 0.07 & \\
\hline $\mathrm{Li}$ & 0.006 & $\mathrm{Yb}$ & 0.5 & \\
\hline $\mathrm{Lu}$ & 0.1 & $\mathrm{Zn}$ & 0.1 & \\
\hline $\mathrm{Mg}$ & 0.03 & $\mathrm{Zr}$ & 0.1 & \\
\hline
\end{tabular}

Data compiled by Morrison (75). 
Table 14. Sensitivities for elements by chelation coupled with C.IMSa

\begin{tabular}{|c|c|c|c|c|}
\hline Element & Chelates & Element & Chela & ates \\
\hline Mn & $\begin{array}{l}\operatorname{Mn}(a c a c)_{2}, \operatorname{Mn}(t f a)_{2} \\
M n(t h d)_{3}\end{array}$ & La & $\operatorname{La}(\text { thd })_{3}$, & $\operatorname{La}(f \circ d)_{3}$ \\
\hline $\mathrm{N} 1$ & $\begin{array}{l}\mathrm{Ni}(a c a c)_{2}, \\
\mathrm{Ni}(\text { thd })_{2}(t \mathrm{fa})_{2}\end{array}$ & $\operatorname{Pr}$ & $\operatorname{Pr}(\text { thd })_{3}$, & $\operatorname{Pr}(\text { fod })_{3}$ \\
\hline $\mathrm{Cu}$ & $\begin{array}{l}\mathrm{Cu}(\text { acac })_{2}, \quad \mathrm{Cu}(\text { tfa })_{2} \\
\mathrm{Cu}(\text { thd })_{2}\end{array}$ & $\mathrm{Nd}$ & $\mathrm{Nd}(\text { thd })_{3}$, & $\mathrm{Na}\left(\mathrm{fod}_{3}\right.$ \\
\hline $\mathrm{Zn}$ & $\ln _{\left.\ln (\operatorname{tac} d)_{2}\right)_{2}, \operatorname{Zn}(t f a)_{2}}$ & $\mathrm{Sm}$ & $\operatorname{Sm}(\text { thd })_{3}$, & $\operatorname{Sm}(f \circ d)_{3}$ \\
\hline vo & $V O(t f a)_{2}, V o(t h d)_{2}$ & $\mathrm{Eu}$ & $\operatorname{Eu}(\text { thd })_{3}$, & $E u(f \circ d)_{3}$ \\
\hline $\mathrm{Cr}$ & $\begin{array}{l}\operatorname{Cr}(\text { acac }) \\
\operatorname{Cr}(\text { thd })_{3}, \operatorname{Cr}(t f a)_{3}\end{array}$ & $\mathrm{Gd}$ & $\operatorname{Gd}(\text { thd })_{3}$, & $\operatorname{Gd}(f \circ d)_{3}$ \\
\hline $\mathrm{Fe}$ & $\begin{array}{l}\mathrm{Fe}(\text { acac })_{3}, \mathrm{Fe}(\text { tha })_{3} \\
\mathrm{Fe}(\text { thd })_{3}\end{array}$ & $\mathrm{~Tb}$ & $\operatorname{Tb}(\text { thd })_{3}$, & $\mathrm{Tb}(\text { fod })_{3}$ \\
\hline Co & $\begin{array}{l}\operatorname{Co}(\text { acac })_{3}, \operatorname{Co}(t f a)_{3} \\
\operatorname{Co}(t h d)_{3}\end{array}$ & Dy & $\operatorname{Dy}(\text { thd })_{3}$, & Dy $(\text { fod })_{3}$ \\
\hline $\mathrm{Ru}$ & $\operatorname{Ru}(a c a c)_{3}, \operatorname{Ru}(t f a)_{3}$ & Ho & Ho (thd) 3 , & $\mathrm{Ho}_{\because}(\mathrm{fod})_{3}$ \\
\hline $\mathrm{Rh}$ & $\operatorname{Rh}(a c a c)_{3}, \operatorname{Rh}(t f a)_{3}$ & Er & $\operatorname{Er}(\text { thd })_{3}$, & $\operatorname{Er}(f \circ d)_{3}$ \\
\hline $\mathrm{Pd}$ & $P d(t f a)_{2}, P d(t h d)_{3}$ & $\mathrm{Tm}$ & $\operatorname{Tm}(\text { thd })_{3}$, & $I^{\prime} m(f \circ Q)_{3}$ \\
\hline $\mathrm{Pt}$ & $\operatorname{Pt}(t f a)_{2}, P t(t h d)_{3}$ & $\mathrm{Yb}$ & $\mathrm{Yb}(\text { thd })_{3}$, & $\mathrm{Yb}(\mathrm{fod})_{3}$ \\
\hline
\end{tabular}

acac: 2,4-pentanedionate

tfa: 1,I,1-trifluoro-2,4-pentanedionate

fod: $1,1,-2,2,3,3$-heptafluoro-7,7-dimethy 1-4,6octanedionate

thd: $2,2,6,6$-tetramethyl-3,5-heptanedionate

${ }^{a}$ Dulka and R1sby (2, p. 3I). 
Dilution Mass Spectroscopy has been reported (76), as with SSMS, the equipment expense and, particularly, the tediousness of the technique limits its popularity.

e. Electrochemical methods Potentiometric methods have been the mainstay of electrochemical methods applied to trace elemental analysis in a biological matrix. Gochman and Young have extensively reviewed those potentiometric methods which have been reported in the literature for use on biological matrices (77). The potentiometric analysis with ion selective electrodes of both in situ and in vivo blood serum has been reported (78-81). Coulometry has received limited use in biological trace element analysis: Selenium in urine (81) and chlorine (82), as little as 0.2 micrograms, in serum are examples of the coulometric technique. Some literature values for limits of detection for Anodic Stripping Voltammetry and Differential Pulse Polarography, two of the most sensitive electrochemical techniques, are listed in Table 15. Though sensitive, these methods, as with most electrochemical methods, are particularly susceptible to interferences. For example, with anodic stripping, multi-elemental blood trace analysis Is not possible for elements with similar unmasked electrodeposition potentials. Between the cathodic deposition potentials and the anodic water-salt breakdown potential limit, there is only a 1.5 volt anodic dissolution window, 
Table 15. Detection limits with anodic stripping voltammetry and differential pulse polarography ${ }^{a}$

\begin{tabular}{|c|c|c|c|}
\hline Element & ASV & DPP & \\
\hline $\mathrm{Ag}$ & $0.25 \mathrm{ppb}$ & & \\
\hline $\mathrm{Au}$ & $1.0 \mathrm{ppb}$ & & \\
\hline $\mathrm{BI}$ & $0.01 \mathrm{ng} / \mathrm{ml}$ & $0.2 \mathrm{ng} / \mathrm{mI}$ & \\
\hline $\mathrm{cd}$ & $0.005 \mathrm{ng} / \mathrm{ml}$ & $0.98 \mathrm{ng} / \mathrm{ml}$ & \\
\hline Co & & $0.01 \mathrm{ng} / \mathrm{mI}$ & \\
\hline $\mathrm{Cu}$ & $0.005 \mathrm{ng} / \mathrm{ml}$ & $13.7 \mathrm{ng} / \mathrm{ml}$ & \\
\hline $\mathrm{Eu}$ & & $1.2 \times 10^{-4} \mathrm{~N}$ & $\vdots$ \\
\hline $\mathrm{Fe}$ & & $1 \mu \mathrm{g} / \mathrm{mI}$ & \\
\hline $\mathrm{Ga}$ & $0.4 \mathrm{ng} / \mathrm{ml}$ & $2 \times 10^{-8} \mathrm{M}$ & \\
\hline $\mathrm{Hg}$ & $4.0 \times 10^{-9} \mathrm{M}$ & & \\
\hline In & $0.1 \mathrm{ng} / \mathrm{mI}$ & $8 \times 10^{-9} \mathrm{M}$ & \\
\hline $\mathrm{K}$ & $1 \times 10^{-5} \mathrm{M}$ & & \\
\hline $\mathrm{Mn}$ & & $0.03 \mu \mathrm{g} / \mathrm{ml}$ & \\
\hline $\mathrm{Ni}$ & $0.1 \mathrm{~g} / \mathrm{ml}$ & $0.78 \mathrm{ng} / \mathrm{ml}$ & \\
\hline $\mathrm{Pb}$ & $0.01 \mathrm{ng} / \mathrm{ml}$ & $1.5 \mathrm{~g} / \mathrm{ml}$ & \\
\hline Pd & & $5.0 \times 10^{-8} \mathrm{~g}$ & \\
\hline Pt & $1 \times 10^{-9} \mathrm{M}$ & & \\
\hline $\mathrm{Rh}$ & $0.1 \mathrm{ng} / \mathrm{ml}$ & & \\
\hline $\mathrm{Sn}$ & $2.0 \mathrm{ng} / \mathrm{ml}$ & $1 \times 10^{-3} \mathrm{M}$ & \\
\hline $\mathrm{Tl}$ & $0.01 \mathrm{ng} / \mathrm{ml}$ & $4 \times 10^{-8} \mathrm{M}$ & \\
\hline $\mathrm{U}$ & & $0.18 \mu \mathrm{g} / \mathrm{ml}$ & \\
\hline $\mathrm{V}$ & & $0.08 \mu \mathrm{g} / \mathrm{ml}$ & \\
\hline $\mathrm{Zn}$ & $0.04 \mathrm{ng} / \mathrm{ml}$ & . . & \\
\hline
\end{tabular}

a Tabulated by Dulka and Risby. (2). 
which prevents obtaining separate and distinct dissolution peaks for the large number of different ions present in blood (82).

f. Gas chromatography Gas chromatography (GC) with an appropriate detection system offers a sensitive means for determining some of the trace elemental components in a biological matrix. The intrinsic separations occurring in the GC process can, in some cases, remove most of the interelement and matrix interferences. GC is limited to those elements capable of forming the complexes which are stable under the environment of the GC column. Table 16 includes a listing of some elements which have been separated by GC, but Slevers et al. (83) suggest that due to thermal instabilities, not all of the complexes listed are suitable for quantitative analysis.

Varcoe examined the use of Neutron Activation Analysis (NAA) in conjunction with GC as a method for the analysis of serum for trace elemental components (5). NAA with gamma ray detection provides an excellent means for the identification of the various components separated by GC. However, due to the lack of quantitative chelation and extraction of the complexes from the matrix, the difficulty of obtaining quantitative $G C$ recoveries, and the general sensitivity of the GC step to column conditions, high precision quantitative analysis is possible only in special situations (5). 
Table 16. Metal chelates separated by GC ${ }^{a}$

\begin{tabular}{|c|c|c|c|}
\hline Element & Chelating Agent ${ }^{b}$ & Element & Chelating Agent \\
\hline $\mathrm{Be}$ & acac, tfa, hfa, fod & In & tfa \\
\hline Al & acac, tfa, hfa, fod & $\mathrm{La}$ & thd \\
\hline Sc & acac, tfa, fod, thd & $\operatorname{Pr}$ & fod, thd \\
\hline $\mathrm{V}$ & $a c a c, t f a$ & $\mathrm{~N} d$ & fod, thd \\
\hline $\mathrm{Cr}$ & acac, tfa, hfa, fod & $\mathrm{Sm}$ & fod, thd \\
\hline Mn & $t f a$ & $\mathrm{Eu}$ & fod, thd \\
\hline $\mathrm{Fe}$ & tfa, hfa, fod & Gd. & fod, thd \\
\hline Co & tfa, hfa, thd & $\mathrm{Tb}$ & fod, thd \\
\hline $\mathrm{Ni}$ & hfa, thd, fod & Dy & fod, thd \\
\hline $\mathrm{Cu}$ & acac, tfa, hfa, fod & Ho & : fod, thd \\
\hline $\mathrm{Zn}$ & tfa, hfa, thd & $\mathrm{Er}$ & fod, thd \\
\hline $\mathrm{Ga}$ & $t f a$ & $\mathrm{Tm}$ & fod, thd \\
\hline Zr & tfa, thd & $\mathrm{Yb}$ & fod, thd. \\
\hline $\mathrm{Nb}$ & hfa & La & fod, thd \\
\hline$R u$ & tfa, hfa & $\mathrm{Hf}$ & $t f d$ \\
\hline $\mathrm{Rh}$ & tfa, hfa & $\mathrm{Ta}$ & tfa \\
\hline
\end{tabular}

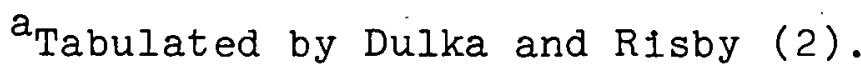

${ }^{b}$ See Table 14 for abbreviations. 
g. Neutron activation analysis With its extreme sensitivity, Neutron Activation Analysis (NAA) has become one of the most important methods for trace element analysis. Theoretical lower detection limits for NAA are. given in Table 17. These values are based on the measurement of forty disintegrations per second in a sample irradiated at $5 \times 10^{13}$ neutrons $\mathrm{cm}^{-2} \mathrm{sec}^{-1}$ for an optimum time period. Many reactors operate routinely at fluxes of $10^{13}$ and some at $10^{14} \mathrm{~ns} \mathrm{~cm}^{-2} \mathrm{sec}^{-1}$, thus indicating that: most elements can be analyzed within the range of $10^{-9}$ to $10^{-14}$ grams, a sensitivity not routinely attainable on a broad scale with other methods $(80)$.

The advantages of multi-element capability, low limits of detection for many elements, and a wide dynamic range has lead to the extensive use of NAA for the analysis of biological matrices, including blood and serum. NAA, in addition, offers two advantages which are unique to trace element methods. Errors typically introduced into an analysis by blank values of reagents used in processing the sample are avoidable in NAA by employing only postirradiation chemical manipulations of the sample. Following irradiation of the sample, the analyst does not have to be concerned with contamination by radioactively stable nuclides since the contaminants will not register on a radiation detection system. 
Table 17. NAA detection 1imits ${ }^{a}$.

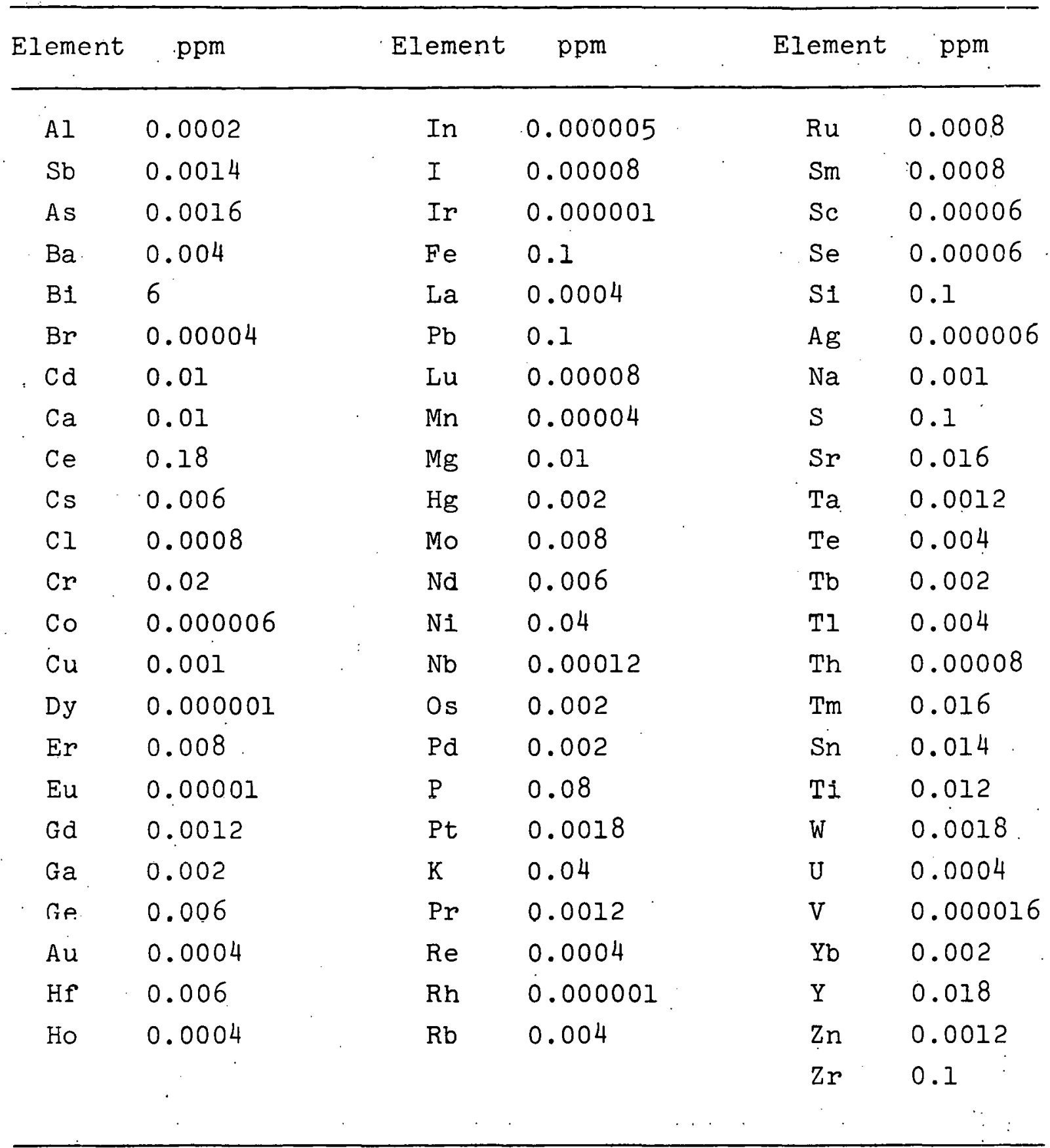

$a_{\text {Data }}$ of Leddicotte (7). 
The freedom from considerations of post-irradiation contamination suggests the second unique advantage of NAA. By adding relatively large amounts of the stable forms of radioactive elements found in the irradiated sample to the sample prior to chemical processing, the analyst has the capability of determining traces of elements while working with micro or semi-micro quantities. The larger quantities of material used for processing alleviates the difficulties associated with quantitatively reacting, separating, and recovering trace quantities. If necessary, corrections for the incomplete recovery of material can be calculated by using radioactive or stable carriers to determine the chemical yield for a particular step or procedure.

Interference-free sensitivities, such as those given in Table 17, can differ significantly from the sensitivities observed during a real analysis. Compton continuum or photopeak overlap can partially or completely obscure a. small photopeak from a trace constituent. In addition, sensitivity is determined by both fixed nuclear parameters (e.g. ., half-life, cross section, and natural abundance), and by variables which differ considerably with each installation (e..g., neutron flux, detector efflciencles, and measurement geometries). If the half-lives of the analyte nuclides and the interfering activities are sufficlently different, a judicious cholce of the durations 
of the neutron irradiation and decay periods with detection by high resolution gamma-ray spectroscopy may allow quantitative analysis. For severe interferences or unfavorable nuclear characteristics, a chemical separation may be performed to remove the interferences.

Compton background due to $15-\mathrm{hr}{ }^{24} \mathrm{Na}$ is the principal detriment to NAA analysis of biological materials. The parent nuclide, ${ }^{23} \mathrm{Na}$, has a large natural abundance, a high thermal neutron cross section, and is present at concentrations from $10^{3}$ to $10^{5}$ times greater than the trace elements of interest. These factors contribute to the production of large amounts of high energy gamma radiation. The resultant compton background obscures the low energy regions of the gamma spectra, preventing the measurement of small amounts of radionuclides in many biological matrices. Yule (84) has published a list of instrumental detection limits for NAA in various matrices, including blood (Táble 18). Note that according to Table 2 , the amounts of trace elements which have been previously determined in blood are present at levels too. low to be detected by NAA without first removing the sodium. Reference to the interference-free sensitivities (Table 17) indicates that combining chemical separations with NAA can result in considerably improved detection limits. 
Table 18. Elemental detection limits in blood with instrumental NAA

\begin{tabular}{|c|c|c|c|c|c|}
\hline Element & ppm & Element & ppm & Element & ppm \\
\hline $\mathrm{Ag}$ & 0.6 & Ho & 0.4 & $\mathrm{Re}$ & 4 \\
\hline AI & --- & I & 4 & $\mathrm{Rh}$ & 4 \\
\hline As & 4 & In & 0.1 & $\mathrm{Ru}$ & 2 \\
\hline $\mathrm{Au}$ & 0.002 & Ir & 0.006 & $S$ & 6000 \\
\hline $\mathrm{Ba}$ & 12 & $\mathrm{~K}$ & 1000 & $\mathrm{Sb}$ & 0.08 \\
\hline $\mathrm{Br}$ & -- & $\mathrm{Kr}$ & 21 & $\mathrm{Sc}$ & 0.04 \\
\hline $\mathrm{Ca}$ & 200 & $\mathrm{La}$ & 0.05 & $\mathrm{Se}$ & 4 \\
\hline $\mathrm{Cd}$ & 500 & $\mathrm{Lu}$ & 0.006 & Si & 500 \\
\hline $\mathrm{Ce}$. & 2 & $\mathrm{Mg}$ & 800 & $\mathrm{Sm}$ & 0.04 \\
\hline $\mathrm{Cl}$ & --- & $\mathrm{Mn}$ & 0.9 & Sn & 300 \\
\hline Co & --- & Mo & 2 & $\mathrm{Sr}$ & 40 \\
\hline $\mathrm{Cr}$ & 3 & $\mathrm{~N}$ & --- & $\mathrm{Ta}$ & 0.1 \\
\hline Cs & 0.4 & $\mathrm{Na}$ & --- & $\mathrm{Tb}$ & 0.2 \\
\hline $\mathrm{Cu}$ & 40 & $\mathrm{Nb}$ & 1000 & $\mathrm{Te}$ & 3 \\
\hline Dy & 0.06 & $\mathrm{Nd}$ & 6 & $\mathrm{Ti}$ & 200 \\
\hline Er & 20 & $\mathrm{Ne}$ & 500 & Ti & 300,000 \\
\hline $\mathrm{Eu}$ & 1 & $\mathrm{Ni}$ & 8000 & $\mathrm{Tm}$ & 2 \\
\hline $\mathrm{F}$ & 30 & Os & 30 & $\dot{\mathrm{V}}$ & 0.8 \\
\hline $\mathrm{Fe}$ & 300 & $\mathrm{P}$ & 1000 & W & 2 \\
\hline $\mathrm{Ga}$ & 300 & $\mathrm{~Pb}$ & 200,000 & Xe & 8 \\
\hline $\mathrm{Gd}$ & 60 & $\mathrm{Pd}$ & 3 & $\mathrm{Y}$ & 10 \\
\hline $\mathrm{Ge}$ & 50 & $\operatorname{Pr}$ & 8 & $\mathrm{Yb}$ & 0.2 \\
\hline $\mathrm{Hf}$ & 0.2 & $P t$ & 3 & $\mathrm{Zn}$ & 2000 \\
\hline \multirow[t]{2}{*}{$\mathrm{Hg}$} & 20 & $\mathrm{Rb}$ & 7 & $\mathrm{Zr}$ & 20,000 \\
\hline & & & . &. & \\
\hline
\end{tabular}


None of the previously considered methods meet all of the criteria for the ideal method (Table 19) in the analysis biological matrices. Undoubtedly, the most formidable prohibition to NAA is the cost. In situations. where the extreme sensitivity, specificity, and mult1elemental capabilities are necessary, the applicability of the method largely offsets the cost. Thus, overall, NAA with chemical separations and high resolution gamma ray spectroscopy represents the method of choice for the trace elemental analysis of biological materials. 
Table 19. Criteria. for an ideal analytical method ${ }^{a}$

1. Extremely sensitive for many elements.

2. Highly specific, but capable of simultaneous multielemental determinations.

3. Nondestructive for solids, liquids, and gases.

4. Independent of matrix effects and chemical interferences.

5. Free from contamination problems.

6. Inexpensive.

7. Simple to operate.

8. Capable of automatic operation.

9. Capable of giving absolute values independent of standards.

10. Highly precise and accurate.

11. Reasonably independent of analyst error.

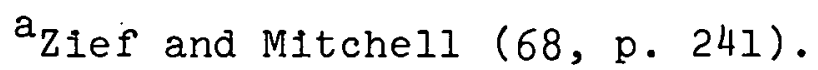


II. LITERATURE REVIEW

A. Destructive Neutron Act1vation Analysis

of primary importance in the determination of elements at the trace level in biological samples is the prevention of sample contamination and the loss of sample components during processing. Analyses of trace elements via destructive neutron activation analysis (DNAA) are particularly susceptible to sample contamination and component losses during five specific stages of processing: 1) pre-irradiation treatment; 2) sample irradiation;

3) removal of the organic matrix; 4) removal of interfering radio-activities; and 5 ) concentration and separation of analyte activities.

Individual studies of the difficulties associated with DNAA have a tendency to concentrate on a specific area of processing, resulting in solutions which eliminate problems in that area without regard to the effect of that solution on other steps in the overall procedure. Thus, it is not unusual to find an author expounding on the benefits of using concentrated hydrochloric acid as an eluent during a sodium decontamination step, while another author dealing with the removal of organic matrices warns of expected losses if the sample is processes in concentrated hydrochloric acid. In developing a complete 
procedure for the routine use of DNAA in the analysis of biologlcal samples, an attempt to synthesize a viable procedure from some of the existing but incompatible "solutions" could be a valid approach. To this end, a review of the methods presently employed to circumvent problems associated with the individual stages in analyses of biological material by DNAA is appropriate.

\section{B. Pre-Irradiation Treatment}

\section{Sample drying}

In their natural state, biological materials which are generally of diagnostic value contain a significant amount of water (e.g., whole blood, plasma, urine, soft tissue). For pathological samples of different types, the amount of water entrained with the sample can vary with sampling and storage techniques, leading to difficulties in interpreting the results on the basis of "wet" weights. In addition, the thermal and radiolysis decomposition products generated by the effects of high temperature and large neutron and gamma ray fluxes on water can create pressures which make the irradiation of samples containing appreciable quantities of water particularly hazardous. The most obvious, and perhaps the most practical, approach is to remove the water from the sample. 
Classically, the application of heat to cause evapora- . tion has'been used to remove gross amounts of water from a sample. However, the loss of elemental components, particularly volatile ones such as mercury and selenium, has been demonstrated for blological samples heated to moderate temperatures $(85-87)$.

Lyophilization or freeze-drying - the removal of water by sublimation and evaporation at low temperature and pressure - has become the most popular method for drying biological samples (85-91). However, the suitability of freeze-drying to biological samples is subject to considerable debate. Most of the uncertainty in lyophilization arises with respect to the behavior of the more volatile components, particularly mercury, during processing. LaFleur (91) reported quantitative retention of organomercury compounds in blological materials following lyophilization, while Pillay et al. (85), and Fourle and Peisach (86) under similar condjtions incurred substantial losses. Fourie also indicated the loss of selenium. Harrison et al. reported essentially quantitative recovery of all elements tested except inorganic mercury from aqueous solutions (87).. On the other hand, Litman et al. (90) experienced up to $80 \%$ losses; Foldzinska and Zmijewsk1 (89) obtalned mixed results; and Friedman et al. (92) reported no loss of mercury from aqueous solutions during freeze-drying. 
Several avenues for the reported loss of volatiles have been proposed. Most of the pathways designate vaporization, either directly due to inherent vapor pressure of the free element or an indigenous compound, or indirectly after the formation of a volatile component during processing as the principal mechanism for losses. The vapor pressure of some free elements (e.p.g., mercury, iodine, bromine, and selenium) and their respective compounds in a sample will be greater than the vapor partial pressure of the respective component in the environment of the sample during freezedrying, and losses will occur through normal vaporization $(85,87,91)$. Fourie and co-workers suggested that with real biological samples the loss of mercury and selenium is predominately through direct vaporization of organo complexes produced by physiological metabolism (86). The gross loss of mercury and possibly other elements through evaporation are also pursued by Litman et al. (90). However, in their model, the conditions of lyophilization lead to the reduction of the element to its zero oxidation state prior to vaporization. Calculations based on the Nernst equation support their model. MacKenzie, while not specific, indicates that some chemical reactions unlikely by thermodynamic considerations are possible in a lyophilized sample wherein finite water activities cannot be demonstrated (89). In his model, trapped residual water 
or another species (notably oxygen) can react with nearest neighbors on a molecular basis, thus opening the possibilities for oxidation - reduction reactions which could lead to losses. In support of vaporization, Litman and co-workers have demonstrated that the primary loss of volatiles cannot be attributed to entrainment of those components in the withdrawn water vapor.

Whatever the mechanism for the elemental losses, a number of factors affecting experimental recoveries have emerged: 1) in "spiking" experiments, where tracers are added to a sample, inorganic and organo-metallic tracers behave differently. Typically, the lower volatility of the inorganic compounds usually results in higher recoveries $(85,90,91) ; 2)$ the results of "spiking" experiments, utilizing either inorganic or organo-metallic compounds, cannot be extended to experiments employing physiologically incorporated tracers (86); 3) many parameters such as total ion content, concentration of a specific element, percent of water initially present, and acidity can influence the retention of components during freeze-drying $(90,91)$; and 4 ) the presence of some functional groups can affect the behavior of an element in a matrix $(89,91,92)$.

With respect to the final point, the presence of sulfhydryl groups as found in proteins correlated with improved recoveries of mercury from biological samples (89, 91). This explains in part the differing results of 
"spiking" tracer experiments and biologlcally incorporated tracer experiments. Indications are that in a natural environment, an element will be contained in an organism in both metabolized and nonmetabolized (absorbed) forms, resulting in variable freeze-drying results. More importantly, the results suggest that samples of differing origins within an organism. will behave differently during freeze-drying. Quantitative recoveries of mercury from blood but significant losses from urine samples may be explained in this manner.

In considering the merits of lyophilization, the analyst is in a difficult position. Most of the information concerning lyophilization was obtained through work with the volatiles mercury and selenium, and the results cannot necessarily be applied to work with the more refractory elements. Although some workers have included data for other elements, the variety of species used for incorporation, the different techniques of incorporation, and the number of matrices employed in the testing make the comparison of results from different experiments dubious. In the face of the discussion concerning lyophilization, the National Bureau of Standards insists that biological Standard Reference Materials should be lyophilized before use (93).

In order to fully exploit the attribute of neutron activation analysis which renders contamination by reagent 
blanks negligible, no other operations are usually performed on the samples prior to irradiation.

2. Containment during Irradiation

The choice of a proper vessel for the containment of biological samples during the irradiation phase of DNAA is critical for a successful analysis. First of all, the vessel must be able to contain the original sample and all radiolysis and thermal degradation products generated at the reactor operating temperature with large radiation fiuxes. The environment within the reactor requires that the vessel material maintain structural integrity at temperatures in excess of $100^{\circ} \mathrm{F}$ in an integrated neutron flux of $10^{17}$ to $10^{18}$ neutrons per $\mathrm{cm}^{2}$, which is approximately equivalent to a 15 hour irradiation at a neutron flux of $3 \times 10^{13}$ neutrons per $\mathrm{cm}^{2}$ per second. (The irradiation time and flux intensity are typical of those reported in the literature, and are quite reasonable parameters for the average research reactor.) Since some of the degradation products are gases, and relatively volatile components are known to be inftially present in most samples, the 1rradiation vessel must also be impervious to gaseous diffusion. The irradiation process drastically alters the sample, and a weighed aliquot of the irradiated residue 
will in most cases not be representative of the original sample. Thus, for the purposes of DNAA, the ideal irradiation vessel should allow complete recovery of any material placed into it. Normally, charring of the organic material and recoil reaction from decaying nuclei cause the adherence or embedding of sample components into the walls of the irradiation container. The embedded materials are particularly resistant to ordinary decantation methods.

Traditionally, polyethylene has been a favorite material for constructing irradiation vessels $(94,95)$. Though avaliable in a variety of forms with a fairly low contamination blank, the polyethylene can be further "cleaned" by treatment with nitric acid (96). A number of authors have investigated losses of mercury during sample irradiation in plastic containers (94, 97-99). The recommendations for controlling losses during irradiation (i.e.., addition of strong mineral acids, oxidizing agents, or hydrogen sulfide) suggest that the mechanism of loss involves vaporization of either a high volatility mercury compound or elemental mercury, followed by diffusion of that component through the plastic. Loss of halogens during irradiation has also been reported (100). At the Ames Laboratory, failure to quantitatively remove some nuclides 
(e.g.g., mercury, arsenic, antimony) from polyethylene vials following irradiation has been experienced (101). Extensive structural damage and a concomitant loss of containment integrity have been experienced with polyethylene vessels when irradiated for $15 \mathrm{hrs}$ in a neutron flux of approximately $3 \times 10^{13}$ at an ambient reactor temperature of $130^{\circ} \mathrm{F}$ (i02).

Some authors have recommended sealing biological samples into quartz ampoules (103-106). They have shown that quartz capsules are able to withstand the reactor. environment during extended radiations if certain packing restrictions and considerations for shock during transport are followed. The elemental blank for natural quartz is generally too large for most applications, but a number of specially fabricated quartz materials, such as Quartex fused quartz and Spectrosil fused sllica, with elemental blanks that are appreciably lower than either natural quartz or polyethylene, are commercially available and have been evaluated (106). Further reductions of the indigenous blanks of the synthetic quartz materials have also been accomplished by treatment with nitric acid and etching with hydrofluoric acid (106). Even after treatment, however, the levels of some elements in the synthetic materials are still comparable to the levels of these elements in blood serum. 
With respect to the total removal of the sample from the irradiation vessel, quartz could represent a significant advantage over polyethylene. Since it has been shown that strong acid oxidizing conditions (1..e., the medium used for "cleaning" the irradiation capsules) can remove elemental components from both polyethylene and quartz, the conditions typically used for the destruction of organic matter in the later stage of a DNAA procedure could remove both the adhering charred organic matter and the recoll - embedded material from the Irradiation containers. However, since polyethylene is an organic material, partial or complete destruction of the container would add a significant.blank from the polyethylene to the sample. In the case of quartz, the blank contribution should be minimized since the bulk of the material will not be affected and any contamination will. be limited to contributions from the surface. The surface contribution should be low if previously described clean-up procedures are employed. Of course, the extent of the surface contribution will have to be examined to ascertain its significance relative to the content of the sample.

\section{Destruction of Organic Matter}

Destructive neutron activation analysis implies that the bulk of the sample along with any components which may be detrimental to determination of the trace elements is removed prior to the measurement of the analyte species. 
The mechanism of most chemically oriented separation processes requires the atoms to be present in an ionic form. Furthermore, the effectiveness of the separation procedures is dependent on the specific ionic states which are present. Thus, an analysis of a biological material for trace elements which may be incorporated into large organic complexes requires the destruction of the organic matrix, subsequently freeing the trace elements as ions. Methods for the destruction of organic material are categorized as either "wet" or "dry" ashing. Wet ashing, generally referred to as "digestion", typically requires an acid oxidizing medium under reflux, whereas dry ashing usually requires only the addition of heat. Although the literature decisively favors wet digestion to dry ashing of biological samples, disagreement over the applicability of different wet digestion systems to blological materials is rampant.

\section{Dry ashing}

Dry ashing proceeds with the heating of a sample contained in either a porcelain or platinum crucible to a maximum temperature between 450 and $700^{\circ} \mathrm{C}$ for periods ranging from a few minutes to a couple of days. Under these conditions, the organic matrix is theoretically oxidized primarily to carbon dioxide and gaseous water, which are removed from the system leaving behind a mineral product which should be soluble in an appropriate solvent, typically 
an aqueous acid. There is general agreement that such a procedure results in the loss of the more volatile components ( $\underline{\underline{i}} . \underline{\mathrm{e}}$, arsenic, selenium, mercury, and halogens) from biological samples (107-109). Evidence suggests that for some elements, the volatile forms indigenous to the samples can be converted to less volatile mineralized forms via the application of ashing aids, such as magnesium nitrate and sulfuric acid, and low levels of heat (preashing) prior to the imposition of the harsher conditions required for ashing (109-123). Pre-ashing has been accomplished through the use of a temperature programmed furnace and by starting with a cold furnace which allows a slow increase to ashing temperature (110-112). One of the most successful applications of the pre-ashing technique was reported by LeBlanc and Jackson who obtained quantitative recoveries of arsenic from fish tissue by pre-ashing with an infra-red lamp, followed by ashing at $500^{\circ} \mathrm{C}$ in a muffle furnace (112). Generally, high temperature dry ashing has been successful only in analyses for the more refractory elements or elements which form refractory compounds. Gorsuch has compiled an extensive collection of data in which elements at the trace level can be successfully determined after dry ashing $(109,123)$. Though the losses of trace elements due to volatility seem to have attracted the most scrutiny, Koirtyohann and 
Hopkins reported that adherence of components to the ashing vessel was the most frequently encountered factor limiting quantitative recoveries (110). Gorsuch and Hamilton indicated that the extent of adherence-type losses was a function of age and history of the containers (108-109). Their work suggests that recovery of the embedded material was not possible.

Orvini et al. employed the volatility of specific elements during dry ashing as a means to separate trace components from organic matrices (114). At a final temperature of $1180^{\circ} \mathrm{C}$, they were able to volatilize selenium, arsenic, zinc, cadmium, and mercury, and quantitatively collect the components downstream in a cold trap. This procedure should work for any elemental components of sufficient volatility, but the charred material remaining in the combustion vessel is not amenable to collection and further analy-sis of the less volatile components.

Low temperature dry ashing which utilizes the energy of an oxygen plasma excited by a radio-frequency generator offers one definite advantage over the standard dry ashing procedure: the ambient operating temperature of the plasma is typically less than $120^{\circ} \mathrm{C}$. The lower ashing temperature should mitigate the loss of volatiles. Since Gleit and Holiand (115) introduced the method with reported favorable results for the determination of volatile components in 
spiked blood, a number of contradictory findings have been reported: Mulford has shown that the loss of arsenic and selenium from biological samples during low temperature dry ashing in a plasma system is a function of the applied radio-frequency power (116). Hamilton et al. referred to the low but consistent loss of seventeen elements from dried ox blood (108). Following a series of experiments with spiked and natural fish tissue, Pilly et al. pronounced low temperature ashing to be unsuitable for the preparation of fish samples for neutron activation analysis (85). To further confuse the problem, Lutz et al. have confirmed the original work of Gleit and Holland, indicating no appreciable losses of volatiles during low temperature ashing with an oxygen plasma (117).

Other difficulties with low temperature oxygen plasma ashing have been reported. Varcoe has stated that ashing times are quite long and that a large surface area of the sample must be exposed if ashing times are to remain practical (5, p. 52). One group of authors has implied that there is some difficulty in ensuring that all of the sample material is removed from the apparatus following ashing (117). In that work, the authors found it necessary to use "nonvolatile"-tracers to determine sample yield from the ashing chamber. Hamilton et al have reported that the plasma does not adequately penetrate. some 
samples (e.g., powdered bone) (118), which necessitates stirring the sample to ensure completeness of ashing operation. Overall, the literature suggests that low temperature plasma ashing can be of value for processing. biological samples. However, the results are dependent on the particular matrix to which the process is applied.

\section{Wet ashing}

Wet ashing is the most commonly used method for the destruction of organic matter (109). Applicable at significantly lower temperatures than dry ashing and usually proceeding under reflux conditions, wet ashing or digestion is a natural choice whenever there is a possibility of loss of components through volatilization. Gorsuch has extensively investigated and reviewed wet digestions with respect to the loss of trace elements and its applicability to various matrices $(107,109)$. The majority of wet ashing methods are variations of the singular or mixed application of nitric, perchloric, and sulfuric acids to organic materials (107,109,113, 120-124). Special low temperature wet digestions requiring the addition of strong oxidizing agents to the basic three acid media have been reported. Malaiyandi and Barrette have described the advantages of lower digestion temperatures and shorter processing times gained by the addition of vanadium pentoxide as an oxidizer/catalyst to the 
nitric - sulfuric acid digestion system (125-127). Other. catalysts proposed for general use in variations of the three acid system include ammonium metavanadate (128), sodium molybdate (129), and chromic acid (130).

Since its introduction by Polley and Miller (131), $50 \%$ hydrogen peroxide has gained wide usage as an oxidizer in variations of the nitric - perchloric - sulfuric (NPS) acid digestion systems. Although originally employed as a secondary of "clean-up" oxidizer, Down and Gorsuch (132) investigated the feasibility of using $50 \%$ hydrogen peroxide as a primary oxidant for organic materials. In systems where volatile components are the object of the investigation, milder digestion conditions employing potassium permanganate have become popular (122, 133-135).

Some insight into the versatility of the basic NPS acid digestion system and its variants is contained in the currently accepted description of the wet ashing process. Shemyakin and Shchukina contend that most wet oxidations are oxidative-hydrolytic processes, with insertion of oxygenated substituents by the oxidizing agent serving to facilitate hydrolysis of the organic material (136). Studies with substituted compounds led them to conclude that the occurrence of general hydrolysis coincldes with the existence or the potential existence of the grouping

$$
\mathrm{HO}^{\prime}-\mathrm{C}-\mathrm{C}-
$$


The formation of this grouping from polarized double bonds is a function of the degree of polarization, and, hence, related to the nature of the substituents on the $\alpha$ and $\beta$ carbon atoms. The presence of electron donating substituents on the $\alpha$-carbon, and electron accepting substituents on the $\beta$-carbon greatly ease hydrolysis, where the presence of similar substituents on both carbons clearly neutralizes the effect. The use of the NPS acid mixtures as digestion medium accords well with these principles if the following points are considered:

1) sulfuric acid is a dehydrating agent which can readily produce double bonds; 2) nitro groups are strong electron acceptors; and 3) hydrogen peroxide readily introduces hydroxyl groups into many molecules.

Even after years of usage, there is still controversy in the literature regarding the loss of trace components from biological samples treated with combinations of the NPS acid-oxidation digestion system. The original procedure required refluxing the sample in a mixture of the three acids, followed by increased heating to drive off the nitric acid and to allow the stronger oxidizing properties of the perchloric acid to act on the sample. In some cases, intense heat was applied with only sulfuric acid to aid the destruction of the sample by charring the organics prior to introduction of the nitric and perchloric aclds. 
The following points have been identified as significant with respect to achieving quantitative retention of trace components during a wet digestion involving the NPS systems $(107,109,119-130):$ 1) the temperature for refluxing the acid mixtures (approx. $120^{\circ} \mathrm{C}$ ) is sufficient to cause losses through the volatilization of some components. 2. Charring the organic materials in sulfuric results in the loss of material because of volatilization of components at the high charring temperatures (approx. $200^{\circ} \mathrm{C}$ ), and through the reduction of some elemental components (e. $\underline{\text { g. }}$, selenium and mercury) to the more volatile zero oxidation state. 3. Halogens, even in the amounts present in analytical grade perchloric acid, should be excluded from the digestion medium due to the possibility of the formation of volatile halides. (Table 20 contains a listing of boiling points for some commonly occurring halides.) 4. With some samples, the amount of sulfuric acid should be limited to prevent the precipitation of insoluble sulfates and the subsequent loss of trace components through co-precipitation.

5.. Perchloric acid in the presence of certain organic materials represents a definite explosion hazard. Charring of organic materials in the presence of perchloric acid and evaporation of perchloric acid mixtures to dryness should be avoided. It is recommended that perchloric acid should. always be used in the presence of sulfuric acid to prevent accidental evaporation to dryness. 
Table 20. Boiling points of halides which could form during wet ashing.

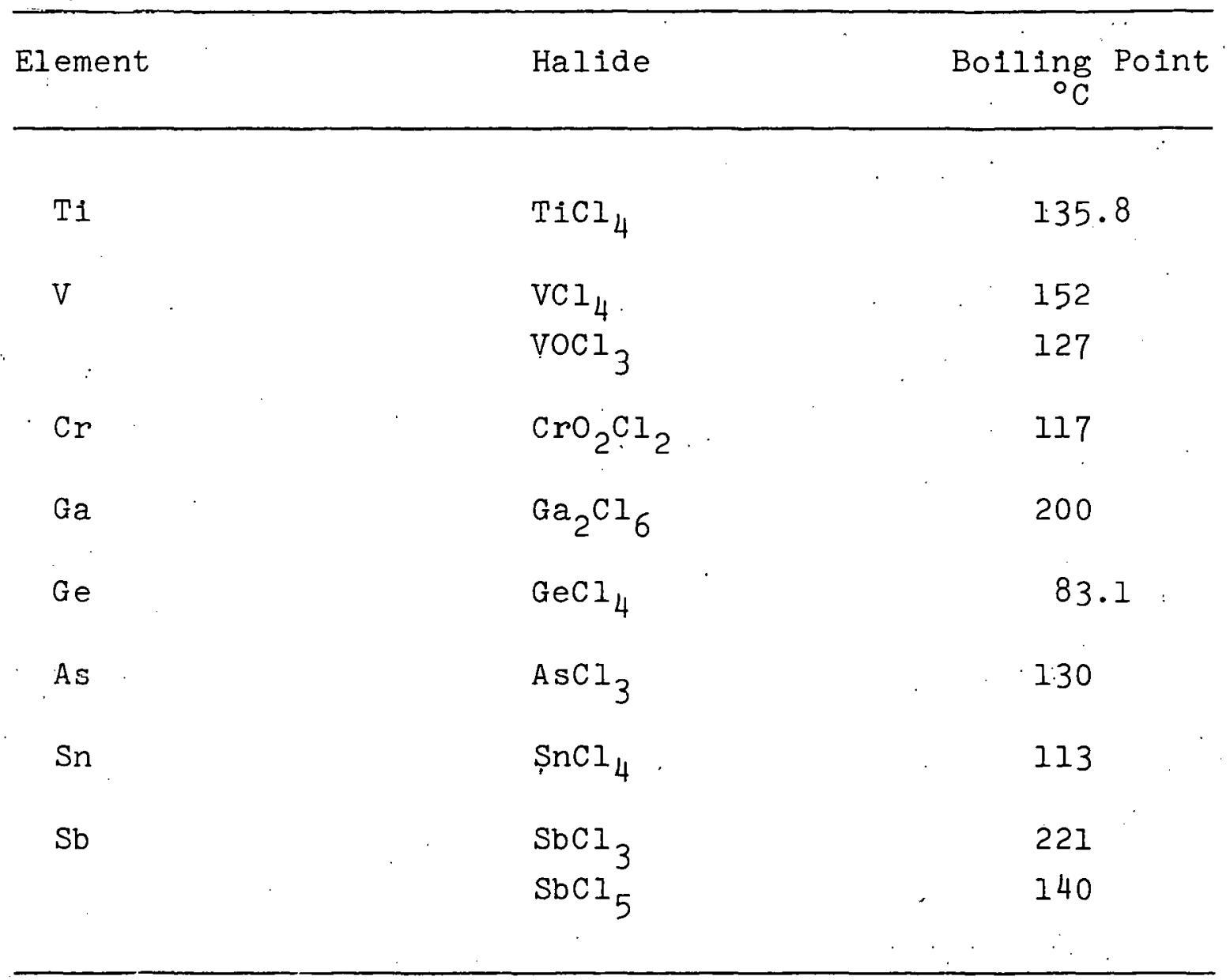


The many variants of the baslc NPS acid digestion system evolved as analysts employed combinations to selectively avold the particular factors listed above. Thus, Chernoff (123) used all three acids in a controlled temperature procedure to digest fish tissue; Isaac and Johnson (113), Feldman (121), and Abu-Samra (124) ut1lized only nitric and perchioric acids in a controlled temperature process for. ashing various biological materials; and Malaiyandi and Barrette (125-127) employed nitric and sulfuric acids along with a catalyst to achieve destruction of biological matrices.

As different modifications on the NPS systems gained in popularity, disputes arose about the effectiveness of some of the milder digestion systems. For example, Portmann and Riley clalmed that the use of sulfuric acid in digestion systems resulted in the loss of arsenic through volatilization (137). They suggested that nitric acid alone is sufficient for tissue samples, and would allow quantitative recovery of arsenic. On the other hand, Sach et al. clalmed that a long period of fuming in sulfuric acid was necessary to destroy carbon-arsenic bonds. Furthermore, they demonstrated that arsenic was not lost in that environment (138). One point of agreement concerning the milder variants is that those systems not employing: perchloric acid or a strong heating step will not achieve complete destruction of the lipids (125). 
The sulfuric acid-hydrogen peroxide ashing system offers a method with a potentially low blank if preirradiation treatment is necessary, and is a procedure which does not require external heating (109). The products of the digestion medium should consist primarily of water and oxygen, which should not interfere with any further chemical processing. Also, in this system removal of excess oxidizer could be accomplished by refluxing the mixture. Gorsuch and Down examined the recovery of trace elements in the sulfuric acid-hydrogen peroxide system during the destruction of organic materials (132). They reported incomplete recovery of germanium, ruthenium, arsenic, and selenium. No one reason could be glven to account for all observed losses. Germanium and ruthenium losses appeared to result from volatilization of the higher oxides, selenium apparentiy volatilized as the hydride and simple alkyls following charring of the organics in the sulfuric acid, and the loss of arsenic was attributed to the formation of high volatility chlorides. Since the reported losses appear to be matrix related, these results cannot be extended to different biological matrices.

The permanganate ashing systems have been developed to avold volatilization problems, excessive oxidation conditions, and general hazards associated with NPS acid systems $(130,132,133)$. In a typical procedure, the sample 
is initially treated with only sulfuric acid, followed by: extended treatment with an excess of potassium permanganate. This procedure has two disadvantages: 1) the method is limited to samples which will not precipitate sulfates; and 2) permanganate is not an effective oxidizer for large quantities of organic material (134,139, p. 840). To ensure complete digestion, some authors have employed potassium persulfate as a stronger oxidizer following the permanganate step (140). Even with the second oxidizer, permanganate digestions typically require significantly longer time periods than other wet digestion methods. There exists a genuine lack of data concerning the behavior of trace elements in these systems because they have been employed almost exclusively in determinations of mercury and selenium.

The acid pressure bomb has not been extensively used for the digestion of biological materials; however, its basic operation indicates that it could perform adequately. Losses of high volatility components should be minimized since the digestions occur in an impermeable container which can be cooled to condense out the volatiles prior to opening ( $68, \mathrm{p} .165)$. A decrease by a factor of eight in the time necessary for acid pressure bomb vs. NPS digestion of fish tissue has been reported (68, p. 165). Also, quantitative recovery of most cations has been reported 
(141). These digestions are usually performed prior to. irradiation, thus requiring ultra-pure reagents to avoid contamination.

The advantages of faster destruction, freedom from gross losses of trace elements, and relative simplicity of equipment indicated that wet digestions are probably the most effective means for the destruction of organic matrices. The extensive data already available, and the versatility of the system, suggest that a variant of the NPS acidoxidizer system can be developed to handle a number of different matrices prior to follow-up chemical processing as part of an overall procedure for DNAA analysis of biological materials.

\section{Decontamination and Concentration}

The advantages, represented as higher sensitivities and lower detection limits, of DNAA over instrumental neutron activation analysis (INAA) are derived from the capability to remove contaminating activities and to concentrate the analyte activities prior to assay by gamma ray spectroscopy. In the analysis of biological materials by DNAA and INAA, the primary sources of radioactivities which interfere with gamma ray spectroscopy are the radioactive 1sotopes of sodium, bromine, phosphorus, and potassium. The occurrence of ${ }^{24} \mathrm{Na}$ in irradiated samples 
poses the most serious detriment to accurate, precise spectroscopic assay. The large natural abundance, sizable cross-section for thermal neutron capture, and pervasiveness of stable sodium $\left({ }^{23} \mathrm{Na}\right)$ in biological systems, coupled with the moderate half-life of ${ }^{24} \mathrm{Na}$, cause the gamma peaks associated with ${ }^{24} \mathrm{Na}$ to be the major activities present following irradiations under all but the most extreme conditions.

The principal gamma rays of ${ }^{24} \mathrm{Na}$ have energies of 2753 and $1368 \mathrm{KeV}$. In gamma ray spectroscopy, the gamma ray is "detected" as the absorption of its energy by the detector material, which is lithium drifted germanium for high precision work. However, the absorption of the gamma ray energy is a multiple event process wherein a portion of the total gamma ray energy is absorbed with each interaction with the detector until the total energy available is absorbed or the remnant gamma ray escapes from the detector. If all of the interactions generated by the entrance of a single gamma into the detector occur within the detector, the gamma ray will be sensed as a photopeak at an energy represented by the sum of the energies absorbed in each interaction. Alternatively, if some of the secondary radiation escapes from the detector, the energy imparted by the partial absorptions of the gamma ray will register as distinct gamma ray peaks. Since the absorption 
processes are not quantized, and all absorptions occurring. within the detector crystal are summed, the virtual photopeaks can occur at all energies below the energy of the full or total gamma peak. As the intensity of the true photo-'. peak increases, the virtual peaks will be manifested as a high background extending up to the full energy peak, but will be particularly evident on the low energy side of the photopeak as a severe distortion of the theoretical Gaussian shape of that photopeak. This background, called Compton background, can obscure lower intensity analytical peaks, and can cause distortions in the shapes of the photopeaks. As the distortion of the peak shape from the idealized gaussian function increases, so does the inaccuracy in the peak areas as determined by peak fitting computer programs.

Radioactive bromine, the second most observable component in the gamma spectra of irradiated blological materials following moderate irradiation periods, produces the same type of Compton interference as ${ }^{24} \mathrm{Na}$. In addition, the primary activity, ${ }^{82} \mathrm{Br}$, has approximately 18 gamma photopeaks which increases the possibility that a bromine photopeak will interfere with or obscure a gamma peak of analytical interest.

Unlike sodium and bromine, the principle activity produced by the irradiation of stable phosphorus, ${ }^{32} \mathrm{P}$, 
decays as beta particles (negatrons) rather than by gamma emission. The negatrons usually do not reach the detector because they are absorbed by air or by polyethylene absorbers placed expressly for this purpose before the detectors. However, the capture of the negatron by the absorber releases electromagnetic radiation, bremsstrahlung, which can reach the detector. The release of negatrons by decaying atoms, the absorption of negatrons by the absorber and the subsequent release of radiation, and the final absorption of the bremsstrahlung by the detector are not discrete processes. Consequently, the bremsstrahlung radiation which reaches the detector will appear as a background. superimposed over the gamma ray spectrum for the sample. The background theoretically extends up to $1.71 \mathrm{MeV}$, the maximum energy possessed by a negatron emitted by. a decaying atom of ${ }^{32} \mathrm{P}$, but is typically most apparent as a maximum below $400 \mathrm{KeV}$. Beside the quantities of stable phosphorus present in hiological materials, ${ }^{32} \mathrm{P}$ can also be produced by the interaction of fast neutrons with stable forms of chlorine and sulfur.

Irradiation of potassium by thermal neutrons produces $42 \mathrm{~K}$, which is a gamma emitter. Consequently, the same type of interference as produced by ${ }^{24} \mathrm{Na}$ and ${ }^{82} \mathrm{Br}$ is encountered. It is interesting to note that the interferences from potassium activities are generally not noticeable in 
irradiated biological samples until after removal of the sodium.

Successful analyses of biological materials have been accomplished without chemical separation of the interfering elements (142). The half-lives of the spectral contaminants, ${ }^{24} \mathrm{Na}$ and ${ }^{42} \mathrm{~K}$, are sufficiently short (‥i.e. 15 and 12.4 hours, respectively) that an appropriate delay before spectroscopic assay can effectively eliminate interferences associated with these components. However, during the delay, the radiation intensity from analyte species having half-lives comparable or less than the contaminants will also diminish. In effect, information on a number of biologically 1mportant elements (e.g.g., copper, molybdenum and arsenic) can be lost. The half-lives of the bromine and phosphorus contaminants ( 35 hours and 14.3 days, respectively) are too long for short decay periods to be effective.

1. Sodium and potassium decontamination

Sodium was recognized early as a detriment to analyses by nonnuclear techniques, and many procedures have been developed for its separation from various matrices. The earliest sodium decontamination procedures employed precipitation or crystallization as isolation methods. In 1927, Kolthoff reported the reduction of sodium content in mineral samples to $10^{-3}$ moles/liter by precipltating the 
sodium with uranylacetate (143). The radioactivity from the fissioning uranium which remained in the solution made the procedure incompatible with assay by gamma ray spectroscopy. Ricq successfully precipitated sodium as sodium chloride by the use of concentrated hydrochloric acid (144). The method was designed for removing sodium from samples which had been previously processed by fusion techniques (……, with sodium. carbonate, caustic soda, or sodium peroxide), and does not effectively remove less than milligram quantities. Menon and Wainerdi also precipitated sodium in the chloride form, but did so from a medium of hydrochloric acid and butanol. According to Torok and Diehl, the procedure must be performed repeatedly on a sample in order to achieve the necessary efficiency (145). Banks and Richards and BockWerthmann precipitated sodium in the form of organic salts of $\alpha$-methoxyphenylacetic acid and S-benzamino-anthraquinonesulphonic acid $(146,147)$. In the latter case, reduction of the sodium concentration to $10^{-6}$ moles/liter was achieved. The precipitation methods suffer from the disadvantage of co-precipitation of trace components. In his precipitation procedure, Bock-Werthmann reported that precautions are taken to avoid co-precipitation of trace elements of interest (147). The organ1c medium used in several of the precipitation procedures also presents difficulties if further separation or concentration methods are required. 
This is particularly critical because precipitation methods always dilute the sample during processing requiring, in some cases, removal of the excess solvent prior to assay. Ion exchange in various forms has been exploited in sodium decontamination processes. In 1963, Spronk reported a low sensitivity anion exchange procedure for sodium removal (148). Tera et al. used precipitation ion exchange in concentrated hydrochloric acid to remove sodium in the chloride form $(149,150)$. The high salt concentration suppressed the distribution coefficients of the trace elements effectively, avoiding co-precipitation. Morrison has referred to another procedure by Tera which removed radioactive sodium by isotopic exchange on a cation exchange column which had been saturated with stable. sodium (147). Tang and Maletskos first reported the 1sotopic separation of radio-sodium $\left({ }^{24} \mathrm{Na}\right)$ on a column of finely divided sodium chloride in an acetone-hydrochloric acid medium (151). Bowen and cook later confirmed this work and extended the procedure to use columns of sodium perchlorate (152). The latter work pointed out the sensitivity of the method to the conditions of the column and to the preparatory history of the salt forming the column. Bowen also demonstrated that other elements in addition to sodium were susceptible to absorption on the salt columns. 
At first glance, hydrated antimony pentaoxide (HAP) seems to possess ideal characteristics for inclusion in a procedure for removing sodium from biological samples following an acid-oxidation digestion. While surveying precipitates of various oxides, Girardi and Sabbioni found that HAP could selectively and quantitatively remove sodium from solutions which were $12 \mathrm{M}$ with respect to hydrochloric acid (153). Of the 60 elements studied for absorption, tantalum was the only other element found to be quantitatively absorbed from the 12M hydrochloric acid solutions. Other reported properties which favored the use of HAP for sodium decontamination include: 1) a batch equilibrium total capacity for sodium of $30 \mathrm{mg} / \mathrm{g}-\mathrm{HAP}$; 2) a column breakthrough capacity for sodium of 12 $24 \mathrm{mg} / \mathrm{g}-\mathrm{HAP}$; and 3) a column equilibrium sodium decontamination factor of $10^{10}$ from $12 \mathrm{M}$ hydrochloric acid.

Although a specific mechanism of operation for HAP was not given, the authors did identify a number of favorable factors with respect to the mechanism. 1) The sodium was irreversibly bonded to HAP. Rinses with more eluents and other alkali metals could not displace the sodium. 2) High loading of the columns did not change the distribution coefficient of sodium, indicating that any amount of sodium could be removed as long as enough HAP was present. 3) The adsorption of sodium by a specific amount of HAP reached a 
plateau which did not increase with time. This indicated that the absorption of sodium was a surface process and the sodium did not diffuse into the bulk of the material.

Since the initial report, HAP has been extensively studied, and inconsistencies and disputations abound (145, 153-161). Krishnan and Crapper, while trying to extend the work of Girardi and Sabbioni to different concentrations of hydrochloric acid and different acids, found that scandium, silver, and potassium were also adsorbed to a limited extent from 12M hydrochloric acid solutions (156). The partial adsorption of scandium on HAP was also supported by Gills et al. (1.54). In direct contradiction to Girardi and Sabbioni is a report which stated that sodium could be eluted from HAP with either nitric acid or ammonium nitrate (155). Konecny and Hartl reported a significantly lower selectivity of HAP for sodium over the other alkali metals (158). The high capacity of HAP for sodium has been verified by Caletka et al. (155), but has been contradicted by Baestle and Huys (159), and Ralston and Sato (157). Baestle and Huys have proposed and shown experimentally that, based on a structure which they determined for HAP and on their mechanism for 1ts operation, the theoretical maximum for adsorption of sodium on HAP is $5.05 \mathrm{mg} / \mathrm{g}-\mathrm{HAP}$. Ralston and Sato reported that with treatment by HAP in hydrochloric acid, they were only able to reduce the sodium 
content of real samples by factors ranging from 0.013 for rocks to $3.8 \times 10^{-5}$ for protein samples.

Similar disagreements are apparent over the mechanism which accounts for the selectivity of HAP. As mentioned previously, Girardi and Sabbioni in their original work did not propose a mechanism for operation of HAP (153), but they did produce experimental results which ruled out simple ion exchange, counter-ion exchange, and isotopic exchange as the singular mode of operation. However, Konecny and Hartl, and Caletka et al. then proceeded to propose explanations for the properties of HAP based solely on ion exchange phenomena $(155,158)$. Their results were only partially successful in describing the behavior of ions on HAP columns. Baestle and Huys showed that the behavior of ions which were not particularly susceptible to absorption on HAP could be accounted for on the basis of an ion exchange mechanism (159). Nagy et al. although not proposing a mechanism, demonstrated that an ion exchange mechanism was valid for absorptions from low acidity solutions but invalid at high acidities (…‥, 12M HCl) (160): The present state of knowledge of the properties and operation of HAP is probably not as bad as a cursory glance at the literature seems to indicate. One reason for the apparent contradictions is that many of the experiments and, therefore, findings are not directly comparable. The 
difficulty in comparing arises because the authors were probably not working. with the same materials. The HAP used in the original work by Girardi and Sabbioni was produced by Carlo Erba of Milan, Italy, via a proprietary process (153). As reported, the synthesis involved the hydrolysis of antimony pentachloride. The studies done by Caletka, Konecny and co-workers used "HAP" synthesized by the hydrolysis of hexachloroantimonic acid $(155,158,161)$. Baestle and Huys produced "HAP" by three different methods, each having the same apparent structure but vastly different absorption properties for sodium in nitric acid (159). Torok and Diehl always used antimony(III) oxide dissolved in aqua regia as the starting material in the synthesis of "HAP" (145). They also showed that variations in the synthesis parameters, such as time for hydrolysis, and time and temperature of drying, would produce chemically similar products with significantly different absorption properties. Even those researchers who had access to HAP prepared by Carlo Erba reported inhomogeneities and varied results with different batches $(145,154,156,157)$. Though there is some ambiguity with respect to overall selectivity, capacity, and mechanism of operation, not one author disputed the fact that HAP quantitatively removed sodium from all of the acid systems which were tested. 
After the removal of radio-sodium, researchers realized that radio-potassium also contributed significant interference to assays by gamma ray spectroscopy. For this reason, methods for potassium removal first appeared as side products of sodium removal procedures. The previously described method of Tang and Maletkos, utilizing finely divided sodium chloride and an organic eluent (acetone-HCl) for the removal of sodium was adaptable to the removal of potassium (151). The disadvantages of an organic solvent and the sensitivity of the columns to preparation methods were still operative with the lower acid concentrations needed for potassium separations. In the same paper where they disclosed the properties of HAP for sodium decontamination, Girardi and Sabbioni demonstrated that potassium could also be removed from acid solutions if the concentration of the acid was decreased (153). At the reduced acid molarities a marked decrease in the selectivity of HAP was encountered.

Massart studied a number of inorganic exchangers for use as a stationary phase in the removal of radio-potassium from. acid solutions (162). Both potassium phosphomolybdate (PPM) and potassfum phosphotungstate (PPT) removed potassium from acid solutions. The latter material, because of its superior characteristics for preparing columns, was chosen for more intensive study. Radio-tracer 
studies showed that sodium, arsenic, and selenium were absorbed to varying extents with potassium on PPT from 9M hydrochloric acid (162). A critical disadvantage of PPT for routine applications is the small grain size of the precipitate, which prevents an adequate flow through columns without a pressurized setup.

Titanium phosphate (TIP) is another Inorganic exchanger used in the removal of radio-potassium from digested biological samples $(163,164)$. Nagy et al. have provided a basis for the synthesis of TIP with an enumeration of the many factors which must be controlled during synthesis (164). The actual synthesis parameters for the optimum material are not given. Considerable care must be exercised to ensure repeated synthesis of the same product. Although no information is provided concerning the selectivity and capacity of TIP for potasslum, a scheme employing the material for the removal of potassium from digested biological samples was presented $(163,164)$.

\section{Phosphorus decontamination}

Following acid digestion of biological materials under oxidizing conditions, phosphorus is usually present as the phosphate anion (165). The methods which have been employed for the removal of phosphate concentrated on using inorganic exchangers. Tin dioxide (TDO), hydrated manganese dioxide (HMD), acid aluminum oxide $(A A O)$, and zirconium phosphate 
(ZRP) have been studied for selectivity, capacity, and decontamination factors in the removal of phosphate from acid solutions (163-167). Following studies of TDO, HMD, and $A A O$, In various eluents, Sabbioni et al. chose AAO as the most promising material for phosphate decontamination (165). TDO was eliminated because of a lower overall capacity for potassium, and HMD was effective only in perchloric acid solutions. The properties of AAO were evaluated in acid molarities up to $7 \mathrm{M}$, which is considerably below the level at which HAP has been found to be most effective for selective removal of sodium. This indicates a need for evaluation of $A A O$ at higher acid concentrations prior to it coupling with a HAP column in a combined sodium and phosphorus decontamination step. Particularly detrimental to the potential coupling of $\mathrm{HAP}$ and $\mathrm{AAO}$ is the inability of AAO to absorb phosphorus from solutions of hydrochloric acid, which is the best eluent for the operation of a HAP column (165). AAO has also been shown to absorb arsenic, molybdenum, tungsten and antimony at all molarities tested, necessitating the determination of yield factors or a different method for those elements $(165,167)$.

Most of the work involving zirconium phosphate (ZRP) has been deta1led by Nagy, Torok, and co-workers (163,.164). Girardi et al. have published data concerning the selectivity of ZRP for other elements (167). The synthesis 
procedure detailed by Nagy et al. is typical of methods for the production of hydrated amorphous precipitates. The properties of the resulting material are dependent on the synthesis conditions to the extent that the consistent production of a satisfactory product becomes an art (164). As with $A A O$, the characteristics of $Z R P$ have been reported for solutions up to. $7 \mathrm{M}$ in acid, and the absorption of trace elements by $\mathrm{ZRP}$ is clearly a function of the acid molarity of the solution (167).

\section{Extraction decontamination methods}

The basic philosophy in the application of extraction chromatography to the problem of removing spectral interferences from irradiated biological samples is just the opposite of the approach followed in those procedures employing inorganic exchangers. The objective with inorganic exchangers was to develop a material which would selectively remove the interfering species from the sample solution prior to assay by gamma ray spectroscopy. With extraction chromatography, the decontamination is usually based on the removal or extraction of an element or, more likely, a group of elements from the digested sample, leaving behind the spectral contaminants (168-176). As such, on an operation basis, column absorption of contaminants on inorganic exchangers would be more efficient than extraction methods. Fewer operations on the columns would 
be necessary to obtain data on a maximum number of elements. Solvent extraction techniques are rarely quantitative, and are typically effective only within a narrow range of solution parameters. For this reason, yield determinations for the extraction steps must be made. The conditions for solvent extractions employing organic complexing agents with narrow functional $\mathrm{pH}$ ranges are incompatible with conditions following an acid digestion step, which requires drastic alteration of the sample prior to extraction with the inherent possibilities for losses and contamination.

\section{Column chromatography}

Ion exchange techniques based on column equilibria have been utilized for separating spectrally interfering activities from digested biological samples (177). Decontamination factors of greater than 1000 for the radioactive forms of sodium, potassium and phosphorus have been reported. Similar to solvent extraction techniques, the procedures have concentrated on conditions which would remove the components of interest from the digested solutions, allowing the interferents to be eluted away. Unlike solvent extractions, the 1solation process concentrates the analyte species which are separated. Further separations of the isolated species are usually achleved by simply altering the eluting solution. 
Individual decóntamination processes for specific components are practically useless if conditions cannot be arranged so that a number of the procedures can be applied to a sample without drastic changes in conditions between applications. In their survey of the literature of the 15 years following 1960 concerning radiochemical separations, Girardi and Pietra noted that approximately 70 separation schemes had been published (178). Of those schemes which were reported for specific application to biological materials, some showed apparent attempts at compatibility between processing operations, while in others, drastic changes in the samples were accommodated in order to. use a specific separation technique (179-186). One of the simplest schemes involved the determination of 11 elements as three groups and required a distillation step, a dryingoff step, and three columns, HAP and two anion exchangers $(179,180)$. A point of dispute concerning this scheme is the low hydrochloric acid concentration (7M) used on the HAP column, which does not guarantee the high selectivity for the elements as indicated by the authors (153,156, 167). One of the more complicated schemes requires an evaporation step, a drying step, five columns, and 15 eluent changes for the determination of 40 elements as 13 groups. Points of disputation concern the claim of quantitative recovery of selenium and arsenic on HAP columns (156), and 
the reliability of quantitative recoveries in the drying and evaporation steps, especially since the evaporation step occurs in the presence of halides, a condition previously noted for the loss of trace elemental components (107, p. 143). Overall, the separation schemes appear to be overly complicated, even though most were intended for automation. The number and nature of the required operations are detrimental to consistent quantitative recoveries (187). The degree of separation attempted in most schemes is more than conceptualiy necessary for obtaining diagnostic information from a biological spccimen. Based on the available literature data, simpler, more concise schemes which would provide adequate decontamination and separations should be possible. 
III. EXPER IMENTAL

A. Physical. Facilities and Equipment

1. Nuclear reactor

All irradiations were accomplished in the Ames Laboratory Research Reactor (ALRR), Ames, Iowa. The ALRR 1s administered by Iowa State University under contract with the Department of Energy. It is a large scale enriched uranium-heavy water reactor designed for operation at power levels in excess of 10 megawatts (MW) but normally operated at $5 \mathrm{MW}$. Two pneumatic tube transfer systems called R3 and R5 were used for long and short irradiations, respectively. Both transfer systems approach the same high neutron flux area immediately below the reactor core from opposite directions. The most recent measurements of the radiation profiles at the R3 and R5 positions while operating at $5 \mathrm{MW}$ indicated the following: a thermal neutron flux in $\mathrm{R} 3$ of $2.8 \times 10^{13}$ neutrons $/ \mathrm{cm}^{2} / \mathrm{sec}$, a thermal neutron flux in $\mathrm{R} 5$ of $2.3 \times 10^{13}$ neutrons $/ \mathrm{cm}^{2} / \mathrm{sec}$, cadmium ratio in both $\mathrm{R} 3$ and $R 5$ between 19 and 20 to 1 , and a gamma dose rate at both positions of approximately $6.5 \times 10^{5} \mathrm{R} / \mathrm{Hr}$.

\section{Freeze-dryer}

The freeze drying apparatus (Figure 1) consisted of a Pyrex glass manifold (fabricated by the Ames Laboratory Glass Shop). with ports for the attachment of four sample 
Figure 1. Freeze-dryer 


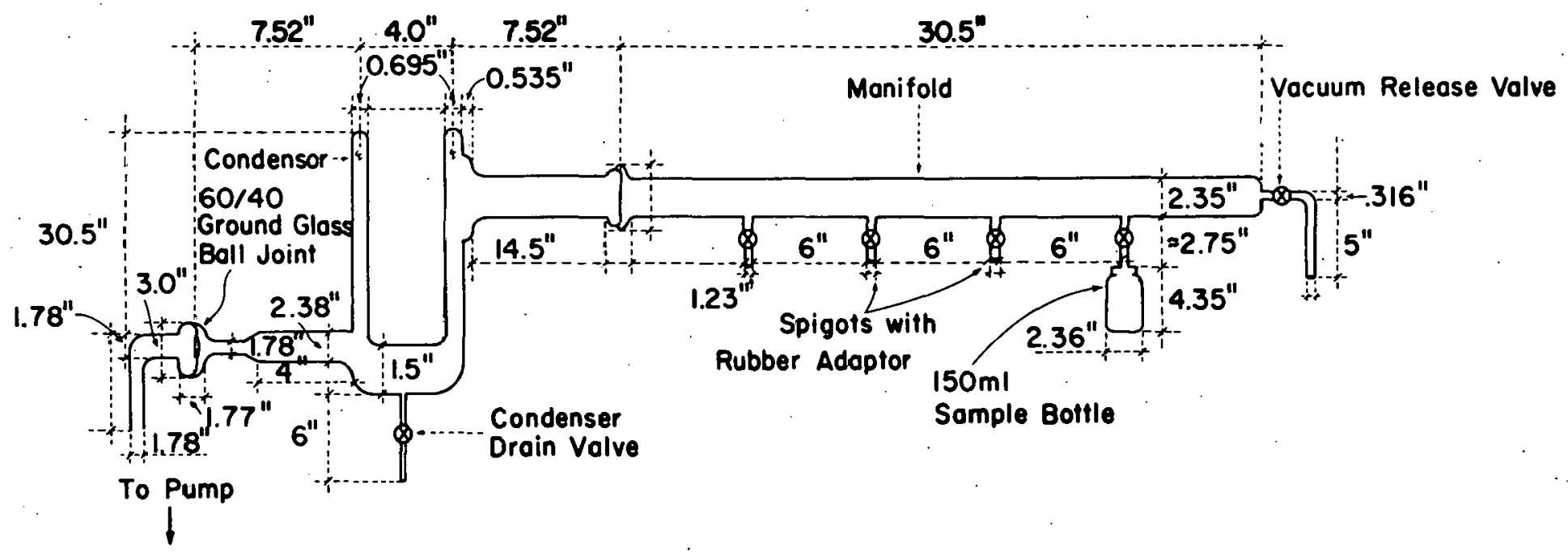


bottles, a commercially available condenser (Kontes Glass Co., Vineland, New Jersey), and a Duo-Seal Single Stage Vacuum Pump (W. M. Welch Manufacturing Co., Chicago, Illinois). The condenser has a volume of approximately 0.5 liters, and can be used with either liquid nitrogen or Dry Ice-solvent mixtures. The commercially available sample bottles are 150-200 milliliters in volume, and are supplied with rubber o-ring fitted caps for an air-tight seal. Each cap has a replaceable fritted glass filter in the opening between the bottle and the manifold spigot.

\section{Capsulation}

The system shown in Figure 2 was developed for sealing a biological sample into a quartz vial without thermal decomposition of the sample from the high temperature used in softening the quartz. The liquid nitrogen reservoir is a commercially available 750-ml Dewar Flask, capped with a shaped styrofoam plug which is protected from heat by a covering of household aluminum foil. The cold-finger which extends through the center of the styrofoam plug is a solid piece of brass which was machined to specifications in the ALRR Machine Shop. A styrofoam cup is provided as a support for the cold-finger and as protection for the glass vialls of the dewar.

The quartz vials (Figure 2a) used for containment of samples during irradiation were fabricated in the Ames 
Figure 2. System for the capsulation of heat sensitive blological materials
a) Quartz vial for containment of the sample
b) Cold-finger device used during sealing of the quartz sample vials 


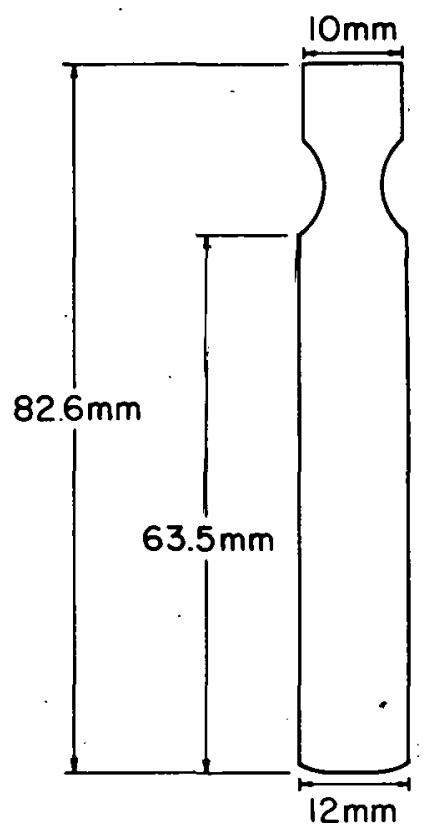

A) QUARTZ VIAL
Hole for insertion of quartz vial<smiles>CCCC(C)CC</smiles>

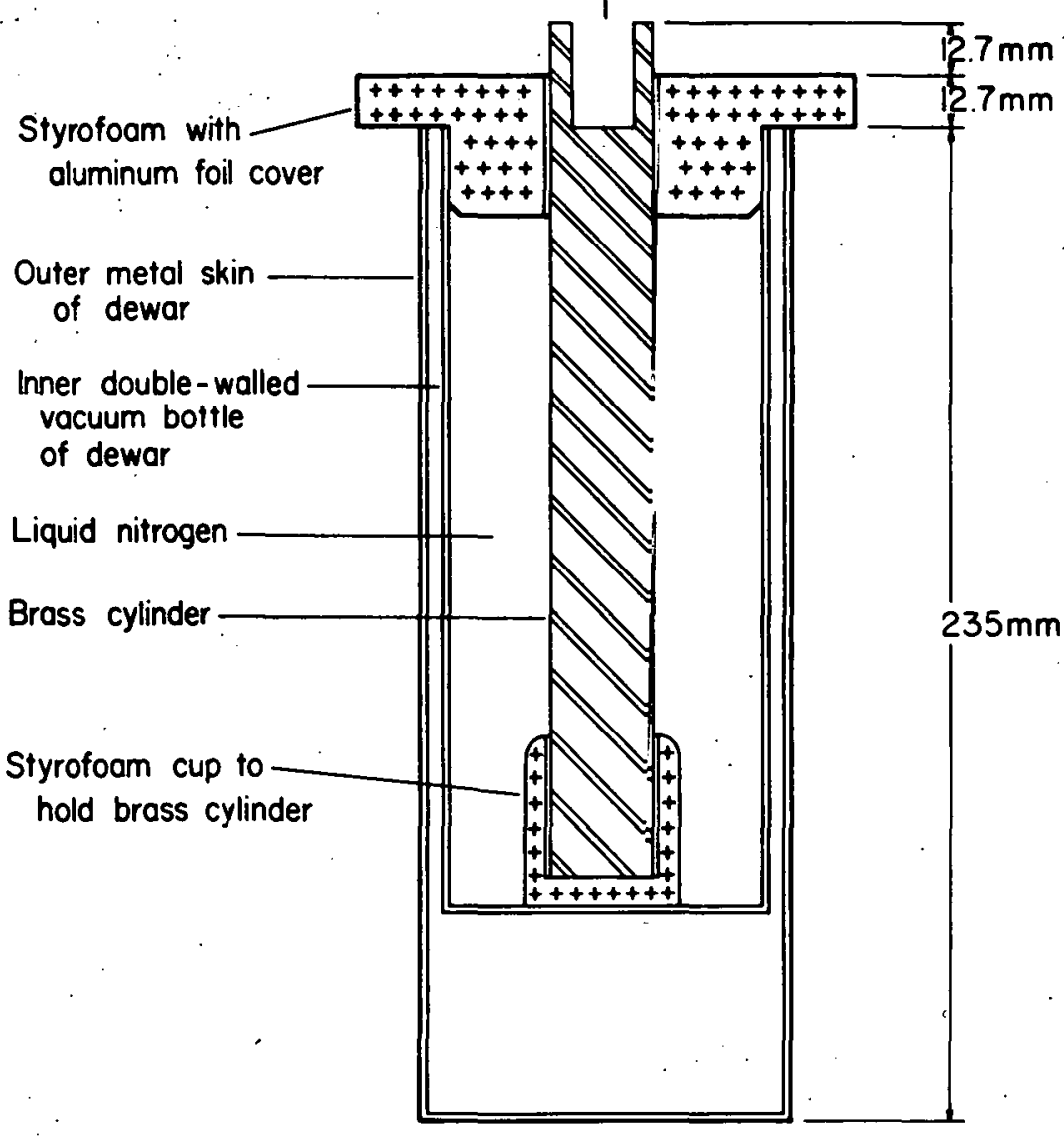

B) SEALING DEWAR 
Laboratory Glass Shop from Superc1l CFQ T21 Tubing (Amercil: Fused Quartz and Silica, Hillside, New Jersey). The original tubing possessed an outer diameter of $12 \mathrm{~mm}$ and an inner diameter of $10 \mathrm{~mm}$.

\section{Wet-ashing apparatus}

During the course of this work, two wet-ashing devices were employed. The first (Figure 3) was a modification purposed by Gorsuch. (113) of an original design by Bethge (188). The second device (Figure 4) represents a further modiflcation of the Bethge device which should ensure against the escape of volatile components from the system. The primary modifications are the introduction of a thistle section between the reaction flask and the air condenser for easier introduction of reagents during a digestion, and the inclusion of the liquid nitrogen cold-finger condenser atop the air condenser. Included in the air condenser of both devices is a three-way stopcock which allows for a cyclic reflux-distillation mode of operation.

\section{Support columns}

The support columns (F1gure 5) for chromatographic studies were fuluricated in the Ames Lahnratory Glass Shop. I'he reservolr of each column was formed from a 24/40 ground glass (g.g.) outer joint, and had a maximum volume of $30 \mathrm{ml}$. The column section was formed from standard wali Pyrex tubing with an outer diameter of $12 \mathrm{~mm}$. 
Figure 3. Bethge apparatus as modified by Gorsuch for the controlled destruction of organic materials 


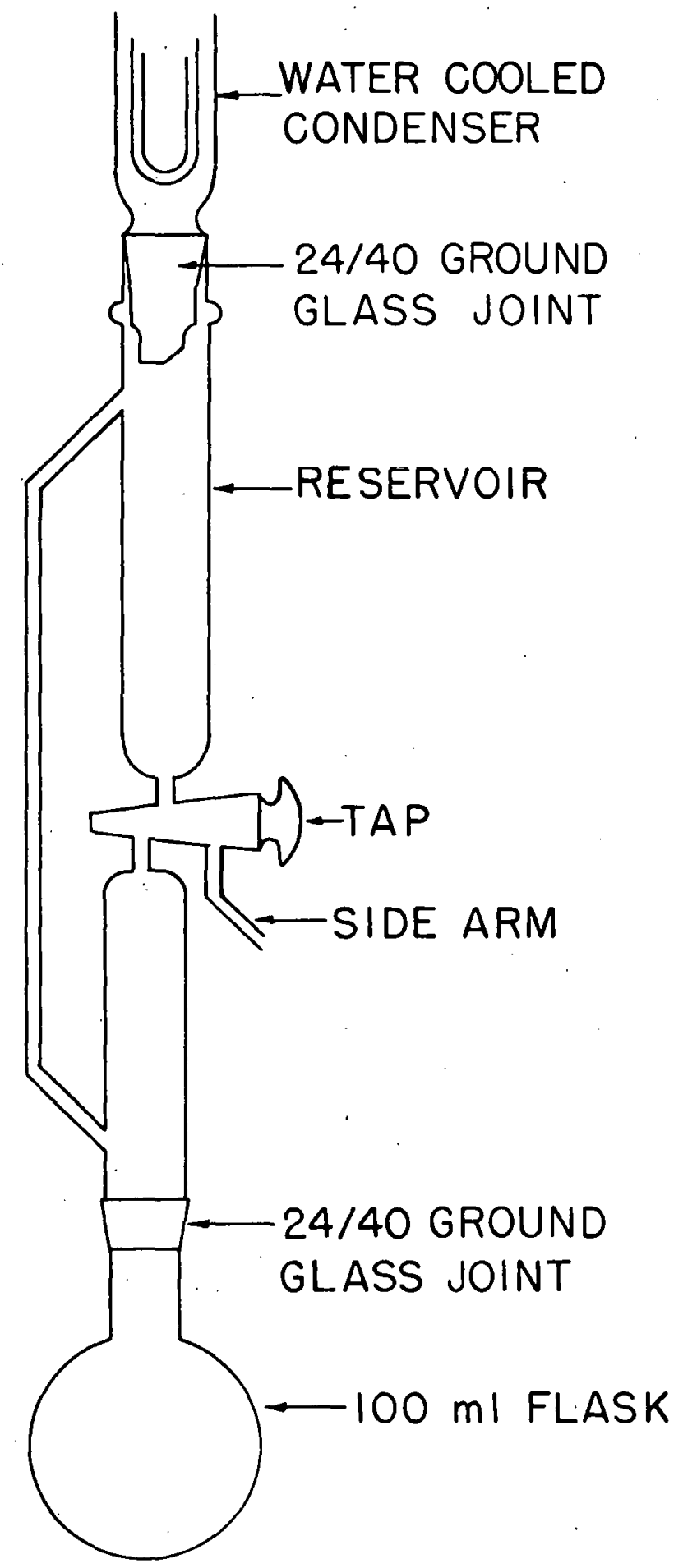


Figure 4. Gorsuch apparatus as modified to enhance the retention of trace components and to facilitate the introduction of reagents during the "wet-ashing" of organic matrices 


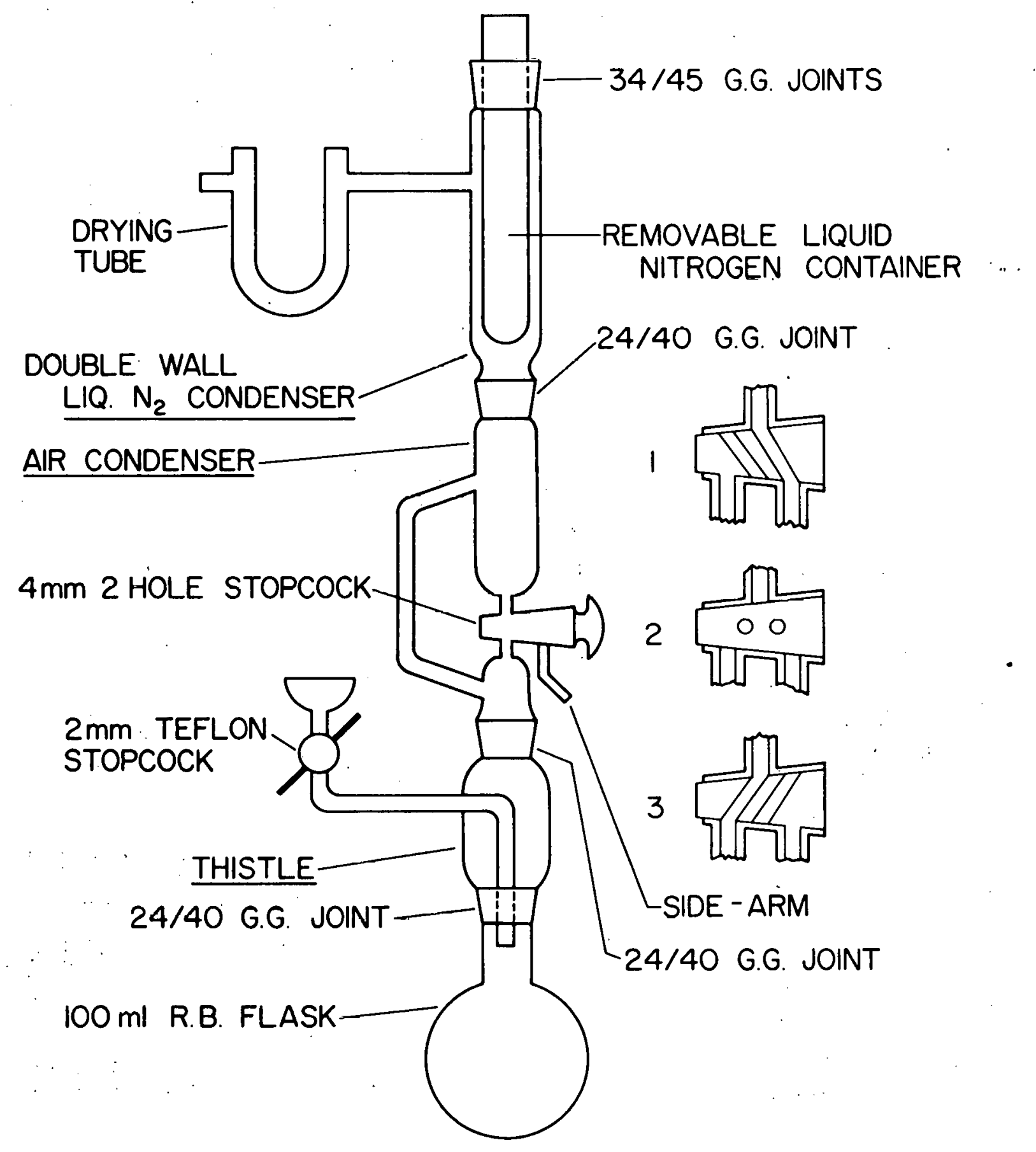


F1gure 5. Chromatographic support column 


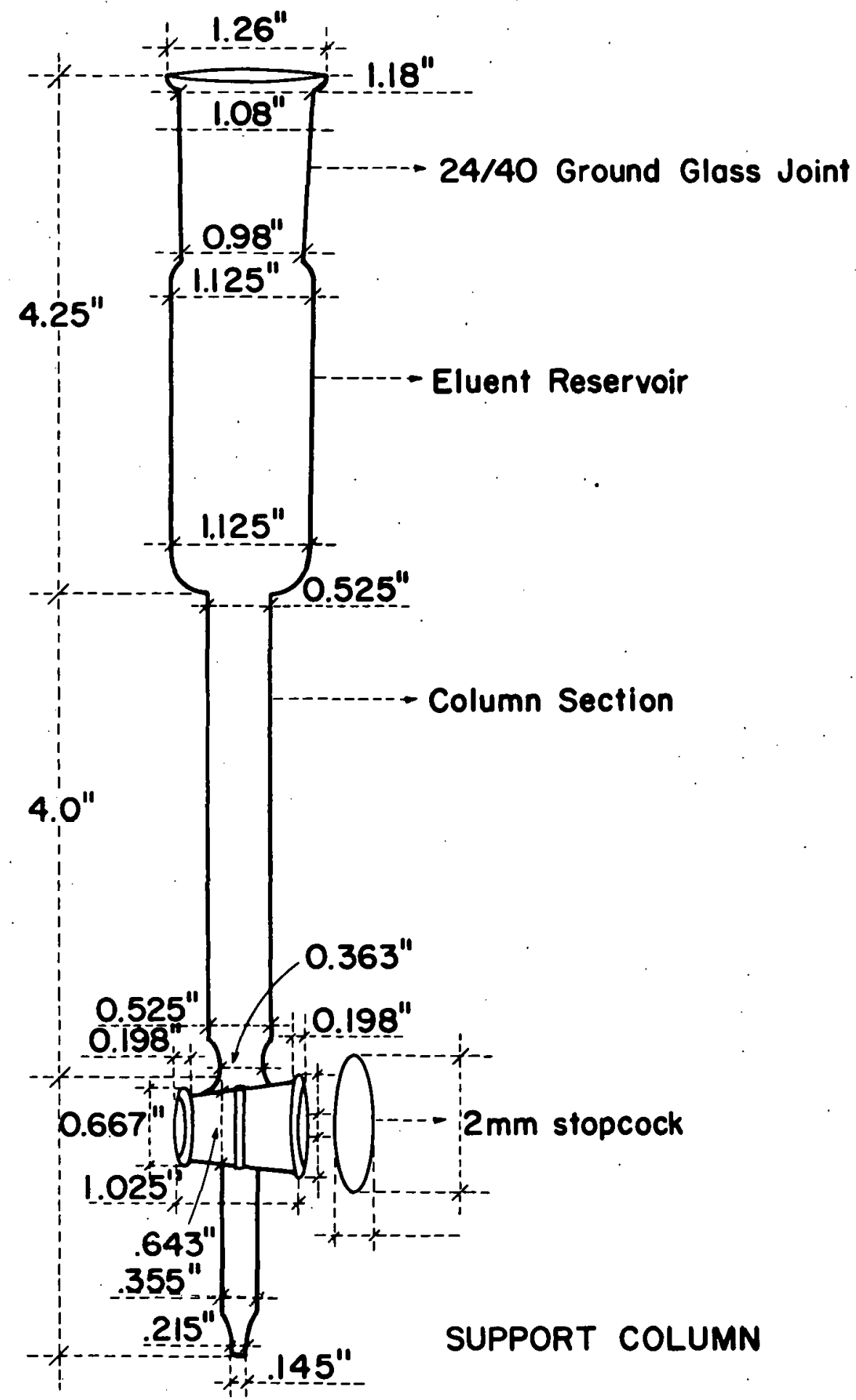




\section{Ovens}

Experimental requirements necessitated modification of a commercially available muffle furnace and a convective drying oven. For more stable temperature control, a Blue.M Electric Furnace (Blue M Electric Co., Chicago, Illinois) was operated with the time controller of the heater out of the circuit, and with the heater temperature control in the "High" position. The current to the heaters and therefore the temperature of the oven was controlled with a Type 136 Powerstat Variable Autotransformer (The Superior Electric Co., Bristol, Connecticut). This system was used to obtain temperatures in excess of $400^{\circ} \mathrm{C}$.

An 850 watt, convection-type Sargent Drying Oven (E. H. Sargent and Co., Chicago, Illinois) was modified for forced air drying of samples at temperatures approaching $400^{\circ} \mathrm{C}$. The modifications were as follows: 1) the heated volume of the oven was restricted by placing a sheet of asbestos on an appropriately positioned shelf within the oven. The asbestos sheet was cut to allow circulation of air. 2) The forced air was obtalned from a laboratory air spigot equipped with moisture änd particulate filters. Rubber tubing coupled the air jet to a glass tube which was inserted through a partially blocked vent atop the oven. The tube extended into the oven cavity through the asbestos sheet, and into a region below the heating coils. 3) The 
thermostat control of the oven was bypassed and a Powerstat Variable Autotransformer was connected for temperature control. The air flow rate was restricted to approximately 30 liters per minute.

\section{7. $\quad$ Reagents}

Commerclally available reagents and chemicals were used without further purification in the production of carrier solutions. Most irradiation standards were produced from special high purity metals refined at the Ames Laboratory. If the high purity form of an element was not available from the laboratory, a commercialiy available electronic or analytical' grade was used without further purification.

High purity water was obtained by passing the effluent of the laboratory deionized water taps through a Barnstead Bantam Demineralizer equipped with a bed of high capacity mixed ion-exchange resins. Only water which demonstrated

a specific resistance greater than $10^{6} \mathrm{ohms} / \mathrm{cm}^{3}$ as measured with a Barnstead direct reading conductivity meter was used for making standards and for special cleaning purposes.

\section{Biological samples}

Two biological standards were used throughout this work: NBS Bovine Liver SRM 1577 and U.K. Human Blood Mastermix. Bovine Liver was obtained from the National Bureau of Staridards, Department of Commerce, Washington, 
D.C., as part of the Standard Reference Materials program. A sample of the United Kingdom Human Blood Mastermix was obtained from Dr. E. I. Hamilton of the Institute for Marine Environmental Research, England.

Human blood samples obtained through the courtesy of $\mathrm{Dr}$. John Fenton formerly of Southeastern Massachusetts University, North Dartmouth, Massachusetts, were used in some of the preliminary work.

\section{B. Counting and Data Processing Equipment}

An Ortec $W_{I N}{ }^{15}$ Series (Ortec, Oakridge, Tennessee). coaxial lithium-drifted germanium $\{G e(L i)\}$ detector was used for high resolution gamma ray spectroscopy. The detector specifications included a measured resolution equal to $2.1 \mathrm{KeV}$ full width at half maximum for the $1.33 \mathrm{MeV}$ photopeak of ${ }^{60} \mathrm{Co}$, a peak-to-Compton ratio of 38 to 1 , and an efficiency warranted by the manufacturer to be $20 \%$ of a $3 \times 3$ inch sodium iodide detector at $1.33 \mathrm{MeV}$. A specially deslgned battery pack (Ames Laboratory Electronic Shop) provided a +4800 volt bias to the detector. An Ortec preamplifier was supplied as an integral part of the detector.

As a method of correcting spectra collection times for the analyzer dead time, a $60 \mathrm{~Hz}$ pulse was fed to the preamplifier during the collection of spectra. The pulses 
were formed by a BNC Tall Pulse Generator Model RP-I (Berkeley Nucleonics, Berkeley, California) which was gated at $60 \mathrm{~Hz}$ by a RIDL Model 47-2 Pulser (Radiation Instrument Development Laboratory, Chicago, Illinois). Primary amplification of sample and timer pulses was obtained with a CI Model 1417B Spectroscopy Amplifier (Canberra Industries, Meridan, California) prior to digitilization and storage with a Nuclear Data 50/50 Analyzer System (Nuclear Data, Inc., Chicago, Illinols) which Included a PDP-8/L Computer (Digital Equipment Co., Maynard, Massachusetts) as an integral component. A Nuclear Data Series 2200 ADC, capable of 4096 channel resolution at a conversion frequency of $50 \mathrm{MHz}$, performed the analog-todigital conversions in the 50/50 analyzer system. The PDP-8/L is a 12 -bit machine with $4 \mathrm{~K}$ core storage. The Interface between the $\mathrm{ADC}$ and the computer allowed for independent operation of elther device.

Input and output devices employed with the analyzer system included a Model ASR-33 teletype (Teletype, Skokie, Illinois), a Nuclear Data Series 2200 BRPE Punch/Reader, and a PEC Model $6 \times 40$ Synchronous Read After Write Tape Transport (Peripheral Equipment Corp., Chatsworth, California). A visual display of the ADC memory was available on a Tektronix Type 602 Display Unit (Tektronix, Portland, Oregon). 
Software was available with the 50/50 Analyzer which allowed data processing of gamma ray spectra stored in the memory of the ADC. The need for operator intervention for isolating each photopeak made the analysis procedure excessively tedious and time consuming when processing complete 4096 channel spectra. The simplicity of some data processing routines, particularly the peak area calculation and background correction algorithms, could result in significant errors and low precision when processing complicated spectra (1․․‥, spectra containing partially or completely overlapping photopeaks). Therefore, data reduction of the high resolution gamma ray spectra was usually accomplished on one of the large ISU computer systems, either an IBM $360-65 /$ IBM $370-158$ or an IBM 360-65/ITEL AS-5 tandem.

After collection, each gamma spectrum was transferred from the 50/50 Analyzer to magnetic tape for temporary storage. All data tapes written by the PEC tape drive were Initially processed by the computer program DOGGIT (189). The PEC tape drive wrote each spectrum on tape as a stream of 24 bit words. However, the large computers were designed to operate on 32 bit words. DOGGIT read the PEC generated tapes and converted the data to 32 bit words which were compatible with the IBM and ITEL computers. 
The identification of photopeaks in gamma ray spectra was performed by ICPXGT, a Fortran-coded peak finding routine. After ICPXGT detected potential photopeaks by analysis of the smoothed second derivative of the gamma spectrum, an attempt was made to fit a Gaussian curve to each of the peaks. The Gaussian fitting routine, which was essentially the one described by Heath et al. In AEC-Report IDO-17017, evaluated three parameters for the top $75 \%$ of the peak, a region which has been found empirically to consistently yield the best results by minimizing errors from sources such as poor background corrections, nonGaussian peaks, etc. Background corrections were made by fitting a least-squares straight line through five channels on either side of the peak and subtracting the result from the region to be fitted. Printed output for each peak identified in the preliminary search included the exact channel location, standard deviation of the location, peak width, peak height, peak area, standard deviation of the area, the energy calculated from a quadratic calibration line, and a code indicating whether the Gaussian fitting routine converged. Optionally, the same information could be obtalned on punched cards, magnetic tape, or a direct access device like a disk pack.

As an option, ICPXGT provided sem1-log graphical representations of selected spectra. SIMPLOTTER (190), a high 
level plotting system maintained as an on-line procedure by the I.S.U. Computation Center, created the plots from data passed by ICPXGT. The finished plots were available on a line printer or an incremental plotter. For most work, the plots were produced on a Calcomp Digital Incremental Plotter with a resolution of 0.01 inches.

ICPXGT was designed to identify and resolve multiplets into their component photopeaks. However, when a multiplet consisted of photopeaks with significantly different intensities, ICPGXT would not "see" the smaller peak even though the graphical output showed that it existed. In those few cases where ICPXGT was inadequate, SKEWGAUS (19I) was used to resolve the multiplet. SKEWGAUS, unlike IC PXGT, was not designed to search gamma ray spectra for peaks. The user had to supply SKEWGAUS with the locations of the multiplet and of each component suspected of being present in the multiplet. With this information, SKEWGAUS estimated seven parameters for each potential component and attempted to fit each peak as part of the multiplet. The name SKEWGAUS is applicable because the fitting routine was not based on a true Gaussian function. The fit was made to a Gaussian function with the "skewness" term added to account for the distortion in the tail on the low energy side of a photopeak when measured with a semiconductor detector. 
After the gamma spectra were reduced by ICPXGT to a serles of peak areas, locations, etc., the Fortran program ANALYZ3 (102) was executed to obtain information on an elemental basis. The versatility of ANALYZ3 allowed the user to obtain a listing of the elements present in a sample alorig with their respective count rates, a comparison of the decay rates of elements in different spectra, or a listing of the elements present in a spectrum along with its concentration (ppm).

Each of the previously described computer programs, except for SKEWGAUS, was designed to provide information in a form suitable to input to that program which would logically follow in a data reduction scheme. Thus, in one computer pass, it was possible to go from the raw spectral data on magnetic tape to a listing of the elements and respective concentrations in a sample.

A thallium-activated sodium iodide [NaI(TI)] scintillation detection system was utilized for low resolution gamma ray spectroscopy. The system consisted of a 4 x. 4 inch well-type Harshaw $\mathrm{NaI}(\mathrm{TI})$ Matched Window Scintillation Detector with an optically coupled, photomultiplier tube (Nuclear Chicago Corp., Des Plalnes, Illinois), a RIDL Model 30-19 Linear Amplifier and Diseriminator, a RIDL Model 33-10B Anti-walk single Channel Analyzer, a RIDL Preset Counter Model 49-43, and a RIDL 
Model 40-I2B High Voltage Power Supply. The samples assayed by low resolution gamma spectroscopy were of high radiochemical purity and contained species with moderately long half-lives. Operating the single channel analyzer in the. "differential" mode with the proper discriminator settings allowed only impulses pertinent to the species of interest to reach the scaler. This meant that the data necessary for determining the area of the photo-peaks could be obtained directly from the counter without an analysis of the complete gamma spectra.

\section{Experimental Procedures}

\section{Special cleaning}

All quartz, glass, and plastic articles used in the preparation or storage of irradiation standards were cleaned to minimize the contamination blank from the surfaces of those articles. Initially, the labware was washed in a solution of Alconox detergent and water. After a thorough rinsing in deionized water, the articles were placed in a bath of analytical grade nitric ac1d, and kept at an elevated temperature for at least 48 hours. If plastic items were involved, the temperature of the bath was not allowed to exceed $80^{\circ} \mathrm{C}$. For all other materials, the temperature was maintained between 110 and $120^{\circ} \mathrm{C}$. After removal from the ac1d, the articles were rinsed in 
high purlty delonized water and then placed into a bath of high purity water to soak for at least 24 hours. Finally, the labware was alr dried in a protective enclosure to prevent contamination by settling airborne particulates.

\section{Standards and carriers}

During the course of this work, the standard and carrier solutions had to be remade a number of times. Initially, the procedures for making the carriers and standards differed significantly. The carriers were originally produced with available analytical grade materials, while extra efforts were made to obtain special high purity components for the irradiation standards. Because of the large number of solutions this procedure generated, the production methods for the solutions were changed. During the later stages of this work, single standards of unusually high concentrations (typically in the range $5-50 \mathrm{mg} / \mathrm{ml}$ ) were made from the highest purity materials available. After appropriate dilutions with high purity water, these solutions were usable as either carriers or standards. In addition, this method of production reduced the frequency at which the stock solutions had to be remade, because the high concentrations negated any adsorption or desorption effects with the walls of the storage contilner's. 
Table 21 provides information concerning the materials used in the production of both standards and carriers in the later stages of this work. Unless otherwise noted, the dissolutions were accomplished in water with nitric acid. applied as needed. When necessary, all stock solutions, carriers, and standards were adjusted to $\mathrm{pH} I$ with nitric acid.

\section{Freeze-drying}

Freeze-drying was used to dry all biological materials employed in this work. In each case, the sample was transferred from its original container to a sample bottle whlch had undergone the special surface cleaning procedure. Liquid nitrogen was used to freeze the material in the sample bottle prior to connecting the bottle to the one of the ports of the freeze dryer (Figure 1). Only one sample was dried at a time. Samples of NBS Bovine Liver and U. K. Master Mix were dried for 24 hours with no special arrangements to prevent defrosting after the initial freezing. During the drying of a whole blood sample, it was necessary to refreeze the sample at least seven times during the first 24 hours to prevent material losses from excessive frothing and sputtering. After the first. 24 hours, the mass of blood in the sample bottle was broken up with a Teflon coated spatula, refrozen in liquid nitrogen, and freeze-dried for an additional 24 hours. 
Table 21. Stock solutions used in the production of carriers and s.tandards.

\begin{tabular}{|c|c|c|c|}
\hline Element & Compound & $\begin{array}{l}\text { entration } \\
(\mathrm{mg} / \mathrm{ml})\end{array}$ & Notes \\
\hline As & $\mathrm{As}_{2} \mathrm{O}_{3}$ & 10.00 & $\begin{array}{l}\text { Initially dissolved in } \\
\text { small amount of } \mathrm{NH}_{4} \mathrm{OH}\end{array}$ \\
\hline $\mathrm{Au}$ & $\mathrm{HAuCl}_{4} \cdot 3 \mathrm{H}_{2} \mathrm{O}$ & 9.887 & Very deliquescent \\
\hline Co & Co metal & 50.95 & -- \\
\hline $\mathrm{Cr}$ & $\mathrm{CrO}_{3}$ & 25.15 & Slightly deliquescent \\
\hline $\mathrm{Cu}$ & Cu metal. & 49.96 & $\cdot--$ \\
\hline $\mathrm{Fe}$ & Fe wire & 51.43 & -- \\
\hline $\mathrm{Hg}$ & $\mathrm{HgO}$ & 50.04 & -- \\
\hline Mo & $\left(\mathrm{NH}_{4} \cdot{ }{ }^{\mathrm{Mo}} 7^{\mathrm{O}} 24 \cdot 4 \mathrm{H}_{2} \mathrm{O}\right.$ & 25.38 & $\begin{array}{l}\text { Does not form stable } \\
\text { solutions at low pH }\end{array}$ \\
\hline $\mathrm{Sb}$. & $\mathrm{Sb}$ metal & 5.190 & $\begin{array}{l}\text { Dissolved in conc. } \\
\mathrm{H}_{2} \mathrm{SO}_{4} \text { Cleared solu- } \\
\text { tion with Aqua Regla }\end{array}$ \\
\hline Sc & $\mathrm{Sc}_{2} \mathrm{O}_{3}$ & 0.7920 & $\begin{array}{l}\text { Heated at } 800^{\circ} \mathrm{C} \text { for } \\
4 \text { hrs before welghing. } \\
\text { Dissolved siowly in } \\
\text { conc. } \mathrm{HNO}_{3}\end{array}$ \\
\hline $\mathrm{Se}$ & Se metal & 50.08 & -- \\
\hline $\mathrm{Rb}$ & $\mathrm{Rb}_{2} \mathrm{CO}_{3}$ & 31.57 & $\begin{array}{l}\text { Heated at } 800^{\circ} \mathrm{C} \text { for } \\
4 \text { hrs before welghing }\end{array}$ \\
\hline $\mathrm{w}$ & W metal & 49.97 & $\begin{array}{l}\text { Dissolved in minimum } \\
\mathrm{HF}\end{array}$ \\
\hline $\mathrm{Zn}$ & Zn metal & 50.65 & -- \\
\hline
\end{tabular}


A mixture of either Dry Ice/acetone or Dry Ice/propanol was used to charge the water vapor trap in the freeze drying unit. The pressure in the evacuated system was not measured, but the pump specifications indicated a capability to pull a vacuum of less than 5 microns of mercury.

\section{Supercil quartz}

The following procedures were developed to determine the extent to which proposed digestion systems would result in contamination of biological samples by species indigenous to quartz of which the irradiation vials were fabricated. Th1s study was necessary to determine whether the radioactive species from the irradiation vial during a post-irradiation digestion procedure would be significant relative to the corresponding species originally present in the sample. Two approaches were used in this evaluation. In the first, a crushed quartz vial and a biological sample were individually capsulated in quartiz vials and irradiated in facility $R-3$ of the ALRR for 15 hours. The containers were cut open and a weighed portion of the contents of each vessel along with $200 \mathrm{mg}$ of bovine liver. was transferred to the previously described digestion apparatus (Figure 3). Digestion procedure DG-2 (See section entitled "Digestion schemes".) was performed on each sample. The specific activities of radionuclides detectable in the digests of both samples were compared. 
The second approach was based on approximately the amount of material actually extracted from a crushed quartz vial during a post-irradiation wet ashing operation. An empty, weighed, quartz vial and a.quartz vial containing $1 \mathrm{ml}$ of a mixed elemental standard solution were irradiated for 15 hours in facility. $R-3$ of the ALRR. The vials were individually frozen in liquid nitrogen, wrapped in a small Kimwipe, crushed, and placed into separate digestion apparatus along with carriers and $200 \mathrm{mg}$ of bovine liver. Digestion procedure DG-3J was performed on each sample. The digests were collected and assayed by gamma ray spectroscopy. Calculation of the elemental concentrations extracted from the quartz was possible after the activities present in the standard were corrected for the respective activities detected in the quartz sample.

\section{Capsulation system}

A series of experiments was executed to study the loss of sample components during the three stages of processing which directly involved the capsulation system: 1) preirradiation sealing of a sample into sample containers, 2) irradiation of sample/container system, and 3) postirradiation removal of a sample from the container. In order to avold the difficulties associated with the intense backgrounds in the spectra, the evaluation was accomplished 
through the use of tracer solutions with an oven to simulate the thermal conditions within a reactor.

The tracer solution was produced from multi-element standards which were irradiated in the ALRR. Table 22 contains a listing of the elements which were investigated, and the approximate amounts of elements present in each vial during testing. (Stable carrier nuclides were not added to the test vials.) Concentrated sulfuric acid was added to $0.5-g$ samples of bovine liver and blood to form a slurry. Three test vials were assembled as follows: 1) $400 \mu \mathrm{l}$ of tracer solution and $400 \mu \mathrm{l}$ of bovine liver slurry; 2) $400 \mu l$ of tracer solution and $400 \mu l$ of blood slurry; and 3) $400 \mu l$ of tracer solution, $200 \mu l$ of bovine liver slurry, and $200 \mu 1$ of blood slurry. Each vial was capped with a sheet of aluminum foll to prevent the loss of components through vaporization. The radioactive species in each vial were measured with the high resolution gamma spectroscopy system.

Vial \#3, containing the blood and liver slurries, was set aside for reference. The cold-finger system (Figure $2 b$ ) and a gas-oxygen torch were used to seal the remaining vials. The gamma spectra of the three vials were collected. Vials \#I and \#2 were placed into a Sargent drying oven for at least 24 hours at $150^{\circ} \mathrm{C}$. After cooling to room temperature, the gamma spectrum of each of the three vials was 
Table 22: Elements comprising tracer solution used in capsulation experiment.s.

\begin{tabular}{|c|c|c|}
\hline & Element & $\underset{(\mu \mathrm{g})}{\operatorname{Amount}}$ \\
\hline$\therefore$ & Co & 0.03 \\
\hline & $\mathrm{Cr}$ & 0.08 \\
\hline & $\mathrm{Fe}$ & 2.27 \\
\hline & $\mathrm{Hg}$ & 0.05 \\
\hline & Mo & 0.14 \\
\hline & $\mathrm{Rb}$ & 0.08 \\
\hline & $\mathrm{Sb}$ & 0.03 \\
\hline & $\mathrm{Sc}$ & 0.003 \\
\hline & $\mathrm{Se}$ & 0.19 \\
\hline & $\mathrm{Zn}$ & 0.76 \\
\hline
\end{tabular}

again collected. Each vial was frozen in liquid nitrogen, wrapped in a plastic glove and crushed. The vial fragments and contents were rinsed into 10 dram plastic containers and assayed for gamma activities. Data reduction proceeded as previously described. 


\section{Digestion schemes}

A blological matrix, usually bovine liver, spiked with a solution of radionuclides was used to test wet ashing schemes. The principal variant between schemes was the specific oxidizing medium and required modifications for its application. Each digestion system was evaluated for optimum ashing conditions, completeness of ashing, and susceptibility of the ashing system to losses of elemental components.

In the component recovery tests, an aliquot of a radiotracer solution was diluted to a specific volume for use as a reference solution, while an identical aliquot of the tracer solution was added to $200 \mathrm{mg}$ of a biological matrix and subjected to a wet ashing procedure. Carrier nuclides (Table 23) were added to the reference solution and to the digest mixture to reduce losses associated with low component concentrations. After diluting the ashed material to a specific volume, a comparison was made between aliquots to the reference and ashed solutions to determine material losses.

a. Nitric acid (DG-I)

1. In the reaction flask of a Bethge digestion apparatus (Figure 3). place $400 \mathrm{mg}$ of bovine liver, $5 \mathrm{ml}$ of concentrated nitric acid, an aliquot of a radio-tracer solution, and an aliquot of a carrier solution of stable nuclides. 
Table 23. Composition of typical carrier solutions used throughout the project.

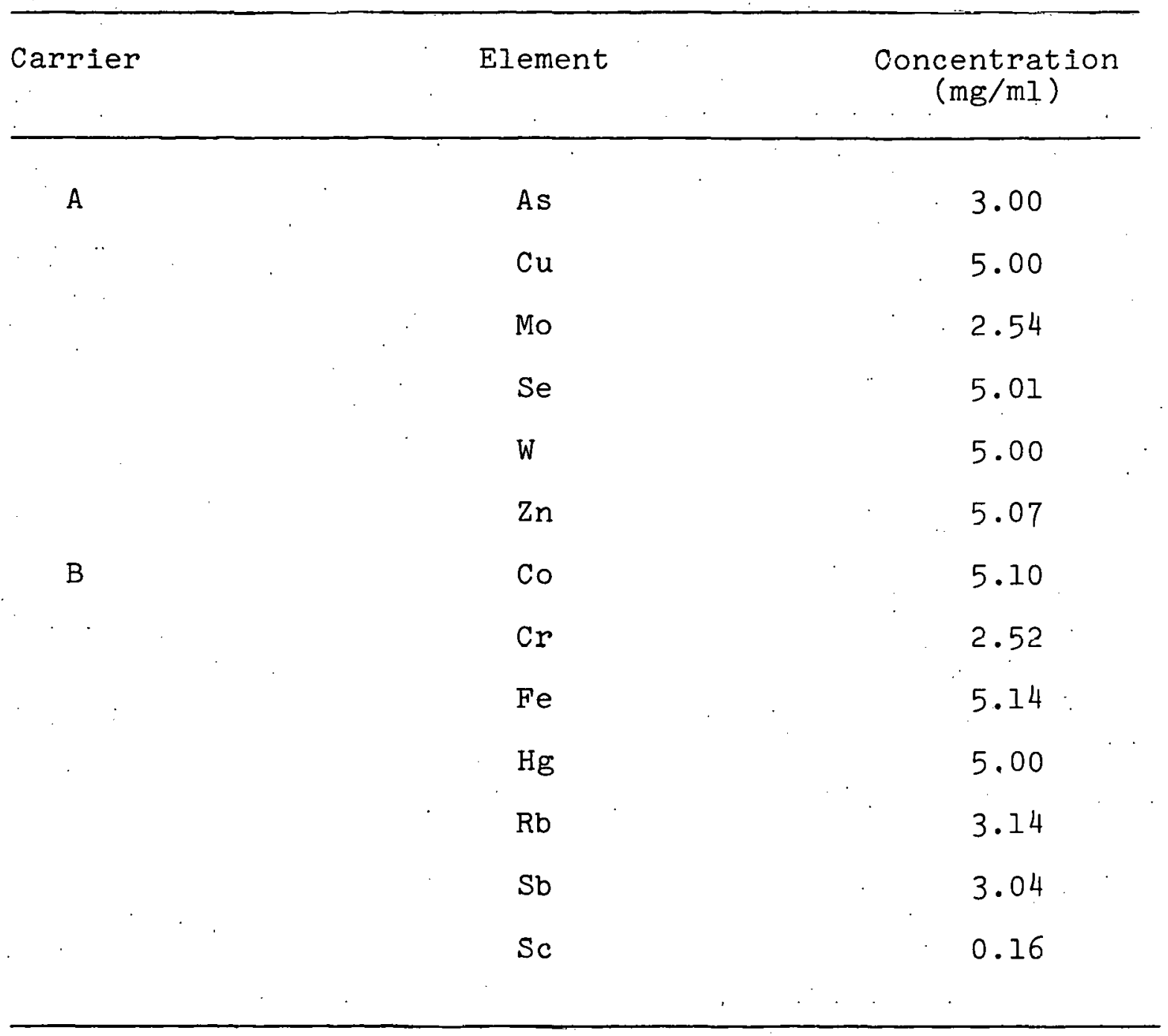


2. Swirl the flask to wet the matrix and reconnect the flask to the apparatus.

3. Place digestion apparatus on a hot plate and heat to boiling. With the three-way stopcock in the reflux position (Figure 3, position 3), reflux the solution until it clears.

4. Allow. the apparatus to cool. Collect the ashed sample and all rinses of the apparatus in a 50-ml volumetric flask and dilute to volume.

b. Nitric and perchloric acids (DG-2)

1. Place $400 \mathrm{mg}$ of a biological matrix, $5 \mathrm{ml}$ of concentrated nitric acid, an aliquot of a radio-tracer solution, and an aliquot of a carrier solution into the reaction flask of the Bethge digestion apparatus. Swirl flask to wet the matrix. Reassemble the apparatus and place. it on a hot plate.

2. With the three-way stopcock in the reflux position, bring the digestion medium to a boll. Allow the mixture to reflux for $15 \mathrm{~min}$.

3. Remove from heat and allow the sample to cool. Slowly add $8 \mathrm{ml}$ of $70 \%$ perchloric acid to the reaction flask through the condenser system.

4. Return the apparatus to the hot plate and bring to a boil. Allow the mixture to reflux for $10 \mathrm{~min}$. Close the three-way stopcock and collect the distilling nitric acid 
in the air condenser. After most of the nitric acid has collected in the air condenser, carefully reopen the three-way stopcock and allow the nitric acid to return to the reaction flask. An explosion hazard exists if the acid mixture is distilled to dryness.

5. If necessary, repeat step 4 until the solution clears.

6. Remove the sample from the heat and allow to cool. Collect the digest solution in a $50-\mathrm{ml}$ volumetric flask. Rinse the apparatus with water and combine all rinses with the ashed sample in the volumetric flask. Dilute the sample to volume with water.

c. Sulfuric ac1d and hydrogen peroxide (DG-3)

Evaluation of the sulfuric acid/hydrogen peroxide digestion medium was begun in the Bethge apparatus as shown in Figure 3. Quite early in the evaluation, the Bethge apparatus modified with liquid nitrogen cold-finger and thistle section (Figure 4) replaced the original system. The following procedure was employed with the earlier version of the Bethge apparatus in the initial work with the sulfuric acid/hydrogen peroxide system:

1. Place $400 \mathrm{mg}$ of the blological material into the reaction vessel of the Bethge apparatus (Figure 3). While cooling the flask in an lce bath, slowly cover the material with $5 \mathrm{ml}$ of concentrated sulfuric acid and swirl or use a 
magnetic stirring bar to mix. Add aliquots of radio-tracer and carrier solutions.

2. Remove the flask from the ice bath and connect it to the digestion device. Warm the flask and contents by gently heating with a Bunsen burner. After a few minutes, intensify the heating until fumes of sulfuric acid are produced.

3. Allow the flask to cool. Very carefully add $10 \mathrm{ml}$ of $90 \%$ hydrogen peroxide through the condenser system to the reaction vessel. Additions must be made incrementally with sufficient times between additions to allow the reaction to subside.

4. Collect the digest and rinses of the apparatus in a 50-ml volumetric flask and dilute to volume with water.

A number of variations on the above procedure ( $D G-3$ ) were tested. The differences between the variations and $D G-3$ are listed below.

DG-3A: All steps are as indicated in $D G-3$, except an 0 il both regulated at a temperature between 70 and $90^{\circ} \mathrm{C}$ is used for all heating purposes. Naturally, the ashing medium is not heated to fumes of sulfuric acid.

$D G-3 B$ : $A l l$ steps are as in $D G-3 A$ except the modified Bethge apparatus (Figure 4 ) is used. 
$D G-3 C$ : The procedure is identical to $D G-3 B$ except heat is supplied by a Bunsen burner and the sample is heated to fumes of sulfuric acid.

DG-3D: The procedure follows the outline of $D G-3 B$. However, after the final addition of hydrogen peroxide, the temperature of the 011 bath is raised to $100^{\circ} \mathrm{C}$ and the mixture is stirred for 15 minutes before proceeding. DG-3E: The procedure follows $D G-3 B$ except after the final addition of hydrogen peroxide, granular manganese dioxide is washed with water through the thistle section into the reaction vessel until effervescence subsides before proceeding.

DG-3F: Proceed as in DG-3E except 1.5 to $3.0 \mathrm{ml}$ of a saturated solution of ferrous sulfate is added instead of manganese dioxide.

$D G=3 G$ : Proceed as In $D G-3 E$ except $2.0 \mathrm{ml}$ each of carrier solutions "A" and "B" (Table 23) are added instead of the manganese dioxide.

DG-3H: Proceed as in DG-3G except $50-100 \mathrm{mg}$ of: chromic acid is included in the reagents Inftially added to the sample in the reaction flask. 
DG-3I: Proceed as in DG-3H except 50-100 $\mathrm{mg}$ of vanadium pentaoxide in sulfuric acid is added to the reaction vessel instead of chromic acid.

DG-3J: Proceed as in DG-3G except a 9:1 mixture of sulfuric and nitric acid is used in the inftial treatment of the sample in the reaction flask.

\section{Synthesis of hydrated antimony pentaoxide (HAP)}

Hydrated antimony pentaoxide was selected for use in the removal of radio-sodium from solutions of ashed biological materlals. In order to avoid shipping delays and reported inconsistencies in the commercial preparation, HAP for use in this project was synthesized locally. The false starts and failures which marked the attempts to synthesize a second batch of HAP eventually evolved into a study of how various parameters of HAP syntheses affected the characteristics of the final products.
a. HAP IA and IB
The synthesis procedures for HAP materials $I A$ and $I B$ are based on the information provided in the original article by Girardi and Sabbioni (153). on the properties of hydrated antimony pentaoxide in sodium decontamination. Under an evacuating hood, the contents of a l-lb bottle of antimony pentachloride $\left(\mathrm{SbCl}_{5}\right)$ were slowly added with stirring to $500 \mathrm{ml}$ of deionized water 
In a 2-1. beaker. The vigorous, exothermic hydrolys is yielded a fine, white precipitate. As excess $\mathrm{SbCl}_{5}$ was added, the precipitate turned yellow and redissolved. With the addition of more water, the white precipitate returned. As the hydrolysis continued, water was added as necessary to reverse the formation of the yellow coloration. The final volume of $\mathrm{SbCl}_{5}$ and water was approximately 1.8 I1ters. The precipitate had a light green tint and the odor of hydrogen chloride over the beaker was strong. After allowing the precipitate to settle, the supernatant was decanted, and more water was added to the precipitate. The three step operation was repeated three more times. After the final addition of water, the precipitate was stirred overnight. During filtration through a Buchner. with aspiration, the precipitate formed an apparently dry. mass. However, the material would liquify if pressure, as when pressing or stirring with a spatula, was applied. After liquification, more water could be removed with the Buchner funnel. The final precipitate was pasty, white and without the odor of hydrogen chloride. The pH of the supernatant was always less than 1 . In order to test the drylng procedure the precipitate was split into two unequal portions.

The smaller portion of the precipitate was placed in a drying oven for 5 hours at $150^{\circ} \mathrm{C}$ to remove excess molsture, 
then transferred to a muffle furnace for 5 hours at a temperature which varjed between 270 and $290^{\circ} \mathrm{C}$. During the high temperature treatment an uneven yellow color developed in the precipitate which by this time had formed large chunks. To ensure a homogeneous transformation, the material was broken up with a mortar and pestle and returned to the muffle furnace to complete the five hour treatment. The final material was pale yellow and crystalline. After noting the results of this procedure on the second portion of the precipitate, this material was returned to the muffle furnace for five additional hours at $270^{\circ} \mathrm{C}$. The only apparent change was a darkening of the yellow color. This material was designated HAP IA.

The second portion of the synthesis product was placed in a drying oven at $130^{\circ} \mathrm{C}$ for 1.0 hour prior to transferring it to the muffle furnace at $270^{\circ} \mathrm{C}$ for 5.0 hours. During the high temperature treatment, the sample was fractured as with HAP 1A. The final product of this operation (HAP IB) was a yellow material with a powdery texture. The color was darker than the initial HAP IA product, which is the reason IA was reheated.

The total production of HAP material. was approximately $200 \mathrm{~g}$. Before use, however, the material was sized and the fraction between 150 and 250 microns was kept for testing. This operation reduced the amount of usable material by half. 
b. HAP 2 The second attempt to synthesize HAP was a failure, but the method is included because the final material was used in an attempt to gain information about the composition of hydrated antimony pentaoxide. The synthesis proceeded as described in the synthesis of HAP IB. However, during the high temperature drying step, temperature control in the muffle furnace falled. Instead of drying for 5 hours at $270^{\circ} \mathrm{C}$, the materlal was exposed to a temperature between 650 and $700^{\circ} \mathrm{C}$ for an indeterminate amount of time. The final product (HAP 2) was a powdery, grayish-brown material. Approximately $190 \mathrm{~g}$ of material was recovered. A portion of this material was fractioned ( $150 \leq X \leq 420$ microns) and tested for sodium decontamination and selectivity.

c. HAP 3 This synthesis of HAP followed the same sequence of operations described in the synthesis of HAP 1 products. A noted deviation from the HAP I routine was the presence of the pungent odor of hydrogen chloride following the last filtration step. The odor became much stronger and white fumes developed as the precipitate was treated at $270^{\circ} \mathrm{C}$ in the muffle furnace. The material at the end of the heat treatment was translucent, white and crystalline. Additional drying at $270^{\circ} \mathrm{C}$ did not produce the expected yellow coloration. The material was subjected to a series of water additions and subsequent dryings at 
$270^{\circ} \mathrm{C}$ until a yellowish-white color developed. When further treatment did not increase the extent or intensity of the color, the treatments were stopped. The final yellowish-white crystalline material was designated HAP 3 . After sizing, a portion was subjected to decontamination and selectivity tests.

d. HAP 4A and 4B The work of Torok and Diehl (145) provided the basis for the following synthesis procedure. The contents of a l-1b bottle of $\mathrm{SbCl}_{5}$ were slowly mixed with 1.0 liter of a $10 \% \mathrm{NH}_{3}$ solution. The interaction was more violent than hydrolyses with plaln water. After the white precipitate formed, it was allowed to remain in contact with the mother liquor for 4 hours. The mother liquor was then filtered off, and the precipitate was redispersed in 1.0 liter of deionized water and left to stir overnight. After the water was filtered off, the precipitate, unlike HAP 1 at the same stage of processing, was very tacky and tended to form lumps. Also, the odor of hydrogen chloride was distinctly present. After two washes with the $\mathrm{NH}_{3}$ solution, the odor subsided, but the consistency of the precipitate did not change. The precipitate was dried inftially at $100^{\circ} \mathrm{C}$ for 1.0 hour in a Sargent drying oven, then transferred to a muffle furnace to dry for 5 hours at $270^{\circ} \mathrm{C}$. The resulting product (HAP 4A) was light yellow with a powdery texture. 
Approximately one-half of product $4 \mathrm{~A}$ was returned to the oven for an additional five hours. The resulting material (HAP 4B) was crystalline and had a deeper yellow coloration than HAP $4 \mathrm{~A}$.

e. HAP $5 A$ and $5 B$ HAP $5 A$ was produced by following as closely as possible the procedure described by. Torok and Diehl (145). Five $\mathrm{ml}$ of $\mathrm{SbCl}_{5}$ was hydrolyzed with $25 \mathrm{ml}$ of $1 \% \mathrm{NH}_{4} \mathrm{OH}$. The resulting precipitate was pasty and lumpy with a slight odor of hydrogen chloride. After standing four hours in contact with the mother liquor, the precipitate was filtered and redispersed in $500 \mathrm{ml}$ of deionized water for 12 hours. After collection, the material was washed twice, then transferred to a muffle furnace to dry at $270^{\circ} \mathrm{C}$ for five hours. Approximately $2.1 \mathrm{~g}$ of a pale yellow, powdery precipitate (HAP 5A) was recovered.

HAP $5 B$ was produced with an abbreviated form of the procedure used in producing the HAP $I$ variants. Five $\mathrm{ml}$ of $\mathrm{SbCl}_{5}$ was hydrolyzed with $100 \mathrm{ml}$ of deionized water. Another $200 \mathrm{ml}$ of water were added after the addition of $\mathrm{SbCl}_{5}$ was completed, and the mixture was allowed to stir overnight. The precipitate in solution was finely dispersed and had a very strong odor of hydrogen chlorlde. Following filtration and a single washing (the pungent odor was not removed), the precipitate was dried in a muffle furnace for five hours at $270^{\circ} \mathrm{C}$. The resulting 
product. (HAP 5B) was crystalline with a yellow color which hecame off-white and translucent as the material cooled. f. HAP 6A and 6B A dripper system with a 250-mI separatory funnel as the reservoir was employed to add $185 \mathrm{ml}$ of $\mathrm{SbCl}_{5}$ to 1.0 liter of a stirred $1 \% \mathrm{NH}_{4} \mathrm{OH}$ solution over a perlod of 2.3 hours. After four hours of stirring in contact with the mother liquor, the precipitate was removed. The mother liquor possessed a slight green tint and a pungent odor. Treatment of the mother liquor with more of the $\mathrm{NH}_{4} \mathrm{OH}$ solution yielded more precipitate. All of the precipitates were gathered and dispersed into 1.0 liter of deionized water for 12 hours. After collection, the precipitate was dried at $270^{\circ} \mathrm{C}$ for five hours in a modified Sargent drying oven. The resulting material was in fairly large chunks which accounted for the uneven yellow and white coloration. After an additional 13 hours in the oven, no more of the material changed to yellow. The material was cooled, crushed and sized. The fraction between 155 and 450 microns was collected and designated HAP 6A. A portion of $6 \mathrm{~A}$ was returned to the oven for 10 hours at $300^{\circ} \mathrm{C}$. A golden material (HAP 6B) which lightened to golden-yellow while cooling in a desiccator was obtained.

g. HAP 7 HAP 7 was synthesized according to the same general procedure used in the preparation of the HAP 6 products. The deviations were the inclusion of more $\mathrm{NH}_{4} \mathrm{OH}$ 
solution in the initial hydrolysis, and a prolonged drying period ( 18 hours) at $300^{\circ} \mathrm{C}$ in a sargent drying oven modified for forced air flow. The final product was light yellow with a powdery texture. The total recovery of material was $200.9 \mathrm{~g}$, of which $127.1 \mathrm{~g}$ was usable after sizing to between 150 and 250 microns.

\section{Sodium decontamination with HAP}

The products of each synthesis attempt were tested for sodium adsorption from either hydrochloric or nitric acid. The basic objective of the decontamination test was to compare the activities of ${ }^{24} \mathrm{Na}$ which were present in an untreated aliquot of a reference solution with the activities which were present in an identical aliquot of the reference solution which had been processed through a column of HAP. In the earliest tests, a radio-sodium reference solution was prepared to provide sufficient activity for counting purposes, but the total amount on the column was kept below $30 \mathrm{mg}-\mathrm{Na} / \mathrm{g}$ of HAP which comprised the column. In later testing, an irradiated biological material was used to make the reference solution.

In the sodium decontamination test, a chromatographic column was filled with 1.3 to $1.5 \mathrm{~g}$ of HAP material (column height approximately $3 \mathrm{~cm}$ ) which had been previously washed with the appropriate ac1d to remove fines. Pyrex wool plugs were used above and below the resin bed for 
stabilization. The column material was equilibrated by rinsing with four bed volumes of the acid to be used as the eluent.

Radio-sodium was obtained by irradiating a small amount of sodium carbonate. After the irradiation, the carbonate was dissolved in acid and the sample container. was rinsed with three volumes of acid. The dissolved sample and the rinses were combined. A quantity of the radiosodium solution was transferred with an Eppendorf Automatic Pipette (either 10 or $200 \mu l$ ) to a volumetric flask containing enough inactive sodium to provide a total sodium concentration of $6 \mathrm{mg}-\mathrm{Na} / \mathrm{ml}$ after the solution was brought to volume with the appropriate acid. The amount of radiosodium solution initially transferred was empirically determined such that a 5-ml volume of the final sodium solution would provide approximately $10^{6}$ counts/min at approximately $10 \mathrm{~cm}$ from the face of the $\mathrm{Ge}(\mathrm{Li})$ detector used in the high resolution gamma spectroscopy system. Two different procedures were used to obtain the solutions for comparison of radio-sodium activity. The first approach allowed the collection of data concerning the minimum and maximum amounts of eluents which could be used on the column. With experience, this information became unnecessary and the procedure was considerably simplified. 
a. Decon test I The reference solution was made by pipetting $5 \mathrm{ml}$ of a radio-sodium solution to a $50-\mathrm{ml}$ volumetric flask and diluting to volume with the eluent acid. A 5-ml aliquot of this solution was transferred to a 10-dram plastic vial for use as the reference. Another 5-ml aliquot of the radio-sodium solution was pipetted directly onto the HAP column and allowed to flow through at about $1 \mathrm{ml} / \mathrm{min}$. The column was then eluted with $15 \mathrm{ml}$ of the appropriate acid, either 12M hydrochloric or 12-15M nitric acid. All discharges from the column were collected in a 50-ml volumetric flask and diluted to volume. Depending on the experiment, as many as 6 additional 15-ml elutions were performed with the collected eluent of each elution going into separate volumetric flasks. In all cases the volumetric flasks were diluted to volume with the eluent acid and $25 \mathrm{ml}$ of the resulting solutions were transferred to 10-dram plastic vials for counting on the high resolution gamma system.

b. Decon test 2 The reference solution was prepared by pipetting a known amount of a radio-sodium solution to a 125-ml plastic bottle. The bottle was then filled to a predetermined mark with an acid solution. An identical aliquot of the radio-sodium solution was transferred directly to the HAP column and allowed to flow through at a rate of about $1 \mathrm{ml} / \mathrm{min}$. Depending on the 
experiment, the column was then eluted with up to $60 \mathrm{ml}$ of acid. All of the eluent was collected in a 125-ml plastic bottle. The activity in the two botties was measured on the high resolution gamma system.

\section{Percent antimony in HAP}

The percentage of antimony in most of the HAP materials was determined by Neutron Activation Analysis using the standard-comparator method. The standard consisted of a weighed quantity of potassium antimony tartrate $\left\{\mathrm{K}(\mathrm{SbO}) \mathrm{C}_{4} \mathrm{H}_{4} \mathrm{O}_{6} \cdot 1 / 2 \mathrm{H}_{2} \mathrm{O}\right\}$ irradiated along with a sample of the synthesis product for up to I hour. After a decay period of 10 days, the gamma spectra of the synthesis products and the standard were obtained on the high resolution system and processed as previously described.

10. Water in HAP materials.

A welghed sample of each HAP product was heated in a muffle furnace for 5 hours at $700^{\circ} \mathrm{C}$. The samples were removed to a desiccator to cool prior to reweighing. Each sample was returned to the oven and left for about 10 hours at $560^{\circ} \mathrm{C}$. Following removal, each sample was cooled in a desiccator and reweighed. 
11. Selectivity of HAP materials

The basis of the selectivity test was identical to the method employed in the sodium decontamination tests. A comparison was made between the radioactivities present in an aliquot of a reference solution of mixed radionuclides and an identical aliquot of the reference solution processed through a column of HAP material. The reference solution contained stable carriers for each radionuclide in the solution. In addition, the concentration of stable sodium in the reference was adjusted to have approximately $30 \mathrm{mg}$ of sodium on the column during the testing. Both of the elution techniques described for the sodium decontamination test were also employed in the selectivity testing. Table 24 contains data concerning those nuclides which were checked for sorption by the HAP materials. Some of the elements (․‥e., $\mathrm{Ba}, \mathrm{La}, \mathrm{Sm}$, etc.) inftlally included in the sorption tests were eliminated later as analyses of real biological samples falled to detect them.

12. Sodium capac1ty of HAP materials

As a method for further characterization of the synthesis products HAP 6 and HAP 7 , the capacity of these materials for sodium was experimentally determined. Two techniques were employed. In the first, an aliquot containing a known amount of radio-sodium and stable sodium in the appropriate ac1d was passed through a column of the 
Table 24. Elements tested for sorption on various HAP materials

\begin{tabular}{ll}
\hline Element & Element \\
\hline As & La \\
\hline $\mathrm{Ba}$ & $\mathrm{Lu}$ \\
$\mathrm{Ce}$ & $\mathrm{Na}$ \\
$\mathrm{Co}$ & $\mathrm{Rb}$ \\
$\mathrm{Cr}$ & $\mathrm{Sb}$ \\
$\mathrm{Cu}$ & $\mathrm{Sc}$ \\
$\mathrm{Eu}$ & $\mathrm{Se}$ \\
$\mathrm{Fe}$ & $\mathrm{Sm}$ \\
$\mathrm{Hg}$ & $\mathrm{Yb}$ \\
$\mathrm{K}$ & $\mathrm{Zn}$ \\
\hline
\end{tabular}


material that was being tested. The column was then eluted with three more column volumes of eluent. All eluents were combined in 50-ml plastic bottles for assay with the low resolution system. These operations were continued until more than $30 \mathrm{ml}-\mathrm{Na} / \mathrm{g}-\mathrm{HAP}$ in the column was added to the resin. The ${ }^{24} \mathrm{Na}$ activity of each collected sample was compared with a reference. which consisted of an aliquot of the radio-sodium solution diluted to a predetermined level in a 50-ml plastic bottle. In the second procedure, a solution of known sodium concentration containing radio-sodium was allowed to flow through an equilibrated column of a HAP material at a rate less than $1 \mathrm{ml} / \mathrm{min}$. The eluent was collected in $5-\mathrm{ml}$ volumes and counted on the low resolution system. Information concerning the amount of sodium on the column was obtained by comparing the count rates of the eluents with a 5-ml aliquot of the sodium solution which had not been processed through the HAP material.

\section{HAP and wet ashing compatibility}

Each HAP material which was judged suitable on the basis of sodium retention and nuclide selectivity tests was evaluated for compatibility with wet ashing methods which were potentially usable in the project. The objective of the testing was to discover whether the properties of the HAP materials were adversely affected by 
the composition of the solution resulting from the ashing procedure. Aliquots of the ashed matrix solutions described in the step 4 of the digestion routes listed in the section titled "Digestion Schemes" were used as the test solutions. For the most part, compatibility testing followed the approach outlined in Decon Test 2 of the sodium decontamination tests.

14. Alumina

Chromatographic acid alumina (powder, Brockmann activity grade 1.) was tested for the removal of ${ }^{31} \mathrm{P}$ in the form of phosphates from nitric acid solutions. Solutions of radiotracers were used to ascertain the specificity of alumina for phosphate over other ionic species. The basic approach of the test procedure was the same as outlined in the section concerning the sodium decontamination properties and ionic selectivity of HAP materials. The phosphorus decontamination factors were determined w1th 1rradiated biological samples rather than synthetic tracer solutions. Alumina was evaluated in $10 \mathrm{M}, 12 \mathrm{M}$, and $16 \mathrm{M}$ nitric acid.

\section{AG2-X8 anion exchanger}

The chloride, bromide, and acetate forms of the anion exchanger AG2-X 8 (Bio-Rad Laboratories, Richman, Calif.) were evaluated for sodium, potassium, bromine, and phosphorus decontamination. Each material was tested with a number of 
eluents for selective elution of anionic species as part of a decontamination operation. All experiments involved solutions of ashed biological matrices spiked with radionuclide tracers. The selectivity and elution tests followed the same schemes as described for the HAP evaluations.

a. Chloride form The chloride form of AG2-X8 was obtained commercially in 100-200 mesh. Prior to use, the resin was rinsed in $6 \mathrm{M} \mathrm{HCl}$ to remove fines. The remaining materlal was poured into support columns to form resin beds of 4.5 to $5.0 \mathrm{~cm}$ in helght. The top and bottom of the resin bed was secured with plugs of Pyrex wool. The resin beds were equilibrated by elution with 3 to 4 bed volumes of $10-12 \mathrm{M} \mathrm{HCl}$ prior to application of the test solutions.

b. Bromide form The bromide form of AG2-X8 was synthesized from the commerclally obtained chloride form of the resin. The chloride form was inftially converted to the sulfate form by elution with 0.25 M sulfuric acid until silver nitrate tests showed that chlorine was absent from the eluent. Complete conversion of a $80-\mathrm{ml}$ bed volume of the chloride form to the sulfate form required approximately 1.0 liter of the acid solution at a rate of 2-4 $\mathrm{ml}$ per minute. Without rinsing the resin, the bed was converted to the hydroxyl form by elution with a $2.8 \mathrm{M}$ $\mathrm{NaOH}$ solution. The conversion to the hydroxyl form, which 
was facilitated by a decrease in the affinity of the resin for sulfate anions in a basic medium, was highly favorable and required only 2-3 bed volumes to ensure a complete transformation. Darkening of the resin during formation of the hydroxyl form was a good indicator of the completeness of the conversion. Without rinsing the column, the eluent was changed to $48 \% \mathrm{HBr}$, and the resin was eluted until the entire bed was a uniform dark brown. Two more bed volumes of $\mathrm{HBr}$ were eluted through the column to ensure the completeness of the transformation. After removal from the supporting column, the resin was stored in a $10 \% \mathrm{HBr}$ solution.

c. Acetate form The acetate form of AG2-X8 was synthesized from the commercially obtained chloride form in a conversion procedure identical to the bromide conversion except for the final step. The hydroxyl form was converted to the acetate by elution with glacial acetic acid. A color change useful for following the extent of the transformation did occur. The acetate resin was stored in a $6 \mathrm{M}$ acetic acid solution.

\section{Resin/digestion compatibility}

Each resin/eluent combination deemed suitable for inclusion in a DNAA procedure was tested for compatibility with prospective wet ashing processes. The evaluation 
proceeded according to the procedures indicated for the compatibility studies with the HAP materials.

\section{DNAA Procedure}

The schemes developed while testing the individual operations for inclusion in a DNAA procedure had to be modified for the analysis of real biological samples. The primary alterations were due to the need for larger aliquots of the digested samples in order to obtain sufficient counting statistics without excessively long counting periods. Although the concentrations of elements in the digestion steps during the analysis of real samples and in the primary evaluations were similar, the ratio of radioactive to stable isotopes during the evaluations was kept higher in order to keep the counting times reasonable. The following is a step-by-step description of the procedure developed for the analysis of biological standards by DNAA.

\section{Capsulation}

Approximately $400 \mathrm{mg}$ of the biological materlal were transferred to a tared, acid-cleaned Supercil quartz vial. Any material adhering to the walls of the vial was removed with biasts of filtered air prior to welghing the vial and its contents. After capping with a sheet of high purity aluminum foil to prevent contamination by airborne. particles, the vial was clamped into the recess of the 
liquid nitrogen cooled cold-finger (Figure 2). The vial was allowed to cool until frost was at least $1.9 \mathrm{~cm}$ above the lip of the cold-finger and on the clamp. An oxygengas torch was used to seal the vial.

Capsulation of the standard solutions was achieved in the same manner, except transference of the solution to the vial was acsomplished with fixed-volume 10 and $200 \mu 1$ Eppendorf Automatic Pipettes. The total volume of the standard solution never exceeded $1.0 \mathrm{ml}$.

2. Irradiation

The vials containing the samples and standards were wrapped in aluminum foil and sealed in styrofoam padded irradiation capsules. Since the small rabbit capsules could contain only two vials, a standard and a sample were always irradiated together. Typically, the capsules were irradiated in the R-3 facility of the ALRR for 15 hours and allowed to "cool" for 24 hours.

\section{Digestion}

After removal from the irradiation capsule, the sample vials were stripped of adhering packing materials and aluminum foil. Successive baths of bolling nitric acld, water, methanol, and acetone were used to clean the outer walls of the quartz vessels. Each vial was placed in a bath of liquid nitrogen until boiling at the walls 
of the vials ceased. With a minimum of elapsed time and direct handling, each vial was wrapped in a small Kimwipe (average weight was $0.54 \mathrm{~g}$, dimensions were $21.7 \times 12.3 \mathrm{~cm}$ ), crushed with a lead brick, and transferred to a $100 \mathrm{ml}$ round-bottom flask which constituted the reaction vessel of the modified Gorsuch digestion apparatus (F1gure 4). The flask was immediately immersed in liquid nitrogen unt1l bolling subsided. Using a Pasteur pipette, the entire sample was coated with 5-10 ml of a 9:1 mixture of sulfuric and nitric acids, and $2.0 \mathrm{ml}$ each of carriers "A" and "B" (Table 22). The flask was removed from the Ilquid nitrogen bath, connected to the apparatus, and allowed to warm until the frost cleared before immersing in an oil bath maintained at $90^{\circ} \mathrm{C}$. To prevent foaming, magnetic stirring was not applied until the sample had liquified (1‥e., approximately 5 minutes after placement in the bath). After at least 15 minutes of stirring, Incremental additions of $90 \%$ hydrogen peroxide were initiated. The hydrogen peroxide additions were continued until the digest cleared or until $8 \mathrm{ml}$ of peroxide had been added. During the peroxide additions, the three-way stopcock was in the reflux position and the cold-flnger was kept charged with liquid nitrogen. After the last addition of peroxide, $2.0 \mathrm{ml}$ of carriers "A" and "B". were added to the digest which was stirred unt1l the 
effervescence ceased. The apparatus was removed from the o1l bath and allowed to cool. Afterwards, the contents of the reaction vessel were transferred to a 50-ml volumetric flask. All rinse water was collected and added to the volumetric flask. When the digested samples were transferred from the reaction vessel to the volumetric flask, a funnel with a small amount of Pyrex wool was used to prevent the transfer of pieces of quartz to the volumetric flask. After dilution to volume, aliquots of the digest solution were processed by the decontamination and concentration steps.

\section{AG2-X8 bromide form}

Depending on the experiment, 5-10 $\mathrm{ml}$ of the ashed sample and $2 \mathrm{ml}$ of a $12 \%(\mathrm{w} / \mathrm{v})$ solution of hydroxylamine hydrochloride were pipetted into $30 \mathrm{ml}$ of $48 \%$ hydrobromic acid. The acid solution was eluted through a $5.0-\mathrm{cm}$ column of the bromide form of the AG2-X8 resin. Prior to applying the sample solution, the column was equilibrated with 3 resin bed volumes of the $48 \%$ hydrobromic acid. Flow rates were not allowed to exceed $1 \mathrm{ml}$ per minute. The eluent was collected in 125-ml plastic bottles with screw caps. After the initial sample solution was eluted, the column was rinsed with $50 \mathrm{ml}$ of $\mathrm{HBr}$ which was combined with the initial eluent. The resin bed was rinsed with $48 \%$ hydrobromic acid from the support column into a wide-mouth 10-dram plastic vial. 
5. HAP, alumina, AG2-X8 chloride form

A second 5-10 ml aliquot of the digest solution was pipetted directly onto a 3-cm bed of $A G 2-X 8$ resin in the acetate form which had been equilibrated in $0.03 \mathrm{M}$ nitric acid. Following elution of the sample, the bed was rinsed with $20 \mathrm{ml}$ of $10 \mathrm{M}$ nitric acid. All eluents were collected and mixed with $60.0 \mathrm{ml}$ of concentrated nitric acid. The acid solution was eluted through a column consisting of $3.0 \mathrm{~cm}$ of HAP and $1.0 \mathrm{~cm}$ of alumina which had been equilibrated with several bed volumes of $10 \mathrm{M}$ nitric acid. After elution of the solution at a rate of less than $1 \mathrm{ml} / \mathrm{min}$, the column was rinsed with $10 \mathrm{M}$ nitric acid. All eluents were collected in a 125-ml plastic bottle with a screw cap. The resin beds were discarded. 


\section{RESULTS AND DISCUSSION}

\section{A. Objectives}

The overall objective of this work was to develop and evaluate the schemes utilizing destructive neutron activation analysis (DNAA) without yield determinations for the determination of trace elemental components in blological materials. More specifically, the DNAA scheme was to be evaluated in terms of its possible use as a medical diagnostic tool. This work was not only concerned with the accuracy and precision of the technique, but also with simplifying the processing operations and minimizing the time between securing the sample and obtaining results.

\section{B. Outline of Proposed DNAA Scheme}

Based on the literature review, several points concerning the proposed DNAA scheme were adopted. In order to exploit the full potential of a radiochemical technique to eliminate the problems associated with contamination of a sample by reagent blanks, pre-irradiation treatment of the sample should be limited to freeze-drying. The irradiation container should be fabricated from quartz or silica, preferably of synthetic origin. To eliminate the need for post-irradiation weighing of samples and the subsequent potential for sample losses, the irradiation vial and the sample should be included in the process used to destroy the 
organic matrix. For reasons of versatility, simplicity, and speed of operation, destruction of the organic matrix should be accomplished by a wet ashing procedure. Radioactive species present after ashing which would interfere with the collection and interpretation of gamma spectra of the sample should be removed by chemical processing. Tentative decontamination systems should include hydrated antimony pentaoxide and alumina for the removal of radionuclides of potassium, sodium, and phosphorus. An anion exchange system should be included as a means to concentrate the analyte species prior to assay.

The approach employed in the development of the DNAA procedure required verification of the effectiveness of each proposed operation. Experimental investigations of the various operations were begun simultaneously in four areas:

1) capsulation, 2) wet ashing, 3) decontamination, and 4) concentration and separation.

\section{Freeze-Drying}

In devising the attack on the problems associated with the pre-irradiation aspects of an analysis by DNAA, a: study of the behavior of the biological standards during freezedrying was eliminated. As inferred from the cited literature, the best way to ascertain the effects of freeze-drying on a particular matrix is to compare the results of duplicate analyses performed on freeze-drled and untreated aliquots of 
a sample previously dried by another method. However, the preferred way to accomplish the analyses would be a DNAA procedure valid for biological materials. Since it was the objective of the project to develop this scheme, the freezedrying study was considered premature. No difficulties should arise if the parameters of freeze-drying operations presented in the literature were followed $(92,118)$. This should ensure that the characteristics of the dried samples are identical to samples in previous works for which compositional data is available.

\section{Capsulation}

The objectives of the capsulation studies were as follows: 1) determine the relative "purity" of the container materlal, and consequently, the feasibility of including the container in the ashing step; 2) devise and test a system for sealing the containers without the loss of sample or sample components; and 3 ) devise and test a system for transferring the irradiated samples to the ashing apparatus.

Synthetic CFQ (Clear Fused Quartz) T21 Supercil tubing was tentatively selected as the container material. The imperviousness of the quartz to the ashing systems tentatively selected for inclusion in the DNAA scheme was the primary reasnn its selection. A synthetic quartz was chosen because of the trend for lower blank values in this type of material (106). 
The "purity" tests were actually concerned with the extent to which potentially interfering species were leached from the quartz during the ashing operation. Table 25 lists elements which were identified in the digest remaining after a wet ashing procedure was executed on samples of irradiated CFQ T21 quartz. The relative amounts of elemental components common to digestion extracts of quartz and biological materials are presented in Table 26 as the ratio of their specific activities. Neutron activation analysis was used to approximate the actual amount of elemental species extracted from quartz during ashing (Table 27). The results of the specific activity measurements and the semiquantitative analysis indicated only limited possibllities that materials leached from the irradiation containers would interfere with the analysis of a sample. Significant errors would occur only for determination of gold in blood and antimony in both the blood and bovine liver standards.

Specifics of the two experimental procedures indicated that the quantitative data was more reliable. The specific activities in the biological samples were determined without chemical processing of the samples. Consequently, all of the difficulties which normally plague the analysis of biological materials by neutron activation were present. Decay periods necessary to eliminate interferences resulted in the loss of data for shorter lived nuclides (1․e.., As, Cu; etc.). 
Table 25. Elements identified in digest remalning after "wet ashing" CFQ T21 quartz

\begin{tabular}{ll}
\hline Element & Element \\
\hline $\mathrm{Ag}^{\mathrm{a}}$ & $\mathrm{Na}$ \\
$\mathrm{As}^{\mathrm{a}}$ & $\mathrm{Sb}$ \\
$\mathrm{Au}$ & \\
$\mathrm{Cr}$ & $\mathrm{Sc}$ \\
$\mathrm{Cu}$ & $\mathrm{Se}$ \\
$\mathrm{Hg}$ & $\mathrm{Sm}{ }^{\mathrm{a}}$ \\
$\mathrm{K}$ & $\mathrm{W}$ \\
$\mathrm{La}$ & $\mathrm{Zn}$ \\
\hline
\end{tabular}

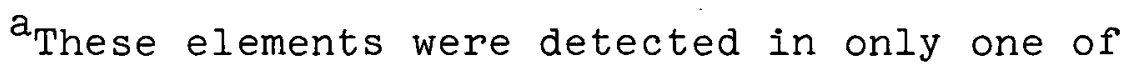
three analyses performed on the synthetic quartz. 
Table 26. Ratio of specific activities of nuclides common to Amercil Quartz and biological samples ${ }^{a}$

\begin{tabular}{|c|c|c|c|}
\hline Nuclide & $\begin{array}{l}\text { Energy } \\
\text { (Kev.) }\end{array}$ & Blood & Liver \\
\hline $76_{\mathrm{As}}$ & 657 & $--^{b}$ & $\ldots-^{b}$ \\
\hline${ }^{60} \mathrm{Co}$ & 1173 & .05 & .05 \\
\hline $5 i_{\mathrm{Cr}}$ & 320 & $--^{b}$ & $--^{b}$ \\
\hline${ }^{24} \mathrm{Na}$ & 1368 & .0002 & .0002 \\
\hline${ }^{4} 2_{\mathrm{K}}$ & 1524 & .0002 & .0001 \\
\hline${ }^{122} \mathrm{Sb}$ & 564 & 0.46 & 1.15 \\
\hline $124 \mathrm{Sb}$ & 603 & 0.78 & 0.28 \\
\hline${ }^{75} \mathrm{Se}$ & 264 & 0.03 & 0.01 \\
\hline
\end{tabular}

$a_{\text {Ratio }}=\frac{\text { SpAc Quartz }}{\text { SpAC Bio. Smpl. }} \times 100$.

$b_{\text {The nuclide was detected in the biological samples }}$ but poor counting statistics prevented calculation of the rat10. 
Tabl: 27. Quantitative results for elements common to CFQ T2l quartz, bovine liver, and U.K. master mix blood

\begin{tabular}{|c|c|c|c|c|c|c|}
\hline Elemənt & $\begin{array}{l}\text { Energy } \\
(\text { Kev.) }\end{array}$ & $\begin{array}{l}\mu g \text { in } \\
\text { Quartz }\end{array}$ & $\underset{\text { Liver }}{\mu g}$ in & $\begin{array}{c}\% \text { Ratio } \\
\text { Qrtz/Liver }\end{array}$ & $\begin{array}{l}\mu \mathrm{g} \text { in } \\
\text { Blood }\end{array}$ & $\begin{array}{c}\text { \% Ratio } \\
\text { Qrtz/Blood }\end{array}$ \\
\hline As & 559 & $\mathrm{ND}^{\mathrm{b}}$ & $2.2 \times 10^{-2}$ & $-\ldots c$ & $1.0 \times 10^{-2}$ & -- \\
\hline $\mathrm{Au}$ & 412 & $6.5 \times 10^{-4}$ & ND & --- & $1.0 \times 10^{-4}$ & 647 \\
\hline \multirow[t]{2}{*}{$\mathrm{Co}$. } & 1173 & $2.6 \times 10^{-3}$ & $7.2 \times 10^{-2}$ & 3.6 & ND & --- \\
\hline & 1332 & $3.2 \times 10^{-3}$ & $7.2 \times 10^{-2}$ & 4.4 & ND & --- \\
\hline $\mathrm{Cu}$ & 1345 & $5.6 \times 10^{-3}$ & 77.2 & 1.4 & 0.01 & 0.40 \\
\hline \multirow[t]{3}{*}{$\mathrm{Sb}$} & 564 & $1.5 \times 10^{-2}$ & ND & -- & $4.0 \times 10^{-3}$ & 382 \\
\hline & 693 & $1.5 \times 10^{-2}$ & ND & -- & $4.0 \times 10^{-3}$ & 374 \\
\hline & 603 & $1.6 \times 10^{-2}$ & ND & --- & $4.0 \times 10^{-3}$ & 412 \\
\hline
\end{tabular}

$\exists_{T h e}$ vial weighed $4.81 \mathrm{~g}$. Each biological sample was approximately $400 \mathrm{mg}$. Both weights were typical of actual experimental conditions.

Jot detected.

Not calculated. 
The quantitative data was obtained by comparing the activities of the quartz extract with the activities of a standard solution. Specific interferences were thus eliminated. Even with the superior spectral characteristics, the results nevertheless represented only approximations of the amounts of materials leached from the quartz. Exact determination of the amount of quartz transferred to the ashing apparatus with the standard was not possible because of deposits left on the vials by the gas-oxygen torch. Further uncertainty resulted because the extent of the leaching process was dependent on the exposed surface area. The degree to which the vials were crushed could lead to variations in the amount of material leached from the quartz.

The trace elemental composition of CFQ T21 Supercil tubing was not determined. The elemental composition of the synthet1c quartz materials, Quartex and Spectrosil, Iisted in Table 28 should provide an idea of the levels found in the Supercil quartz.

\section{E. Sample Containers}

The liquid nitrogen cryostat shown in Figure $2 \mathrm{~b}$ was designed for enclosing biological samples in quartz irradiation vials (Figure 2a) without causing significant thermal damage to the sample. Three questions concerning the irradiation capsule needed to be answered: 1) Were any sample components lost sealing the vials? 2) Could the vials contain the 
Table 28. Masses of elements contained in $4.81 \mathrm{~g}$ of two kinds of synthetic silica glas.s ${ }^{a}$

\begin{tabular}{|c|c|c|}
\hline Element & $\begin{array}{l}\text { Quartex } \\
\text { (Fused Quartz) }\end{array}$ & $\begin{array}{c}\text { Spectrosil } \\
\text { (Fused Silica) }\end{array}$ \\
\hline $\mathrm{Au}$ & $4.81 \times 10^{-2}$ & $6.25 \times 10^{-4}$ \\
\hline Cl & $<4.81 \times 10^{-1}$ & $1.78 \times 10^{1}$ \\
\hline Co & $6.25 \times 10^{-3}$ & $<4.81 \times 10^{-3}$ \\
\hline $\mathrm{Fe}$ & 6.93 & $<2.41$ \\
\hline $\mathrm{K}$ & $<4.81$ & $<2.41$ \\
\hline La & $7.7 \times 10^{-3}$ & $1.11 \times 10^{-2}$ \\
\hline $\mathrm{Mn}$ & $1.3 \times 10^{-1}$ & $1.5 \times 10^{-1}$ \\
\hline $\mathrm{Sb}$ & 1.6 & $1.9 x \cdot 10^{-3}$ \\
\hline $\mathrm{Sc}$ & $7.2 \times 10^{-4}$ & $4.8 \times 10^{-3}$ \\
\hline $\mathrm{Se}$ & $4.4 \times 10^{-3}$ & --- \\
\hline $\mathrm{Sm}$ & $1.4 \times 10^{-3}$ & $1.8 \times 10^{-3}$ \\
\hline $\mathrm{Zn}$ & $3.5 \times 10^{-1}$ & $4.8 \times 10^{-2}$ \\
\hline
\end{tabular}

a Based on data of Maziere, et al. (106). 
pyrolysis and radiolysis products generated in the reactor environment? 3) Could the procedure devised for opening the vials following irradiation prevent the loss of sample components?

Excessive radiation and spectral contaminants would have complicated, if not defeated, any attempt to use irradiated biological materials in this study. Radio-tracers in combination with biological matrices were used to follow trace elemental components through the processing operations. An oven was used to simulate the heating conditions experienced by the sample in the reactor. To ensure the production of similar decomposition products, the oven temperature $\left(150^{\circ} \mathrm{C}\right)$ was intentionally set in excess of the ambient temperature of the ALRR $\left(65^{\circ} \mathrm{C}\right)$. The higher temperature was needed to. account for internal heating of the sample which would occur in the reactor from intense gamma ray flux and induced nuclear reactions.

The data presented in Table 29 represents the recoveries of radio-tracers from vials following each operation normally associated with the vial-sample system (1‥e., sealing, heating or irradiation, and opening). The results indicated that the Irradiation capsules and the sealing and opening procedures were effective for manipulating biological samples without the loss of trace elemental components. Experimental results of the study were similar for the blood and bovine liver matrices. The values presented in Table 29 are the 
Table 29. Summary of ampoule test results. The "pre-sealed" recoveries indicated

that the same amount of each nuclide was. In the test and reference vials.

The remaining recoveries indicated that relative to the reference vials

no material was lost from the test: vials during sealing, heating and

decanting

\begin{tabular}{|c|c|c|c|c|c|c|c|c|c|}
\hline \multirow[b]{2}{*}{ Nuclide } & \multirow[b]{2}{*}{ En } & \multicolumn{2}{|c|}{ Pre-Sealed } & \multicolumn{2}{|c|}{ Sealed } & \multicolumn{2}{|c|}{ Heated } & \multicolumn{2}{|c|}{ Decanted } \\
\hline & & $\% \mathrm{R}^{\mathrm{a}}$ & $\sigma$ & $\% \mathrm{R}$ & $\sigma$ & $\% \mathrm{R}$ & $\sigma$ & $\% \mathrm{R}$ & $\sigma$ \\
\hline \multirow[t]{2}{*}{ Co } & 1173 & 98.3 & 0.8 & 101.5 & 1.1 & 97.2 & 2.4 & 102.9 & 1.9 \\
\hline & 1332 & 97.9 & 0.9 & 98.0 & 1.3 & 97.2 & 2.5 & 99.8 & 1.9 \\
\hline $\mathrm{Cr}$ & 320 & 103.3 & 2.0 & 103.1 & 2.2 & 97.3 & 4.8 & 100.2 & $3 \cdot 3$ \\
\hline $\mathrm{Fe}$ & 1099 & 98.6 & 4.2 & 87.2 & 3.4 & 92.0 & 8.0 & 105.5 & 23 \\
\hline $\mathrm{Hg}$ & 279 & 104.6 & 1.1 & 104.3 & 2.0 & 99.2 & $3 \cdot 3$ & 98.6 & 1.9 \\
\hline $\mathrm{Sb}$ & 603 & 97.4 & 1.6 & 93.2 & $2 \cdot 3$ & 97.3 & 2.7 & 105.2 & 1.5 \\
\hline \multirow[t]{2}{*}{$\mathrm{Sc}$} & 889 & 101.1 & 0.7 & 102.9 & 1.0 & 105.6 & 2.2 & 100.6 & 1.0 \\
\hline & 1120 & 102.1 & 0.8 & 100.2 & 1.0 & 101.7 & 2.3 & 99.4 & 1.7 \\
\hline $\mathrm{Se}$ & 264 & 103.9 & 0.9 & 104.2 & 1.1 & 103.6 & 2.6 & 98.4 & 1.5 \\
\hline $\mathrm{Zn}$ & 1115 & 99.1 & 0.9 & 99.0 & 1.2 & 98.8 & 2.7 & 100.2 & 2.0 \\
\hline
\end{tabular}

$\tilde{\varepsilon}_{R}=$ Recovery. 
average recoveries for both matrices in three to five separate experimental observations.

The tracer solutions used in this study were similar in elemental composition to others used throughout this project. Repeated irradiations of biological matrices under time and neutron flux conditions similar to those anticipated for the final DNAA scheme showed that the elements listed in Table 29 were consistently detectable. Arsenic was included in the tracer solution, but during the delay between irradiation and use of the tracers, the count rate of the arsenic isotope decayed below spectral background levels. When some authors indicated difficulties retaining arsenic, they also expressed concern about volatile forms of mercury and selenium (113). The quantitative recoveries of mercury and selenium in this work implied that arsenic was not lost by volatilization. The apparently low recovery of iron following the sealing operation was due to spectral distortions caused by statistical fluctuations in the small number of counts accumulated for the iron isotope. The shape of the photopeak deviated significantly from a gaussian function, resulting in a negative error in the peak fitting routine. Extended counting periods in later experiments mitigated this problem. 


\section{F. Wet Ashing}

In the wet ashing studies; the objectives were to select an ashing medium and develop a procedure for 1ts application to biological samples. Each ashing system was evaluated with respect to: 1) completeness of the matrix destruction, 2) time required for the operation, 3) parameters controlling the loss of trace elemental components, and 4) compatibility of the ashing medium with other operations in the DNAA procedure.

Some restrictions were initially adopted in choosing an ashing medium. Systems requiring ashing temperatures significantly in excess of $100^{\circ} \mathrm{C}$ were avoided due to previously demonstrated losses of trace components at elevated temperatures (113). Ashing media containing halogens or perchloric acid were initially shunned because of studies demonstrating the loss of trace elements due to the formation of volatile halides $(107,113)$. Sulfuric acid was not considered a viable component for an ashing system because of excessive temperatures usually associated with its use and the possibility for loss of trace components via co-precipitation with insoluble sulfates.

The Bethge apparatus as modified by Gorsuch (Figure 3) was used in the initial studies of ashing systems. The advantages of this type of apparatus were: all operations were:performed in a "closed" system and the ashing operation 
could proceed in either a reflux or distillation mode. (The distillation mode was required with systems like the perchloric-nitric acid mixtures in which the nitric acid had to be removed after an initial pre-digestion in order to utilize the superior oxidizing properties of the perchloric acid.)

The difficulty encountered when successive small additions of reagent to the reaction flask were required was the primary disadvantage of the Gorsuch version of the Bethge apparatus. As designed, the air condenser was the intended avenue for the introduction of reagents. However, this required either the removal of the water-cooled condenser or the addition of the reagent through both condensers. Removal of the water condenser violated the concept of a 'closed' system and was also a cumbersome undertaking. On the other hand, the large surface areas of the combined condensers made that path ineffective for the addition of small.amounts of reagent. The modified Gorsuch version shown in Figure 4 was designed to provide: 1) a more effective condenser to trap volatiles leaving the system, and 2) a better means for introducing reagents to the reaction vessel during an ashing operation.

In the discussion which follows, the characteristics of ashing systems which were extensively studied are detalled. The progression through different systems was not haphazard, 
but usually was determined by the results of compatibility tests. Specific incompatibilities will be described in a separate section. Rather than describing only the ashing system selected for inclusion in the finalized DNAA scheme, information concerning the "failures" is reported so that others may avoid futile efforts.

In accordance with the earlier described restrictions, nitric acid was tested as an ashing medium for blood and bovine liver. Although adequate for destruction of the blood matrix, the nitric acid left clear globules of material floating in the digest solution of bovine liver. Extended refluxing periods did not remove this material. Even though the material was not analyzed, it was tentatively identified as lipids from the bovine liver. Authors have indicated difficulties in destroying this component in most biological matrices $(107,127,134)$.

Efforts to find a stronger oxidizer for the ashing opcration centered on perchloric acid. Use of this reagent necessitates several precautions. Gorsuch noted that free chloride found in perchloric acid could lead to the loss of trace elements via the volatilization of chlorides (109). Girardi also noted that the presence of perchloric acid severely reduced the selectivity of hydrated antimony pentaoxide, a material intended for use in a different stage of the DNAA scheme. In an attempt to mitigate these. potential difficulties, the amount of perchloric acid in the 
ashing procedure was minimized. The reported recoveries of radio-tracers from biological samples ashed by the devised nitric-perchloric acid system (Table 30) demonstrate the Immunity of the system to losses of trace components. In. order to obtain sufficient counting statistics within a reasonable time period, the amount of each radionuclide used in the ashing tesst was four times the amount of that nuclide thought to be indigenous to the blological matrix. However, the total concentration of each element in the test was controlled by the addition of stable carriers, and was fixed at the level expected to be used in the analysis of real samples.

Although the nitric-perchloric system was abandoned because of an unexpected incompatibility with the HAP sodium decontamination step, the ashing system possessed a number of good qualities. The ashing operation could be completed within 0.5 hours depending on the source of heat. No difficulties related to the potential explosion hazard which exists on reacting perchloric acid with biological materials were encountered. The resulting ashed solution was usually clear, and varied from colorless to a faint yellow.

Down and Gorsuch had extensively studied various ashing procedures which incorporated sulfuric acid and $50 \%$ hydrogen peroxide (132). They indicated that in many cases this mixture could replace the nitric-perchloric acid mixtures. Their procedures contained three apparent disadvantages: 
Table 30. Recovery of tracer nuclides following a $\mathrm{HNO}_{3} / \mathrm{HClO}_{4}$

\begin{tabular}{|c|c|c|c|}
\hline Element & $\begin{array}{c}\text { Energy } \\
(\mathrm{KeV})\end{array}$ & $\begin{array}{c}\% \\
\text { Recovery }\end{array}$ & $\sigma$ \\
\hline \multirow[t]{3}{*}{ As } & 559 & 97.1 & 0.4 \\
\hline & 657 & 97.9 & 2.7 \\
\hline & 1216 & 100.2 & 6.9 \\
\hline \multirow[t]{2}{*}{ Co } & 1173 & 99.3 & 6.7 \\
\hline & 1332 & 100.1 & 1.6 \\
\hline $\mathrm{Cr}$ & 320 & 98.9 & 11.1 \\
\hline $\mathrm{Fe}$ & 1099 & 106.4 & 3.2 \\
\hline $\mathrm{Hg}$ & 297 & 97.2 & 4.7 \\
\hline $\mathrm{Na}$ & 1368 & 101.9 & 1.0 \\
\hline \multirow[t]{2}{*}{$\mathrm{Sb}$} & $564^{\circ}$ & 96.2 & 2.3 \\
\hline & 693 & 93.1 & 5.2 \\
\hline \multirow[t]{2}{*}{$\mathrm{Sb}$} & 603. & 97.4 & 1.4 \\
\hline & 1693 & 96.8 & 1.9 \\
\hline \multirow[t]{2}{*}{ Sc } & 889 & 96.6 & 3.4 \\
\hline & 1121 & 103.3 & 7.4 \\
\hline $\mathrm{Se}$ & 264 & 97.5 & 1.2 \\
\hline $\mathrm{Zn}$ & 1115. & 103.4 & 8.2 \\
\hline
\end{tabular}


relative to the analysis of biological materials: 1) the procedures required relatively large volumes of sulfuric acid (e. $\underline{\text { g. }}, 20 \mathrm{ml}$ ) and strong heating for preliminary destruction of the matrix;2) the final volume of reagents required for the operation were large (e.g., approximately $40 \mathrm{ml}$ ); and 3 ) the total time for the ashing operation was in excess of 2 hours. Ashine prosedure DG-3 employing sulfuric acid and hydrogen peroxide was designed to eliminate most of the Inadequacies in the method of Gorsuch and Down. Since the matrices for which the ashing system was developed are not as impervious as

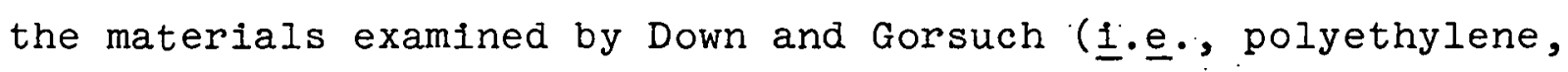
liquid paraffin, etc.), the sulfuric acid was reduced to the minimum amount necessary to wet the sample, and charring was eliminated. To further reduce the volume of the reactants and at the same time improve the oxidizing capacity of the mixture, $90 \%$ hydrogen peroxide was used as the primary oxidant.

Ashing procedure DG-3 gave varlabie results. The effectiveness of the ashing operation was very dependent on the extent of destruction caused to the matrix by the sulfuric ac1d. For optimum destruction, the slurry of sulfuric acid and the matrix had to remain in the oil bath over $1 . .5$ hours. Elevating the temperature of the 011 bath (Procedure DG-3A) improved the overall effectiveness of the system. Table 31 contains the results of tracer recovery experiments executed with ashing scheme $D G-3 A$. 
Table 31. Recovery of tracer nuclides following a $\mathrm{H}_{2} \mathrm{SO}_{4} / \mathrm{H}_{2} \mathrm{O}_{2}$ wet ashing procedure at a temperature between $70^{\circ} \mathrm{C}$ and $9.0^{\circ} \mathrm{C}$

\begin{tabular}{|c|c|c|c|c|}
\hline Nuclide & $\begin{array}{c}\text { Energy } \\
(\mathrm{KeV})\end{array}$ & $\begin{array}{c}\text { Recovery } \\
(\%)\end{array}$ & & $\sigma$ \\
\hline \multirow[t]{3}{*}{ As } & 559 & 98.9 & & 0.2 \\
\hline & 657 & 96.6 & & 4.4 \\
\hline & 1216 & 108.4 & & 3.0 \\
\hline \multirow[t]{2}{*}{ Co } & 1173 & 98.2 & & 2.9 \\
\hline & 1332 & 100.2 & & 2.5 \\
\hline $\mathrm{Cr}$ & 320 & 106.0 & & 3.5 \\
\hline $\mathrm{Cu}$ & 1345 & 98.3 & 1 & 3.6 \\
\hline \multirow[t]{2}{*}{$\mathrm{Fe}$} & 1099 & 114.1 & & 5.5 \\
\hline & 1292 & 102.7 & & 5.7 \\
\hline $\mathrm{Hg}$ & 279 & 97.1 & & 2.9 \\
\hline La & 1596 & 98.7 & & 2.0 \\
\hline $\mathrm{Na}$ & 1368 & 82.0 & & 4.8 \\
\hline \multirow[t]{2}{*}{$\mathrm{Sb}$} & 564 & 100.1 & & 0.3 \\
\hline & 693 & 101.1 & & 4.2 \\
\hline \multirow[t]{2}{*}{$\mathrm{Sb}$} & 603 & 99.6 & & 2.1 \\
\hline & 1292 & 95.6 & & 6.3 \\
\hline \multirow[t]{2}{*}{ Sc } & 889 & 101.6 & & 2.1 \\
\hline & 1120 & 101.1 & & 2.3 \\
\hline $\mathrm{Se}$ & 264 & 89.9 & & 5.2 \\
\hline $\mathrm{Sm}$ & 103 & 84.4 & & 2.0 \\
\hline $\mathrm{Zn}$ & 11.15 & 1.01 .1 & & 3.8 \\
\hline
\end{tabular}


Further improvement of the reaction of sulfuric acid on the matrix was sought by increasing the temperature of the 011 bath to $90^{\circ} \mathrm{C}$. The modified Bethge apparatus was employed to provide a more effective trap for volatiles and a better means for controlling the rate of addition of hydrogen peroxide to the mixture. As indicated in Table 32, the system surressfully sontained the trace elemental components. As an extreme test of the effect of elevated temperatures on the sulfuric acid-matrix interaction, and of the efficiency of the cold trap, ashing scheme $D G-3 C$ (which required heating the sample to fumes of sulfuric acid) was executed. Of the elements listed in Table 32, only selenium was not recovered quantitatively.

$D G-3 B$ represented an effective method for the destruction of the blood and bovine liver matrices, but $1 t$ was not dependable. The viscosity of the sulfuric acid produced the major problem. Even with magnetic stirring, it was difficult to ensure that the entire sample was in contact with the sulfuric acid. Material which had not reacted with the sulfuric acid was not affected during the addition of hydrogen peroxide. The use of secondary or pre-oxidizer in. confunction with sulfuric acid during the initial attack on the matrix was studied. According to the literature, removal of the reducing environment during processing of the sample would also eliminate a situation conducive to the Ioss of selenium and mercury (132). 
Table 32. Recovery of tracers from a $\mathrm{H}_{2} \mathrm{SO}_{4} / \mathrm{H}_{2} \mathrm{O}_{2}$ wet ashing medium and the modified Gorsuch device.

\begin{tabular}{|c|c|c|c|}
\hline Element & $\begin{array}{c}\text { Energy } \\
(\mathrm{KeV})\end{array}$ & $\begin{array}{l}\text { Recovery } \\
(\%)\end{array}$ & $\sigma$ \\
\hline \multirow[t]{3}{*}{ As } & 559 & 96.2 & 1.2 \\
\hline & 657 & 97.7 & 1.8 \\
\hline & 665 & 101.1 & 0.6 \\
\hline \multirow[t]{2}{*}{ Co } & 1173 & 99.8 & 2.0 \\
\hline & 1332 & 99.4 & 0.6 \\
\hline $\mathrm{Cr}$ & 321 & 101.2 & 1.3 \\
\hline $\mathrm{Cu}$ & 1345 & 97.1 & 1.2 \\
\hline $\mathrm{Fe}$ & 1099 & 97.6 & 2.8 \\
\hline $\mathrm{Hg}$ & 279 & 95.4 & 0.8 \\
\hline Mo & 740 & 92.3 & 3.8 \\
\hline \multirow[t]{2}{*}{$\mathrm{Sb}$} & 564 & 97.6 & 2.4 \\
\hline & 693 & 100.8 & 4.2 \\
\hline$S b$ & 603 & 99.8 & 1.0 \\
\hline \multirow[t]{2}{*}{ So } & 889 & 98.7 & 0.8 \\
\hline & 1120 & 96.0 & 0.9 \\
\hline $\mathrm{Se}$ & 264 & 96.2 & 2.5 \\
\hline \multirow[t]{2}{*}{ W } & 606 & 96.8 & 1.5 \\
\hline & 479 & 95.8 & 0.4 \\
\hline $\mathrm{Zn}$ & 1115 & 95.9 & 2.4 \\
\hline & & & \\
\hline
\end{tabular}


Chromic acid (DG-3H), vanadium pentaoxide ( $D G-3 I)$, and nitric acid $(D G-3 J)$ were tested as additives during the treatment of the blological matrix with sulfuric acid. In each case, they were inftially favorable. Liquification of the samples required significantly shorter time periods in the oll bath, and the amount of peroxide needed to complete the matrix destruction was significantly reduced. As Indicated by the clarity of the final solutions, chromic acid and vanadium pentaoxide were more effectlve in destroying the matrices. The inorganic oxidizers notably increased the vigorousness of the reaction of the ashed mixture and the hydrogen peroxide. On the other hand, the ashed mixtures containing the chromium and vanadium species were also sens1tive to excess hydrogen peroxide. With excess peroxide, a reddish-brown precipltate formed with elther oxldizer as the ashed mixtures cooled. The preclpitates were probably peroxychromates and peroxo compounds of vanadium (139, p. 840). The specifics for formation of the precipitates were not developed because incompatibility tests eliminated the procedure. As a side note, recovery tests with tracers did indicate quantitative retention of. all elements in these digestion systems. Inclusion of a small amount of nitric acld with the sulfuric acid was effective in increasing the inftial attack on the matrices. However, it was evident that the nitric acid did not ald the destruction of the matrix during the 
additions of peroxide. Detrimental factors previously attributed to nitric acid were avoided because the acid was converted to oxldes of nitrogen by the hydrogen peroxide. Quantitative recoveries of trace elemental components were also obtained with this system.

\section{G. Decontamination and Separation}

\section{HAP}

Hydrated antimony pentaoxide was selected as the means for removing radio-sodium $\left({ }^{24} \mathrm{Na}\right)$ from solutions of ashed biological materials. As noted in Chapter II, considerable disagreement exists concerning the properties of this material. The disparity was traced in part to the differences in HAP produced by the experimenters and inconsistencies in HAP obtained commercially. In order to avoid this situation, the synthesis and testing of HAP to be used in this project was undertaken.

Nine different products of HAP synthesis procedures and a sample of HAP produced by C. Erba (Milan, Italy) were examined. Table 33 contains a listing of some character-. istics and properties observed for the HAP materials during testing. Full synthesis procedures (1.e., starting with a l-lb bottle of $\mathrm{SbCl}_{5}$ ) yielded approximately $200 . \mathrm{g}$ of produst, hut sieving reduced the amount of usable material to about $100 \mathrm{~g}$. 
In Table 33 "Mechanical Properties" refers to the effectiveness of the material for forming a resin bed for column chromatography. The HAP materials $4 \mathrm{~A}, 4 \mathrm{~B}$, and $5 \mathrm{~B}$ were not extensively tested because on equilibration with an acid eluent, they formed an amorphous mass which blocked eluent flow through the column. HAP IA, although good with respect to sodium removal and nuclide elution, was unstable in extended contact with the principal eluent, 12M HCl. With regard to correlation between observable characteristics and the effectiveness of the material for sodium removal, the best materials had a powdery texture and a yellow color. The deeper the yellow, the more stable the material was in concentrated hydrochloric acid. HAP IB was the only crystalline material that performed satisfactorily in the selectivity and sodium retention tests.

The percent of antimony in each of the samples of HAP was determined by neutron activation analysis using the standard comparator method. Except for HAP 3, the materials are quite similar in this respect. In the original paper concerning the properties of HAP, Girardi and Sabbioni reported an antimony content of $68.3 \pm 0.3 \%$ for their experimental material, which agrees with the value determined In this analysis for the C. Erba material. Since the antimony content of the products 4A, 4B, 5A, and 5B was not determined, correlations could not be drawn concerning the quality of the material and the percent of antimony. 
Table 33. Characteristics of HAP matertals

\begin{tabular}{|c|c|c|c|c|c|c|c|}
\hline Materlal & $\% \mathrm{Sb}$ & $\mathrm{n} \cdot \mathrm{H}_{2} \mathrm{O}$ & $\mathrm{O}+\mathrm{n} \cdot \mathrm{H}_{2}$ & $\% \Delta$. & $\begin{array}{l}\mathrm{Na} \text { Decon } \\
(\%)\end{array}$ & $\begin{array}{l}\text { Mechantcal } \\
\text { Properties }\end{array}$ & Description \\
\hline HAP IA & $67.0 \pm 2.0$ & $2.2 \pm 0.3$ & 15.4 & $13 \cdot 5$ & $99.87-99.94$ & Good & $\begin{array}{l}\text { Powdery, pale yeliow, } \\
\text { unstable in conc. HCl }\end{array}$ \\
\hline HAP IE & $69.8 \pm 1.5$ & $1.4 \pm 0.2$ & 11.9 & 13.5 & -- & Excellent & Crystalline, yellow \\
\hline HAP 2 & $70.4 \pm 0.7$ & $1.2 \pm 2.0$ & 11.3 & 2.5 & $5-7$ & Good & Powọery, grey. \\
\hline HAP 3 & $62.2 \pm 0.6$ & $1.6 \pm 0.2$ & 12.8 & 8.9 & 33.5 & Good & $\begin{array}{l}\text { Crystalline, white } \\
\text { w/yellow }\end{array}$ \\
\hline HAP $4 A$ & --- & --- & --- & --- & --- & Very Poor & $\begin{array}{l}\text { Crystalline, pale } \\
\text { yellow }\end{array}$ \\
\hline HAP $4 \mathrm{E}$ & -- & --- & -- & -- & -- & Poor & $\begin{array}{l}\text { Crystalline, } \\
\text { brilliant yellow }\end{array}$ \\
\hline HAP $5 f$. & --- & -- & -- & --- & 79.98 & Good & Powdery, light yellow \\
\hline HAP $5 \mathrm{E}$ & -- & --- & --- & -- & 22.8 & Good & $\begin{array}{l}\text { Crystalline, white } \\
\text { translucent }\end{array}$ \\
\hline HAP 6 & $68 \cdot 2 \pm 3 \cdot 9$ & $1.7 \pm 0.4$ & 13.0 & 7.8 & 99.998 & Excellent & $\begin{array}{l}\text { Powdery, golden } \\
\text { yeliow }\end{array}$ \\
\hline HAP 7 & $69.5 \pm 0.5$ & $1.5 \pm 0.2$ & 12.2 & $7 \cdot 5$ & $>99.99$ & Excellent & $\begin{array}{l}\text { Powdery, light golden } \\
\text { yellow }\end{array}$ \\
\hline C. Erba & $68.4 \pm 0.7$ & $1.6 \pm 0.2$ & 12.7 & $12.9=$ & -- & Good & $\begin{array}{l}\text { Powdery, yellow } \\
\text { w/orange }\end{array}$ \\
\hline & & & & & & & $\cdots$ \\
\hline
\end{tabular}


Confounding any correlation are HAP 3 which had a significantly lower percentage of antimony and performed poorly in sodium removal, and HAP 2 which had a reasonable percentage of antimony but was absolutely worthless for sodium decontamination. The inclusion of HAP 2 in the comparison may not be valid because there is uncertainty in the molecular formula of this material. While HAP 2 was drying, the temperature accidentally exceeded $500^{\circ} \mathrm{C}$ for at least 4 hours. At this temperature, $\mathrm{Sb}_{2} \mathrm{O}_{5}$ should have been converted to the tetraoxide (192), whlch consists of $79.0 \%$ antimony. With only $70.4 \%$ antimony, HAP 2 could not be $\mathrm{Sb}_{2} \mathrm{O}_{4}$

Using the values for percentage of antimony, and assuming no other major constituents besides water, were present (as confirmed during the analysis for antimony), the percentage of $\mathrm{Sb}_{2} \mathrm{O}_{5}$ and consequently the mole ratio $(n)$ of water molecules to formula welghts of the pentaoxide were determined for some HAP materials. For comparison, Girardi and Sabbioni (153) reported that $n$ equalled 1.5 for their product. Torok and Diehl reported n-values from 1.1 to 2.4 for a series of HAP synthesis procedures (145). Their best product for sodium retention had a mole ratio of 2.4 . Interestingly, this material was not rated among the best with respect to mechanical properties. Also, they produced another product with a similar molar water ratio (1..e., $n=2.4$ ) that performed poorly in the sorption of sodium. 
The extraordinary heating of HAP 2 apparently caused that material to lose more water than the others. Overall, the suitability of a precipitate for the production of chromatographic columns varied inversely with the mole ratio of formula-water to formula-pentaoxide.

As a means to further evaluate the structure of the precipitates, a sample of each HAP material was equilibrated in an oven at $700^{\circ} \mathrm{C}$. The column in Table 33 labeled "O + $\mathrm{nH}_{2} \mathrm{O}$ " lists the percentage change in weight that would be expected of each material if an oxygen atom and all of the bound water was lost from the empirical formula as previously determined. Under the heading "\%", the actual percentage changes which occurred following equilibration at $700^{\circ} \mathrm{C}$ are Iisted. The products HAP IA, HAP IB, and C. Erba lost enough weight to represent removal of an oxygen atom and " $n$ " molecules of water. Weight losses in HAP 3, HAP 6 and HAP 7 only indicated the loss of bound water.

Table 33 also includes sodium decontamination factors which indicate the percentage of sodium the HAP material removed from a reference solution. The precision of the decontamination factors was dictated primarily by the counting statistics. In many cases, the sodium content was reduced below the spectral background and the factor was based on the maximum possible sodium activity which could have been present but not detected (1‥e., twice the square root of the background count rate in the region of the 
expected peak). For HAP 6 and HAP 7 similar decontamination factors were obtained in $12 \mathrm{M} \mathrm{HCl}$ and $15 \mathrm{M} \mathrm{HNO}_{3}$.

Table 34 contains the results of nuclide selectivity or elution tests on several of the synthesis products and the c. Erba material. The elution tests for HAP 6 were performed in both $12 \mathrm{M} \mathrm{HCl}$ and $15 \mathrm{M} \mathrm{HNO}_{3}$, while the other materials were tested in $12 \mathrm{M} \mathrm{HCl}$ or $15 \mathrm{M} \mathrm{HNO}_{3} \cdot \mathrm{HAP} 1 \mathrm{~A}, \mathrm{HAP} 1 \mathrm{~B}$, and the $\mathrm{C}$. Erba material were tested at approximately the same time, and the other products were tested over a year later. Part of the improvement in the later materials was probably due to better manipulation techniques. The most important point in this data is the failure to obtain quantitative recoveries of arsenic and selenium from the materials: This directly contradicts the original claims made concerning the inorganic exchanger (153). These results also cast doubts on those DNAA procedures which claim quantitative retention. of arsenic and selenium on HAP columns. Typically, the recovery of mercury from the HAP materials was not quantitative. However, it was found that the elution of mercury was dependent on the eluent flow rate. In a few specially designed experiments, mercury was quantitatively eluted when flow rates significantly below $1 \mathrm{ml} / \mathrm{min}$ were used. At least $30 \mathrm{ml}$ of eluent were required to ensure quantltatlve elution of moot elements from a $3-5 \mathrm{~cm}$ column of the HAP material. Significantiy, the selectivity of the HAP materlals did not vary appreclably with respect to nuclides other than sodium. 
Table 34. Recovery of nuclides from several HAP materials

\begin{tabular}{|c|c|c|c|c|c|c|c|c|c|c|c|c|}
\hline \multirow[t]{2}{*}{ Element } & \multicolumn{2}{|c|}{ HAP IA } & \multicolumn{2}{|c|}{ HAP IB } & \multicolumn{2}{|c|}{ C. Erba } & \multicolumn{4}{|c|}{ HAP 6} & \multicolumn{2}{|c|}{$\frac{\mathrm{HAP}}{\mathrm{HNO}_{3}}$} \\
\hline & $\% \mathrm{R}^{\mathrm{a}}$ & $\delta$ & $\% \mathrm{R}^{\mathrm{a}}$ & $\delta$ & $\% \mathrm{R}^{\mathrm{a}}$ & $\delta$ & $\% \mathrm{R}^{\mathrm{HC}}$ & $\delta$ & $\% \mathrm{R}^{\mathrm{HN}}$ & 3 & $\begin{array}{l}\text { HNO } \\
\% \mathrm{R}^{\mathrm{a}}\end{array}$ & $\delta$ \\
\hline As & $91.8^{b}$ & 0.3 & 65.3 & 1.5 & $63.3^{c}$ & 1.9 & 0.95 & 0.03 & $\ldots d$ & --- & --- & --- \\
\hline $\mathrm{Ba}$ & 98.2 & 2.0 & --- & -- & --- & --- & -- & -- & --- & --- & --- & --- \\
\hline Co & 98.1 & 0.7 & 72.2 & 1.2 & 95.8 & 4.2 & 100.2 & 0.3 & 100.0 & 1.2 & 98.9. & 0.4 \\
\hline $\mathrm{Cr}$ & 100.5 & 0.7 & 95.5 & --- & 97.1 & 4.1 & 99.1 & 0.4 & 97.4 & 0.8 & 99.2 & 0.6 \\
\hline $\mathrm{Eu}$ & 85.4 & 5.4 & --- & -- & --- & -- & -- & -- & $-\cdots$ & --- & -- & --- \\
\hline $\mathrm{Fe}$ & 98.8 & 1.7 & 94.6 & --- & $86.1^{e}$ & 3.5 & 98.5 & 0.6 & 98.2 & 1.2 & 97.1 & 0.8 \\
\hline $\mathrm{Hg}$ & --- & -- & $73.9^{f}$ & 2.0 & 90.7 & $7 \cdot 3$ & 99.4 & 0.3 & 98.6 & 0.5 & 5.1 & 0.1 \\
\hline La & 98.9 & 0.5 & 100.7 & 1.0 & 100.1 & 2.0 & --- & --- & --- & --- & --- & --- \\
\hline $\mathrm{Lu}$ & 98.9 & 0.5 & 86.6 & --- & 89.1 & 6.1 & $-\cdots$ & --- & --- & -- & --- & -- \\
\hline Mo & --- & -- & --- & -- & --- & --- & 96.5 & 1.2 & --- & --- & --- & -- \\
\hline $\mathrm{Rb}$ & --- & -- & --- & --- & --- & --- & 85.3 & 0.7 & 99.3 & 2.2 & 100.3 & 2.0 \\
\hline $\mathrm{Sb}$ & 99.3 & 0.3 & 99.6 & 1.6 & 93.1 & 1.6 & 98.4 & 0.2 & 2.5 & 0.1 & 0.36 & 0.02 \\
\hline $\mathrm{Sc}$ & $97.7^{g}$ & 0.6 & 98.3 & 1.8 & 99.4 & 2.1 & 99.1 & 0.2 & 5.3 & 0.1 & 98.4 & 0.3 \\
\hline $\mathrm{Se}$ & 89.4 & 0.6 & $70 \cdot 3^{g}$ & --- & $84.4^{\mathrm{f}}$ & --- & 92.0 & 0.2 & 99.2 & $0.4^{\circ}$ & --- & -- \\
\hline $\mathrm{Sm}$ & 100.6 & 0.6 & 100.2 & --- & 97.7 & 7.0 & --- & -- & --- & -- & --- & -- \\
\hline W & --- & --- & --- & --- & --- & $-\cdots$ & 93.0 & 1.1 & 11.8 & 0.1 & 75.8 & 0.2 \\
\hline$Y b$ & 100.8 & 0.4 & 101.6 & 1.0 & 102.9 & 2.6 & -- & --- & --- & -- & --- & --- \\
\hline $\mathrm{Zn}$ & 103.8 & 1.7 & 103.1 & --- & 102.6 & 5.4 & 99.7 & 0.4 & 99.9 & 0.6 & 99.6 & 0.4 \\
\hline
\end{tabular}




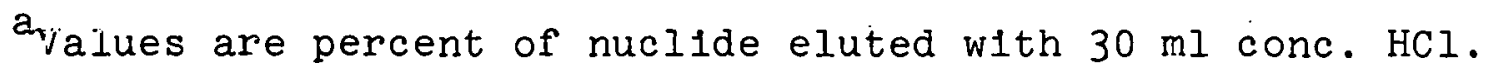

$\mathrm{b}_{\text {J }}$ sing $60 \mathrm{ml}$ eluent, recovery was $93.7 \pm 0.1 \%$.

$c_{\text {Jsing }} 60 \mathrm{ml}$ eluent, recovery was $68.8 \pm 1.8 \%$.

$\mathrm{d}_{\text {Not }}$ determined or not detected.

Using $60 \mathrm{ml}$ eluent, recovery was $103.5 \pm 2.5 \%$.

$f_{\text {Using }} 60 \mathrm{ml}$ eluent, recovery was $97.5 \pm 4.7 \%$.

Using $60 \mathrm{ml}$ eluent, recovery was $90.5 \%$ for HAP $4,79.5 \%$ for HAP 5 , and $95.1 \%$ for HAP 6 . 
On the other hand, the nuclide selectivity of the HAP materials was dependent on the eluent system. With concentrated hydrochloric acid as the eluent, all elements tested except sodium, arsenic, selenium and mercury could be readily eluted from a HAP material. In concentrated nitric acid, additional elements were retained on the column. As the acid concentration of the eluents decreased, so did the selectivity of the HAP materials.

Following the synthesis of HAP 6 and HAP 7 , a study was undertaken to determine the specific sodium capacity of these HAP materials. Figure 6 illustrates the results obtained from elution experiments with HAP 7 in nitric and hydrochloric acids. The maximum capacity was determined by extrapolating from the plateau of the curve to the ordinate $(145,153)$. Values of $5.83,2.12$ and $1.77 \mathrm{mg}-\mathrm{Na} / \mathrm{g}-\mathrm{HAP}$ were determined for HAP 6 and $\mathrm{HAP} 7$ in $\mathrm{HCl}$, and $\mathrm{HAP} 7$ in $\mathrm{HNO}_{3}$, respectively. Girardi and Sabbioni initially reported a sodium capacity of $30 \mathrm{mg}-\mathrm{Na} / \mathrm{g}-\mathrm{HAP}$ (153). Torok and Diehl obtained values in the range $5-11 \mathrm{mg}-\mathrm{Na} / \mathrm{g}-\mathrm{HAP}$.

Several facts were suggested by the synthesis and testing data. The degree of sorption of sodium ions from acid solutions was dependent on the amount of bound water in the HAP. However, the structures of the HAF materials could be different even when the mole ratios of bound water were nearly equivalent. Apparently, the temperature at 
Figure 6. Integral sodium elution curve for HAP materials using hydrochloric and nitric acids 


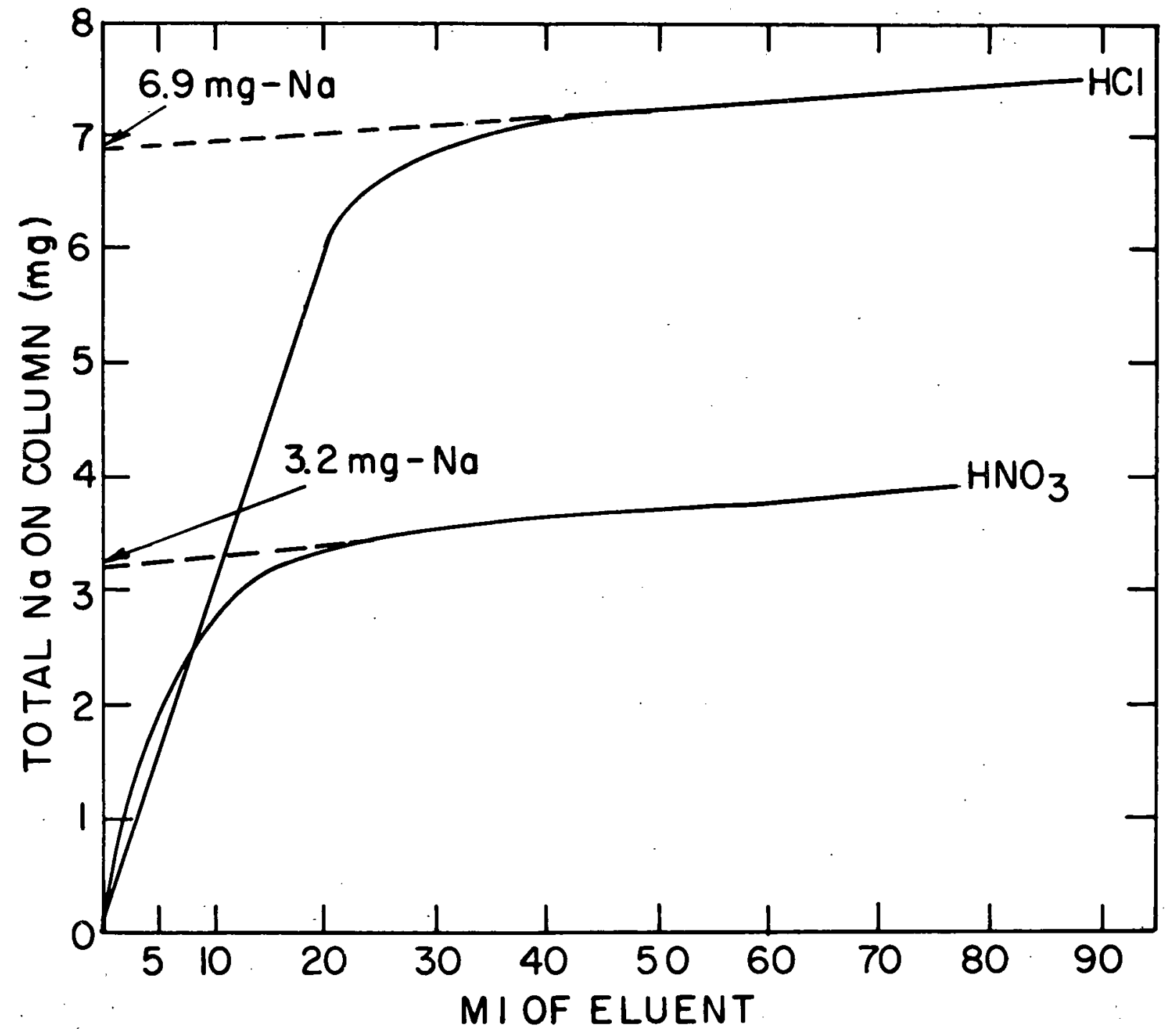


which the amorphous $\mathrm{Sb}_{2} \mathrm{O}_{5}$ was initially dried set the structure of the oxide, while the duration of drying determined the amount of bound water remaining in the compound.

The conditions within the oven were also significant in determining the structure of the oxide. If the excess water was not removed from the precipitate and final drying was attempted in a closed system (e.g., a muffle furnace) the water from the precipitate was held in contact with the precipitate and a white translucent material of no significant value was produced. The differences between the products HAP $I$ and HAP 5B support this point.

As the mole ratio of water in the compounds decreased, the mechanical properties of the precipitates improved and the intensity of the yellow color increased. At the same. time, the capacity of the materials for sodium apparently decreased. These factors suggested that solvation trapping (145) of sodium ions within the structure of the oxide was a significant mechanism for the Irreversible sorption of sodium by HAP.

2. $\underline{A G 2-X 8}$

A disadvantage in using a wet ashing step in a radiochemical procedure is the relatively large volume of the final solutions in which the analyte species are usually. found. Gamma spectroscopy of species dispersed within a large volume is hampered by geometry effects produced by the 
small size of the detector relative to the sample, and by self-absorption and attenuation of gamma rays by the bulk of the sample. Typically, an allquot of a larger sample is used for gamma assay. In the case of biological samples with. inherently low elemental concentrations and correspondingly low radionuclide count rates, it is particularly advantageous to include as much of the total content of the analyte species as possible.

Ion exchange was selected as the method for collecting trace components in a solution of an ashed blological matrix prior to spectroscopic analysis. Ion exchange offered the possibility of selective elution of components from the resin after collection. Selective elution would have allowed the separation of analyte species which were mutually detrimental to their quantification by gamma spectroscopy, either from unresolvable gamma rays (e. $\underline{\text { g. }},{ }^{203} \mathrm{Hg}$ and ${ }^{75} \mathrm{Se}$ ) or significantly overlapping photopeaks (e.g.e, ${ }^{65} \mathrm{Zn}$ and ${ }^{46} \mathrm{Sc}$ ).

The anion exchange resin AG2-X8 was selected for use in this project because of its documented capability for removing selentum and mercury in the form of anionic complexes from acid solutions. Initially, experiments were directed towards sorption of the maximum number of different nuclides onto the resin, followed by the selective stripping of the nuclides from the resins. Tables 35 and 36 contain a summary of results obtained with radio-tracer solutions and 
Table 35. Elution characteristics of AG2-X8 bromide form with various solvents

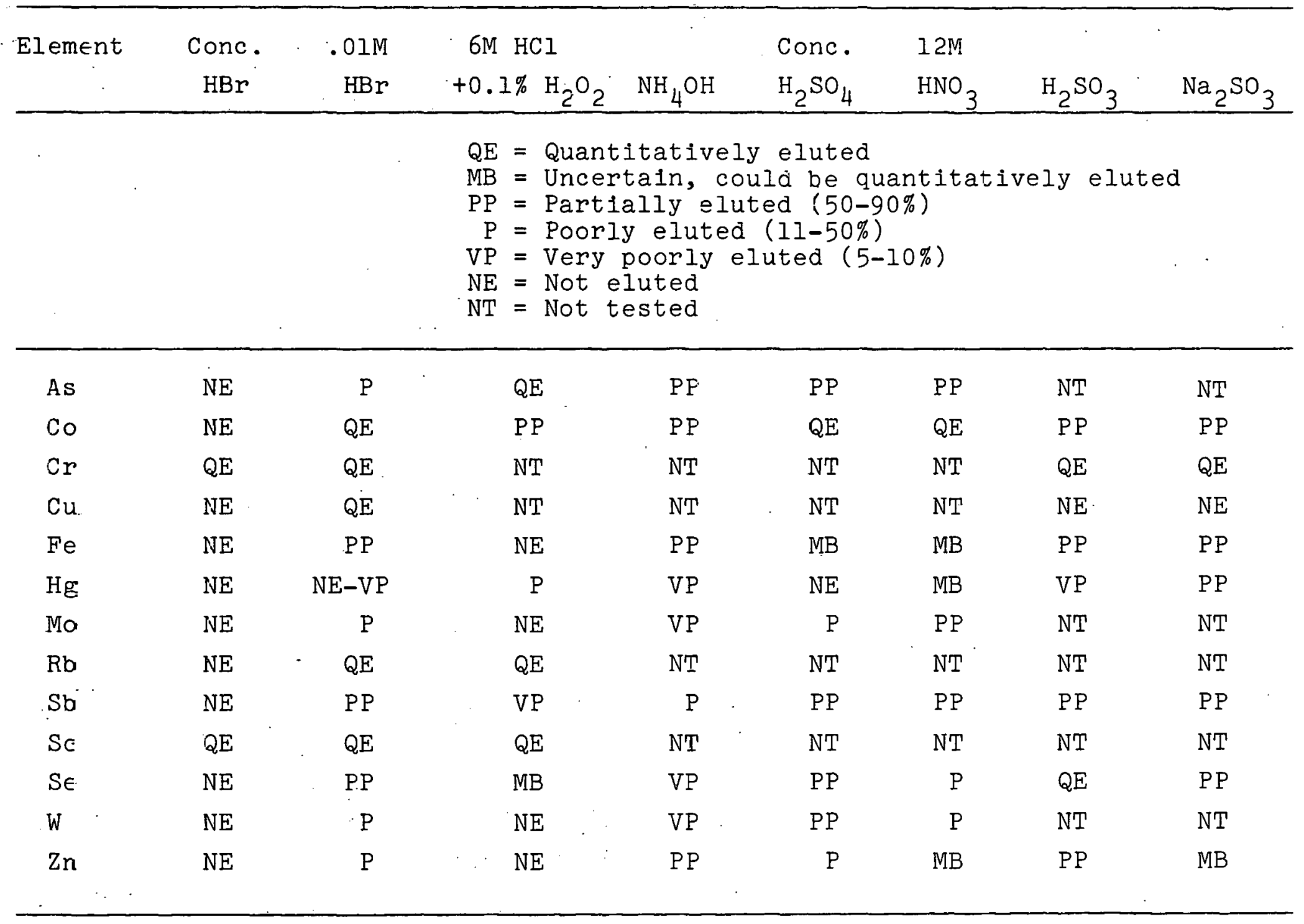


Table 36. Elution characteristics of AG2-X8 chloride form with various solvents

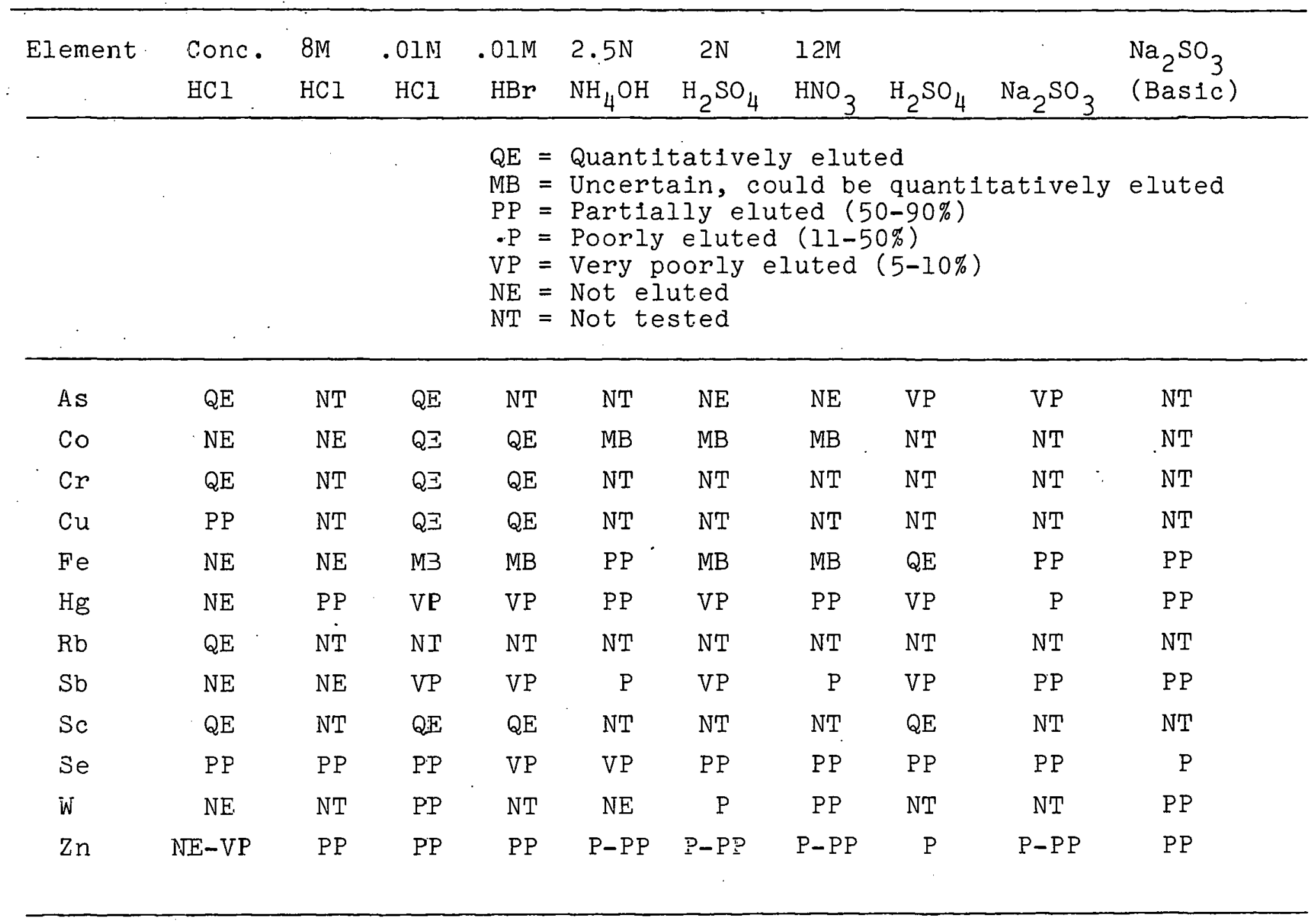


a series of eluents on the bromide and chloride forms of the resin $A G 2-X 8$

The eluent systems were chosen to identify different properties of the resin and the ionic species which affect the selectivity of the resin. Ammonium hydroxide was used to identify the properties of resin in a basic medium. The other eluents were selected to provide a variety of oxidizing and reducing conditions which allowed an assessment of the specificity of the resin to different ionic forms of a nuclide.

of the nuclides tested, only chromium and scandium were not quantitatively collected on the bromide form of the AG2-X8 resin from a 48\% hydrobromic acid solution (Table 36 ). After sorption, elution with up to $80 \mathrm{ml}$ of $48 \% \mathrm{HBr}$ failed to remove any of the ionic species from a $5.0 \mathrm{~cm}$ column of the resin. As the concentration of the acid was decreased, more elements could be quantitatively eluted. No eluent or combination of eluents was found which could strip all the tested nuclides from the resin. Except for the concentrated acid, no eluent was found which could quantitatively remove one group of nuclides and leave another group entirely on the resin. Partial success was obtained for the separation of the nuclides of selenium and mercury. After sorption from solutions of concentrated $\mathrm{HBr}$, selenium was elutable with $.01 \mathrm{M} \mathrm{HBr}$ followed by $10 \mathrm{M} \mathrm{HNO}_{3}$ or $6 \mathrm{M} \mathrm{HCl}$ containing $0.1 \% \mathrm{H}_{2} \mathrm{O}_{2}$ 
to the extent of $88-96 \%$. Usually less than $1 \%$ mercury was also eluted.

Complexes collected on the chloride form of the AG2-X8 resin were not as strongly held as on the bromine form. Concentrated $\mathrm{HCl}$ quantitatively eluted $\mathrm{As}, \mathrm{Cr}, \mathrm{Rb}$ and $\mathrm{Sc}$ with all of the other species in the test remaining entirely on the column. Repeated elutions with 12M HCl eventually lead to the breakthrough of Co from the column. However, Co could not be quantitatively eluted with a reasonable volume (1..e., <100 ml) of the eluent. No eluent combination was found which could quantitatively strip all test nuclides from the resin.

Elution of ashed biological materials through beds of the AG2-X8 resin also produced a decontamination effect for nuclides not of analytical interest. Evidently, the ionic species of sodium, potassium and phosphorus formed anionic species which interacted poorly with the resin, and were eluted with rinses of the concentrated acids. Elution of a sample which was sorbed on the bromide form of the resin with concentrated $\mathrm{HBr}$ removed radio-bromine from the column by an isotopic exchange process. Due to the higher selectivity of the resin for $\mathrm{Br}^{-}$over $\mathrm{Cl}^{-}$, elution of the chloride form of the resin. with concentrated $\mathrm{HCl}$ resulted in the near quantitative retention of bromine nuclides from solutions of ashed biological materials. The ion exchange decontamination factors were not as impressive as those reported for the 
inorganic exchangers (Table 37). The degree of phosphorus removal could not be measured directly.

Table 37. Percent removal of interfering activities from solutions of irradiated standard biological materials

\begin{tabular}{cccc}
\hline & $\mathrm{AG} 2-\mathrm{X} 8(\mathrm{Br})$ & $\mathrm{HAP}_{2} \mathrm{Al}_{2} \mathrm{O}_{3}$ & $\mathrm{HAP} / \mathrm{Al}_{2} \mathrm{O}_{3}$ /Acetate \\
\hline $\mathrm{Br}$ & 90.2 & 10.0 & 62.0 \\
$\mathrm{~K}$ & 95.0 & $\sim 10.0$ & $\sim 10.0$ \\
$\mathrm{Na}$ & 98.0 & $>99.99$ & $>99.99$ \\
\hline
\end{tabular}

The experiments performed with the acetate form of the $A G 2-X 8$ resin were for the expressed purpose of finding a method for removing $\mathrm{Br}^{-}$from solutions of nitric acid. The best decontamination factor achieved with this system was approximately $67 \%$.

\section{Alumina}

of the materials employed for removing phosphorus nuclides from acid sulutions, acid alumina was the most. readily avallable and the least complicated to use. With 
respect to this project, alumina was found to have the distinct disadvantage of being inoperative in hydrochloric acid solutions. The principal concern of the selectivity tests with alumina was to determine behavior of ionic forms of $\mathrm{Cr}, \mathrm{Sc}$ and $\mathrm{Rb}$ in solutions of nitric acid of various concentrations. Elution tests were performed with alumina in $15 \mathrm{M}, 12 \mathrm{M}$ and $10 \mathrm{M}$ nitric acid. Concentrated nitric acid reacted when initially mixed with alumina, producing oxides of nitrogen. Whether or not this reaction was significant in determining the properties of the alumina was not determined. Selectivity experiments showed that the sorption of test nuclides by alumina decreased with decreased concentrations of the acid. However, since the eluent from the alumina column was to be eluted through a column of HAP, it was necessary to keep the acid concentration as high as possible to prevent the sorption of specific nuclides by the $\mathrm{HAP}$. Recoveries of $\mathrm{Co}, \mathrm{Cr}, \mathrm{Fe}, \mathrm{Rb}$, and $\mathrm{Sc}$ from solutions which were 10M in nitric ac1d exceeded $97 \%$ for elutions through $2.0 \mathrm{~cm}$ columns of alumina.

The extent of phosphorus decontamination was measured semi-quantitatively by calculating the level of the background in the low energy region (1 1 .. ., $100-200 \mathrm{keV}$ ) of a high resolution gamma ray spectrum. Using irradiated blologleal materials, the background in the region of $320 \mathrm{keV}$ (energy of the ${ }^{51} \mathrm{Cr}$ gamma ray) was reduced by approximately a 
factor of 10. The primary detriment to larger decontamination

- factors was an apparently low specific capacity of alumina for the phosphorus nuclides and a slight but significant Inverse correlation between recoveries of chromium and the amount of alumina in the column. The capacity of alumina for phosphorus was estimated to be considerably less than.

$1 \mathrm{mg}-\mathrm{P} / \mathrm{g}-\mathrm{glumina}$. Since the primary reason for investigating the removal of phosphorus was to obtain better data on the partially obscured chromium peak, the extensive use of alumina for removing phosphorus was self-defeating. A column bed of $2.0 \mathrm{~cm}$ was a compromise which obtained a reduction in the background and still malntained nearly quantitative recoveries of chromium.

\section{H. Compatibility Tests}

As shown in the Literature Review, a variety of methods were usually available to accomplish the chemical processing typically required in a DNAA procedure: destruction of the organic matrix, removal of Interfering radionuclides, and concentration and separation of the analyte species. The most stringerit criteria limiting the inclusion of a particular operation in a DNAA procedure was the effect of the parameters of that operation on other stages of the procedure. For example, a digestion medium which allowed quantitative recoveries of all trace constituents but 
dissolved the material used in the sodium decontamination step was of little use.

The presence of excessive sodium radioactivity during gamma spectroscopy is the predominant detriment to the analysis of blological materials. Therefore, development of a successful sodium decontamination step was considered to be the most cruclal phase in formulating a feasible DNAA procedure. The conditions required to exploit the optimum performance characteristics of the HAP material were initially considered an invariable part of the proposed procedure. All operations in the tentative DNAA procedures were originally designed to allow execution of the sodium decontamination operation on a HAP column in a medium of concentrated hydrochloric acid. As combinations of operations were examined, it became apparent that numerous incompatibilities existed between the first-choice methods for the ashing, sodium decontamination, and concentration phases in the procedure. The nature of the incompatibilities caused compromises which resulted in a DNAA procedure based on operations executed under less than optimum conditions.

\section{HAP columns}

HAP exhibited maximum absorption of radio-sodium from solutions which were I2M in hydrochloric acid. The earliest wot ashing sohemes involving nitrie acid or nitric and perchloric aclds were unacceptable because of an 
oxidation-reduction reaction which occurred when the digest was diluted to volume with concentrated hydrochloric acid. This problem was foreseen in designing the operations, but was thought to be avoidable by limiting the amount of nitric acid in the digestion vessel. Tests eventually showed that the problem persisted even when the concentration of nitric acid in the aliquot of sample transferred to the column was as low as 0.2 molar. Further reduction of the amount of nitric acid added to the digestion flask resulted in an insufficient amount of medium to ensure complete ashing of the sample.

Individually, neither concentrated nitric nor hydrochloric acids detrimentally affected the HAP column. In combination, the acids caused extensive dissolution of the columns, resulting in less sodium removal. The dissolution was apparently associated with the redox reaction which was initiated when hydrochloric acid was added to the digest mixtures. Although the ratio of components was not correct, the color of the mixed acid solution and the apparent. evolution of nitrogen oxides indicated a reaction similar to the formation of nitrohydrochioric acid. The generation of gas bubbles in the digest solutions reduced the accuracy of pipetting and caused disruption of the HAP columns. Volatilization of mercury halides during this processing could have accounted for the particularly low recoveries of mercury in the early HAP tests. A mechanism for the possible 
loss of mercury in the zero valence state from this medium has also been described ( 90$)$.

Switching to an ashing medium of sulfuric acid and hydrogen peroxide did not provide an immediately compatible digestion system. Hydrogen peroxide increased the solubility of the HAP material in concentrated hydrochloric acid and also prevented the quantitative recovery of some trace components (Table 38 ).

A number of methods were employed to destroy the peroxide before processing the samples through the decontamination and concentration steps. Bolling, a commonly cited means for decomposing hydrogen peroxide (139), was tested and abandoned for the following reasons: 1) in order to ensure destruction of the peroxide, excessively long periods of bolling ( 45 - 60 minutes) were necessary. 2) Extended boiling of the mixtures was undesirable because the condenser system was less than $100 \%$ efficient under harsh conditions. Catalytic agents were examined for the destruction of hydrogen peroxide. Solld manganese dioxide (Digestion DG-3E) and a saturated solution of iron(II) sulfate (Digestion $D G-3 F$ ) were evaluated as decomposition agents. Both materlals effect1vely destroyed the peroxide without interfering with the quantitative recovery of trace components. The iron solution was by far the more convenient to use. The actual destruction of the peroxides was achieved through a stoichiometric rather than a catalytic mechanism. Early 
experiences w1th the system demonstrated that minimal amounts of the reagents could have accomplished the destruction if sufficlent time was allowed. Rather than walt, an excessive amount (relative to catalytic quantities) was added with a resultant reduction in the processing time. Typlcally, either 10 to $30 \mathrm{mg}$ of manganese dioxide or $3 \mathrm{ml}$ of the iron solution was sufficient to ensure destruction of the peroxide within a 5 minute period.

The addition of 2 to $3 \mathrm{ml}$ of carriers "A" and "B" (Table 23) to the digest after the treatment with peroxide also eliminated the problems assoclated with residual hydrogen peroxide. Using the carrier solutions for the destruction of peroxide avolded the situation in which one analyte component was present at a radically higher concentration than the others. This situation was significant during the anion exchange operations. Apparently, differences in selectivity coupled with the high concentration of one component caused the elution of trace components which had previously been retalned quantitatively. Color changes during the addition of the carrier and an elution phenomena discussed in the following section indicated that chromium In a lower oxidation state was involved in the mechanism governing the decomposition of the peroxide. Obviously, any other easily oxidized species could have been involved. 
Table 38. Ashing and HAP recoveries from a medium containing $\mathrm{H}_{2} \mathrm{O}_{2}$

\begin{tabular}{lrccc}
\hline Nuclide & \multicolumn{2}{c}{ Ashing } & Recoveries & \multicolumn{2}{c}{ HAP Recoveries } \\
& $\%$ & $\sigma$ & $\ldots$ & $\%$ \\
\hline As & 97.8 & 4.4 & 48.3 & 0.5 \\
$\mathrm{Co}$ & 99.2 & 3.8 & 93.3 & 5.9 \\
$\mathrm{Cr}$ & 106.0 & 3.5 & 94.6 & 3.7 \\
$\mathrm{Cu}$ & 98.3 & 3.6 & 83.8 & 3.3 \\
$\mathrm{Eu}$ & 91.0 & 1.2 & 39.1 & 1.4 \\
$\mathrm{Fe}$ & 102.7 & 5.7 & 62.6 & 6.8 \\
$\mathrm{Hg}$ & 97.1 & 2.9 & $\mathrm{ND}$ & $\mathrm{ND}$ \\
$\mathrm{La}$ & 96.1 & 3.4 & 25.8 & 1.5 \\
$\mathrm{Sb}$ & 100.3 & 2.1 & 89.8 & 1.6 \\
$\mathrm{Sc}$ & 101.1 & 2.3 & 27.4 & 2.9 \\
$\mathrm{Se}$ & 89.9 & 5.2 & $\mathrm{ND}$ & $\mathrm{ND}$ \\
$\mathrm{Yb}$ & 95.9 & 3.6 & 93.4 & 5.4 \\
\hline
\end{tabular}


2. AG2-X8 bromide form

Procedural incompatibilities affecting the anion exchange operations occurred only with the bromide form of the AG2-X8 resin. Reagents which promoted the oxidation of bromide to bromine were the central factor in all disorders. Specific problems were encountered with nitric ac1d, hydrogen peroxide, and chromium. Residual hydrogen peroxide and nitric acid caused the release of bromine gas from the AG2-X8 resin in the bromide form. In addition to disrupting the columns, the gaseous emissions probably resulted in the loss of trace components in the form of volatile bromides. If the concentration of peroxide on the column was reduced to approximately $0.1 \%$, the formation of bromine subsided. The difficulties associated with hydrogen peroxide and nitric acid were countered with the methods described in the previous section.

In the presence of an ashed organlc matrix, chromium reacted with the $A G 2-X 8$ resin, resulting in the release of bromine. Initial elution tests demonstrated that the oxidation-causing agent could be eluted with concentrated hydrobromic ac1d. Further tests with the species eluted with concentrated hydrobromic acid ( $\mathrm{Rb}, \mathrm{Sc}$ and $\mathrm{Cr}$ ) Indicated that chromium was the source of difficulty and suggested the oxidation of Ionic species of chromium by hydrogen peroxide in the digestion step as the contributing factor. After testing a number of reagents, hydroxylamine hydrochloride was 
selected as the best reducing agent for converting species of chromium to lower oxidation states. Hydroxylamine hydrochloride was selected because of 1 ts ease of use, mildness of reaction with the digestion mixture, and freedom from severe complications.

As expected, hydroxylamine hydrochlorlde could not be added directly to the total volume of the digestion mixture. If this were done, the digestion mixture would react on the HAP columns when eluted with nitric acid. The reducing agent was added directly to the column of the anion exchanger with an aliquot of the ashed sample. Complete suppression of the chromium reaction was accomplished with approximately. $2 \mathrm{ml}$ of a $12 \%$ hydroxylamine hydrochloride solution. Excess reducing agent caused the precipitation of a reddish-brown material which contained a significant amount of ${ }^{75} \mathrm{Se}$. The precipitation of selenium and possibly mercury and copper could have occurred in a strongly reducing environment. However, the presence of radionuclides of copper and mercury was not positively detected. Further testing showed that if the amount of the reducing agent was controlled, the behavior of trace elemental components on the resin bed was not detr1mentally altered.

- I. Analyses of Blological Materials

The results of analyses of samples of Unlted Kingdom Master M1x Blood and NBS Bovine L1ver (SRM 15.77) are 
presented in Tables 39 and 40. By design, the AG2-X8 resin in the bromide form was intended to allow the determination of $\mathrm{As}, \mathrm{Au}, \mathrm{Co}, \mathrm{Cu}, \mathrm{Fe}, \mathrm{Hg}, \mathrm{Mo}, \mathrm{Sb}, \mathrm{Se}$ and $\mathrm{Zn}$. According to earlier testing, these elements should have been quantitatively retalned on the resin with a concurrent separation of sodium, potassium, bromine and phosphorus species during elution with concentrated hydrobromic acid. Figures 7 through 10 illustrate the advantages achleved with gamma spectroscopy. Approximately 90 - $96 \%$ of the sodium, $96 \%$ of the potassium, and $90 \%$ of the bromine present in the blood and liver samples were removed by this treatment.

The column of HAP, alumina, and AG2-X8 with nitric acid elutions was designed specifically for determining those elements which were not retained on the AG2-X8 resin in the bromide form ( $\mathrm{Sc}, \mathrm{Rb}$ and $\mathrm{Cr}$ ). Unlike the anion exchange operation, the components of interest were to be eluted from the columns. Therefore, the decontamination column was formulated to retain the interfering species $(\mathrm{Na}, \mathrm{K}, \mathrm{Br}$ and P). Approximately $99.99 \%$ of the sodium, $80-90 \%$ of the potassium, and 60-65\% of the bromine present in the blood and liver samples were retalned by this treatment.

The actual reduction of the phosphorus in both materials could not be determined. All gamma rays in a multi-component sample contribute to the Compton background in the energy range where the phosphorous activities are prominent. Since the decontamination steps remove other components in addition 


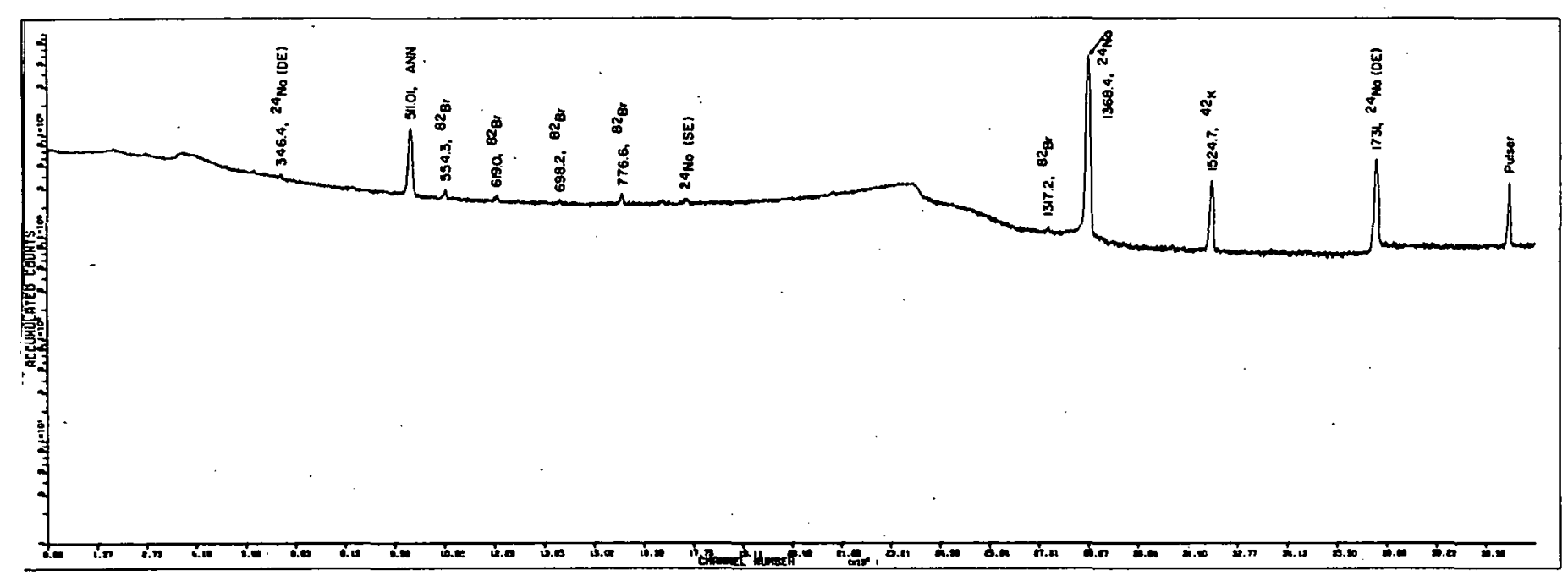

Figure 7. Spectrum of digested bovine liver sample without decontamination. processing: . sample decay time $=2.84$ days; sample counting time $=0.50$ hour $(\mathrm{s})$ 


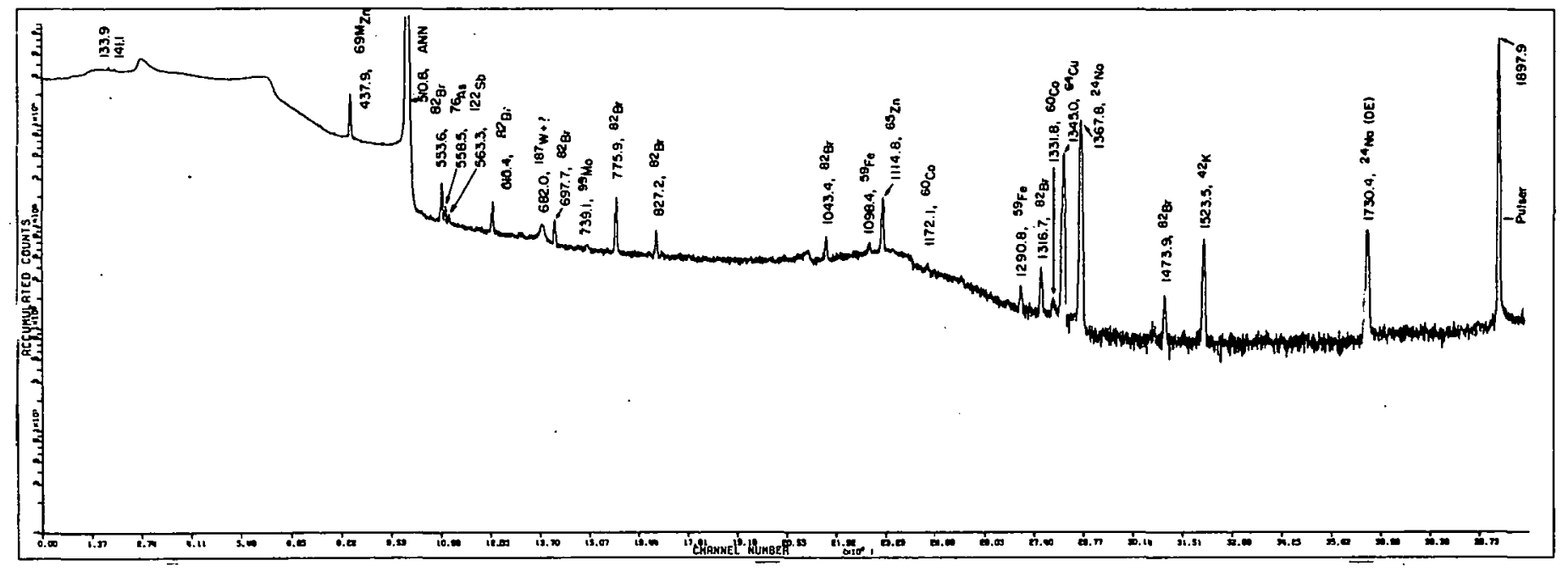

Figlire 8. Spectrum of digested bovine liver decontaminated by elution through $A G 2-X 8$, in the bromide form, with concentrated hydrobromic acid eluent: sample decay time $=1.49$ days; sample counting time $=1.85$ hours 


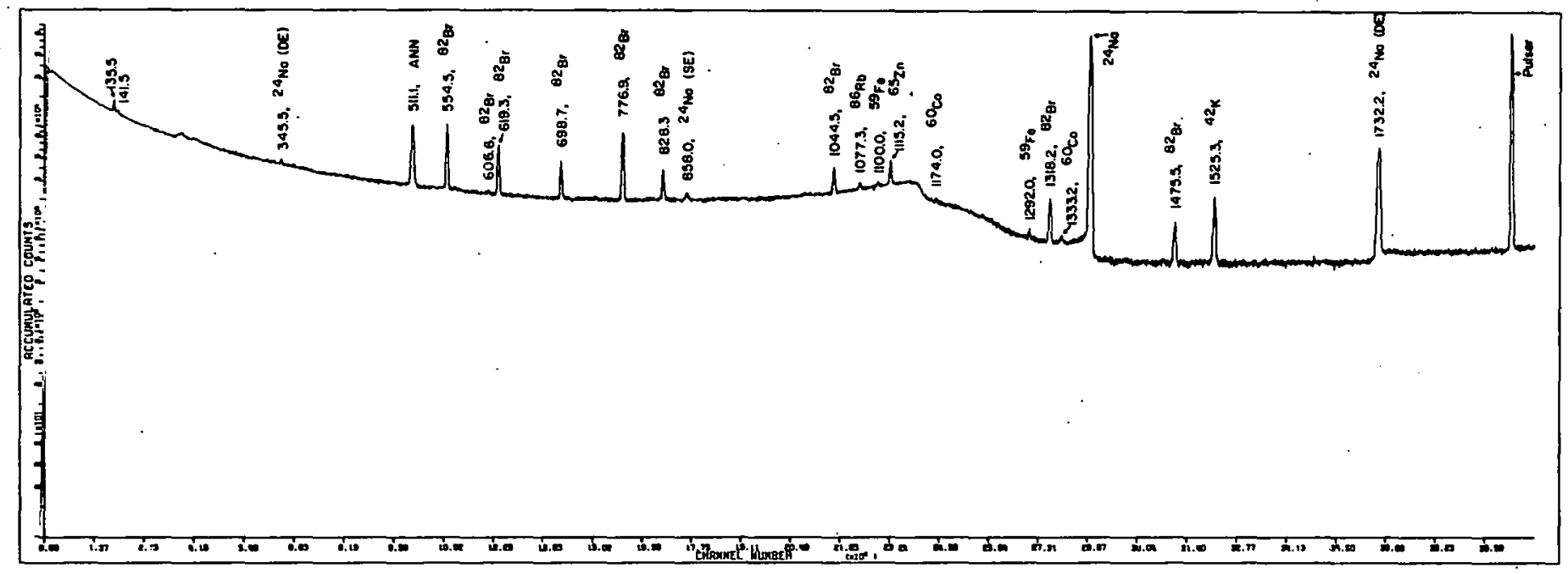

Figure: 9. Spectrum of digested bovine liver sample without decontamination processing: sample decay time $=5.91$ days; sample counting time $=2.00$ hours 


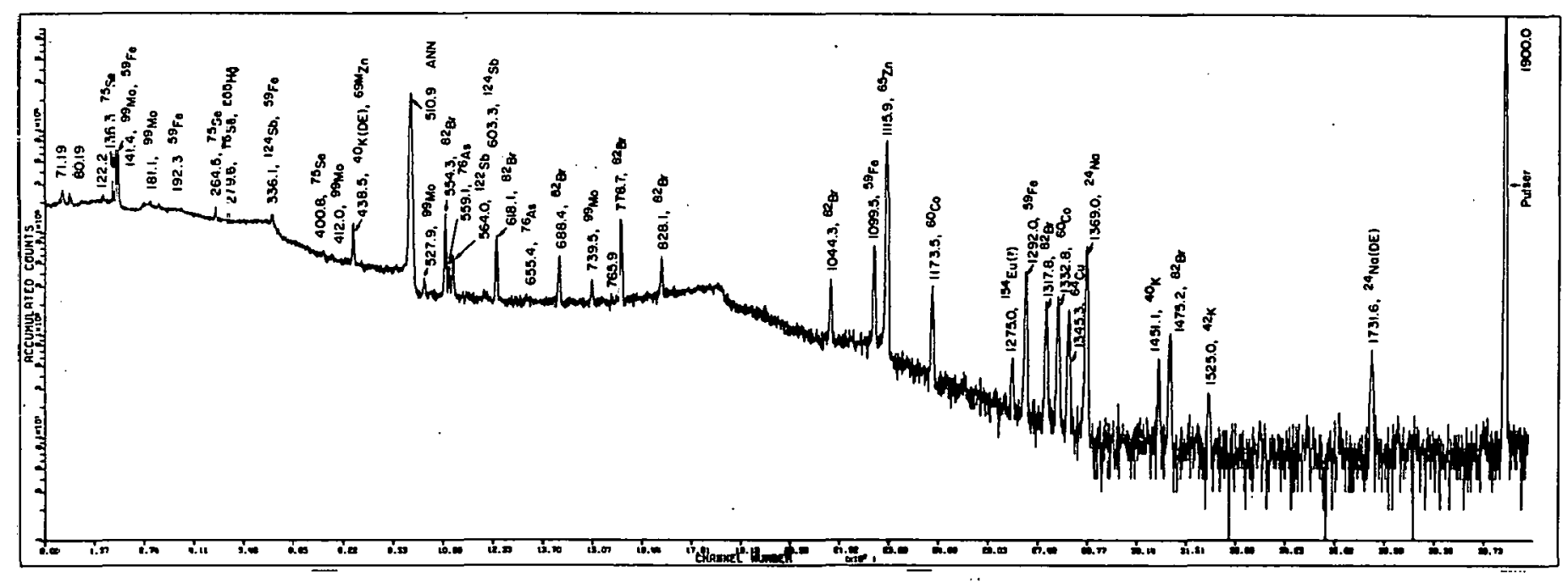

Figure 10. Spectrum of digested bovine liver decontaminated by elution through $A G 2-\mathrm{X} 8$; in the bromine form, with concentrated hydrobromic acid eluent: sample decay time $=5.30$ days; sample counting time $=3.06$ hours 
to phosphorus species, the reduction in the background level which was due specifically to the removal of phosphorus could not be isolated.

Tables 39 and 40 contain the results of analyses of blood and liver samples by DNAA, INAA and Inductively coupled plasma emission spectroscopy (ICPES). The DNAA values and standard deviations were based on 3 to 6 determinations of the element using the procedure developed over the course of this work. The INAA values were determined along with the DNAA analyses by using aliquots of the digested blood and liver samples which were not processed further. Decay intervals ranging from 12 to 28 days were needed in order to obtain the listed data.

The ICPES data was obtained on a routine basis by personnel in the EmIssion Spectroscopy section of Analytical Services Group II of the Ames Laboratory at Iowa State University. The results are based on two determinations with one gram samples of the blood and one determination with a one gram sample of the bovine liver. The samples were digested by slowly heating each material in a vessel containing a 5:2 ratio of nitric-to-perchloric acid. Digestion was assumed complete when perchloric acid fumes were observed. The samples were filtered through millipore filters into $25-\mathrm{ml}$ volumetrics. The sample solutions, blanks and standards were $8 \%$ perchloric acid by volume when 
Table 39. Summary of analyses of United Kingdom Master Mix B.1.o.od

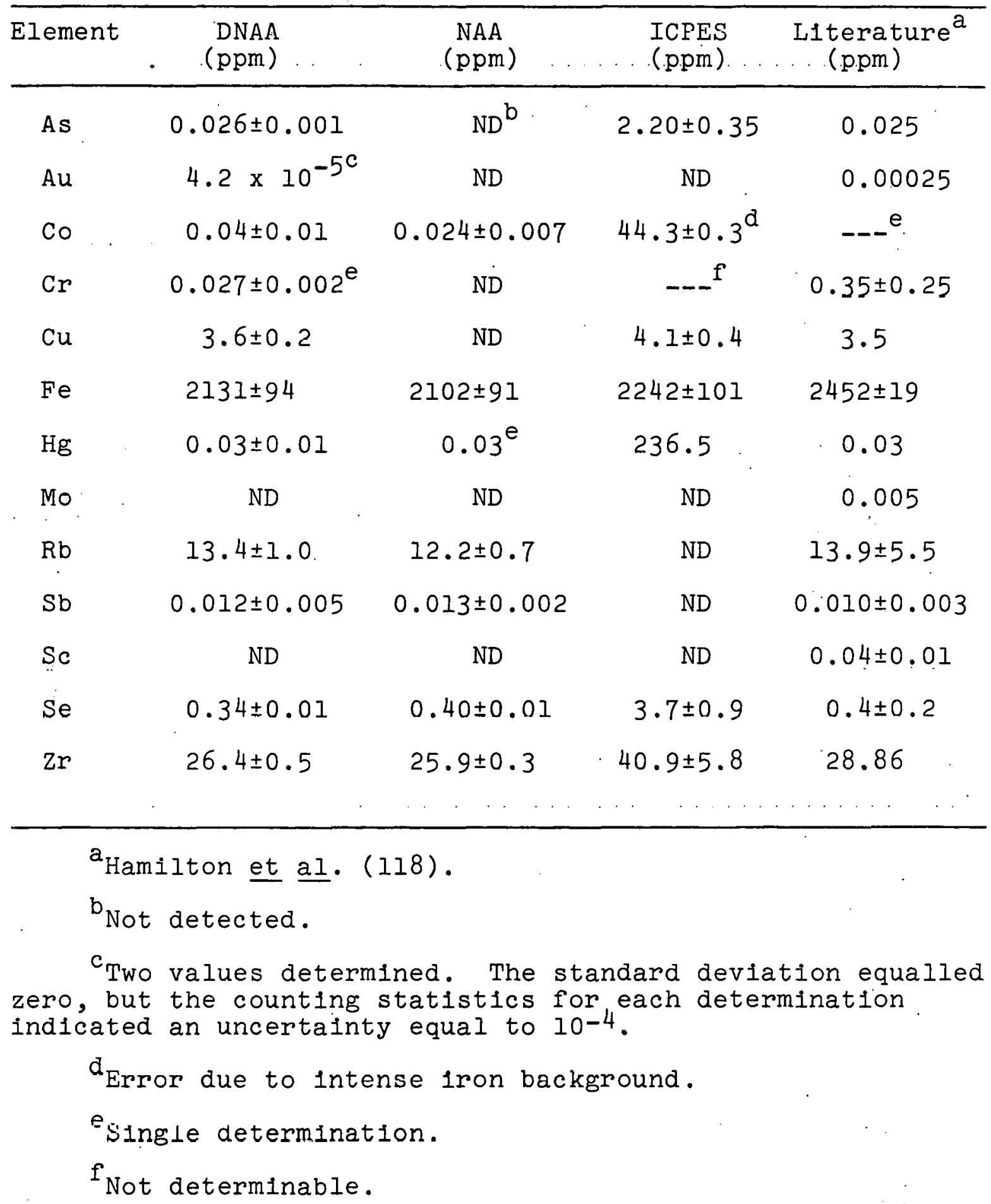


Table 40. Summary of analyses of NBS. Bovine Liver SRM 1577

\begin{tabular}{|c|c|c|c|c|}
\hline Element & $\begin{array}{l}\text { DNAA } \\
(\mathrm{ppm})\end{array}$ & $\begin{array}{l}\text { NAA } \\
(\mathrm{ppm})\end{array}$ & $\begin{array}{l}\text { ICPES } \\
(\mathrm{ppm})\end{array}$ & $\underset{(\mathrm{ppm})}{\text { Literature }^{a}}$ \\
\hline As & $0.045 \pm 0.005$ & ND & ND & 0.055 \\
\hline $\mathrm{Au}$ & ND & ND & ND & --- \\
\hline Co & $0.26 \pm 0.01$ & $0.29 \pm 0.02$ & ND & 0.018 \\
\hline $\mathrm{Cr}$ & ND & ND & ND & $90 \pm 15^{b}$ \\
\hline $\mathrm{Cu}$ & $200 \pm 18$ & ND & 219 & $193 \pm 10$ \\
\hline $\mathrm{Fe}$ & $260 \pm 20$ & $275 \pm 28$ & 232 & $270 \pm 20$ \\
\hline $\mathrm{Hg}$ & $0.013 \pm 0.001$ & ND & 24 & $0.016 \pm 0.002$ \\
\hline Mo & $3.2 \pm 0.2$ & ND & ND & 3.2 \\
\hline $\mathrm{Rb}$ & $19 \pm 2$ & $19.4 \pm 0.02$ & ND & $18.3 \pm 1.0$ \\
\hline $\mathrm{Sb}$ & $2.2 \times 10 \pm 8 \times 10^{-4}$ & $2.7 \times 10^{-3} \pm 4 \times 10^{-4}$ & ND & $-\cdots$ \\
\hline Sc & ND & ND & ND & -- \\
\hline $\mathrm{Se}$ & $0.98 \pm 0.02$ & $0.81 \pm 0.12$ & $2 \cdot 3$ & $1.1 \pm 0.1$ \\
\hline $\mathrm{Zn}$ & $131 \pm 3$ & $128.5 \pm 0.2$ & 115 & $130 \pm 10$ \\
\hline & & & $\ldots$ & . \\
\hline
\end{tabular}


diluted. Values determined by ICPES were reported only for those elements for which DNAA results were avallable.

The literature values for the elemental concentrations found in the United Kingdom Master Mix Blood were provided in an article by Hamilton et al. (118) in which the details of producing the material were described. The concentrations were converted from a "wet" basis to a "dry" basis using values provided by the authors for the average percentage of water in the samples. Information concerning the NBS Bovine Liver was obtained from the NBS circular describing SRM 1577 (93).

DNAA provided data on more elements than INAA or ICPES for the elements of interest. On the other hand ICPES provided information on $\mathrm{Cd}$ and $\mathrm{Pb}$, two biologically significant elements for which neutron activation techniques have limited sensitivity. Based on the literature values, DNAA provided the most accurate information. The ICPES determinations were hampered by significant interference from the iron. However, according to information provided with the analysis results, only the values for $\mathrm{Hg}$ and $\mathrm{Co}$ were affected. The agreement between the DNAA and INAA results is quite good, confirming the validity of the DNAA procedure after the digestion step. Significantly, the DNAA values were determined within 1 to 5 days after the irradiation while the INAA values could not be obtained without decay periods ranging from 12 to 28 days. 
Based on the analysis of CFQ T2l Quartz, high values were expected for gold and antimony determinations. In the bovine liver, the only matrix for which a value for antimony was 1isted, the antimony value by DNAA is within standard error of the Iisted literature value. However, the value determined for gold in the blood samples was noticeably high. Two independent measurements yielded the same value for the gold concentration: $4.2 \times 10^{-5} \mathrm{ppm}$. Based on counting statistics, the standard error in these values was of the order of $10^{-4}$. An extremely low count rate for the $411 \mathrm{keV}$ peak in the samples led to the large uncertainty in the peak areas

There appear to be two different factors causing the high values for cobalt in the liver matrix and the disagreement of the DNAA and INAA values for cobalt in the blood samples. In both cases, the anomalous values were in part related to the fitting routines of the computer program and the shape of the gamma spectra. The Compton shoulder from the $1332 \mathrm{keV}$ cobalt gamma ray distorted the background on the low energy side of the photo-peak. Plots of the gamma spectra Indicated that the apparent background on the low energy side ranged from 10 to 100 times higher than the background on the high energy side. The $1173 \mathrm{keV}$ cobalt peak was positioned on the Compton shoulder from the $13332 \mathrm{keV}$ and generated 1ts own Compton shoulder. This peak was also distorted by the proximity of nonanalytical peaks. As the 
blood samples decayed, the values determined for cobalt decreased significantly, indicating that as the background leveled out and interfering activities decayed, the accuracy of the computer fitting routines improved. Compounding the situation, the low concentration of cobalt in the blood samples led to low count rates with an increased statistical fluctidation in the counting data. The combination of distorted spectra and poor counting statistics resulted in values for cobalt ranging from 0.15 to $0.03 \mathrm{ppm}$.

The cobalt values reported for the liver samples were based on the average of all determinations. The consistently high values indicated that a common source of error affected each determination. Three possible sources of error were considered: a high radio-cobalt background in the detector system, an error in calculating the concentration of the standard, and contamination of the liver sample. The contribution of background levels of ${ }^{60} \mathrm{Co}$ at 1173 and 1332 $\mathrm{keV}$ was determined to be negligible. The concentration of the standard solution was measured by neutron activation and was found to be accurate. No explanation was developed to account for possible contamination of the liver samples by cobalt.

The HAP, Alumina, and AG2-X8 (Acetate) columns did not achieve the desired goal with respect to chromium. A value for chromium was provided in the literature for both the blood and liver, but the chromium photopeak was detected in 
gamma spectra of only one sample. The high background in the region of $320 \mathrm{keV}$ could have obscured the chromium photopeak. However, the absence of a chromium photopeak in the INAA samples after a 12 to 28 day decay period suggested that the chromium peak was not present and that the single determination was based on a statistical fluctuation and not a "reap". photiopeak.

Analysis of individual count data indicated that decay periods of less than 2 days prior to gamma spectroscopy produced highly variable results for components present at particularly low concentrations. Even after chemical. processing removed interfering specles, the Compton background generated by the analyte species still presented difficulties with respect to computer analysis of the spectra. Since this problem was more evident with the AG2-X8 bromide column, it was probably accentuated by the lower decontamination efficiency of the process for concentrating the analyte species. Perhaps a high degree of sodium removal would allow valid determination after shorter decay periods.

\section{J. Conclusions}

There were two significant provisions shaping the development of the DNAA procedure in this project: I) the procedure had to be applicable to blological samples, and 2) the procedure had to be developed with possibility for inclusion in routine analyses. To a large extent these 
objectives were achleved. The simplified DNAA system developed during the course of this work was shown to be applicable to the determination of some components in biological materials ( $\mathrm{As}, \mathrm{Cu}, \mathrm{Fe}, \mathrm{Hg}, \mathrm{Mo}, \mathrm{Rb}, \mathrm{Sb}$, Se and $\mathrm{Zn}$ ) without yield determinations. Decay periods of 2 to 4 days coupled with 15 hour frradiations and computer analyses of the results could allow a turn-around time of approximately 4 or 5 days in processing a diagnostic sample. In the case of chronic disorders as listed in Table 3 , the delay would be neither unusual nor untenable.

The suitability of this DNAA procedure for routine analyses was not verified. In addition to the physical requirements for neutron activation, the procedure required the constant supervision of one knowledgeable in the chemistry involved and in the handling of highly radioactive materials. Unless a laboratory is speclally designed to cope with the particular problems of neutron activation analysis, the procedure would most likely not be used.

Automation could be the key to providing a DNAA procedure favorable to routine analyses. Automating the digestion step would remove the need for much of the supervision and reduce the exposure of the operator to radiation. Although automation of the sulfuric acid - hydrogen peroxide ashing step of the present DNAA procedure is not immediately feastble, the concentration and separation steps would be particularly susceptible to automation if the analysis could 
be limited to only one eluent. Eliminating the combination column (HAP, Alumina, and AG2-X8 Acetate) would result in a one eluent process with the subsequent loss of only data on rubidium. Thus, this work provides a framework on which an automated procedure for the analysis of blological samples on a routine basis can be developed.

\section{K. Future Work}

The anion exchanger AG2-X8 in the bromlde form was effective for concentrating the analyte species but was not optimum for sodium decontamination. An effort should be made to develop a concentration process which would be effective in hydrochloric acid. This would enable the use of the superior sodium removal properties of HAP.

It was suggested that the factor determining the minimum decay period before gamma spectroscopy may have been the Compton background produced by the analyte species. Investigations using the DNAA procedure and a Compton suppression spectrometer could determine whether or not this is correct.

More elements ( $\underline{e} . \underline{g} ., C r$ ) could be determined if the background below $400 \mathrm{keV}$ due to phosphorus activities could be lowered. The inorganic exchanger zirconium phosphate has been used for this purpose $(1.65,167)$ and should be further investigated. 
Numerous possibilities exist for automating the present DNAA procedure for developing a procedure more favorable towards automation. Development of a more comprehensive single eluent system would be most advantageous, but most likely unfeasible. Attention should be given towards development of methods for accomplishing drastic changes in the nature of the eluent in an automated system. 


\section{BIBLIOGRAPHY}

1. H. A. Schroeder and A. P. Nason, Clin. Chem. 17, 461 (1971).

2. J. J. Dulka and T. H. R1sby, Anal. Chem. 48, 640A (1976).

3. H. J. M. Bowen, Trace Elements in Blochemistry (Academic Press, New York, 1966).

4. W. G. Hoekstra, Ann. N. Y. Acad. Sc1. 199, 182 (1972).

5. F. Varcoe, Jr., Ph.D. thesis, University of Florida, Gainesvilie, Florida, 1971.

6. I. H. Tipton, in Gross and Elemental Composition of Reference Man, I.C.R.P. Handbook, Report of Subcommittee II (Pergamon Press, New York, 1971).

7. G. W. Leddicotte, in Methods of Blochemical Analysis. edited by D. Glick (Interscience, New York, 1971).

8. W. A. Wolstenholme, Nature 203, 1284 (1964).

9. L. C. Hansen, W. G. Scribner, T. W. Gilbert, and R. E. Sievers, Anal. Chem. 43, 349 (1971).

10. J. T. McCall, N. P. Goldsteln, and I. H. Smith, Fed. Proc. 30, 1011 (1971).

11. E. L. Kanabrock1, L. F. Case, T. Fields, L. Graham, E. B. Miller, Y.T. Oester, and E. Kaplan, J. Nucl. Med. 8, 166 (1967).

12. P. O. Wester, Trace Elements in Human Myocardial Infarction Determined by Neutron Activation, $\mathrm{AE}-188$, Aktiebolaget Atomenerg1, Stockholm, 1965.

13. J. D. Khandekar, D. Mukerj1, and G. C. Sepahn, Indian J. Med. Sc1. 26, 813 (1972).

14. E. L. Kanabrock1, T. Fields, C. F. Decker, L. F. Case, E. B. Miller, Y. T. Oester, and E. Kaplan, Int. J. Appl. Radiot. Isotopes 1 ig, 175 (1964).

15. P. Correa and J. P. Strong, Ann. N. Y. Acad. Sc1. 199, 217 (1972).

16. P. O. Wester, Acta Med. Scand. 178, 765 (1965). 
17. H. A. Schroeder, J. Amer. Med. Assoc. 172, 1902 (1960)。

18. G. Blorck, H. Bostrom, and A. Widstrom, Acta Med. Scand. 178,239 (1965).

19. H. M. Perry, Jr., Ann. N. Y. Acad. Sci. 199, 202 (1972).

20. G. K. Davies, Ann. N. Y. Acad. Sci. 199, 92 (1972).

21. G. L. Curran, J. B1ol. Chem. 210, 765 (1954).

22. D. Brune, B. Fryfberg, K. Samsahl, and P. O. Wester, Determination of Elements in Normal and Leukemic Human Whole Blood by Neutron Activation Analysis, AE - 60, Aktlebolaget Atomenergi, Stockholm, 1961; Chem. Abstr. 59, 12013h (1963).

23. Y. K. Plotnikov, Terapevt. Arkh. 35, 79 (1963); Chem. Abstr. 59, 12013b (1963).

24. R. E. Fredericks, K. R. Tanaka, and W. N. Valentine, J. Clin. Invest. 43, 304 (1964).

25. F. B. DeJorge, J. Sampa1o Goes, Jr., J. L. Guedes, and A. B. DeUlhoa Cintra, Clin. Chim. Acta 12, 403 (1965).

26. W. J. Pories, E. G. Mansour, and W. H. Strain, Ann. N. Y. Acad. Sci. 199, 265 (1972).

27. S. Hamada, K. Torlzuka, K. Hamamoto, T. Mori, R. Moita, T. Nakagawa, and J. Konishi, Radio1sotopes 18, 354 (1969).

28. R. Grunewald, P. L. Zlemer, and J. E. Christian, Anal. Chem. $\underline{36}, 1138$ (1964).

29. A. Dimitriadou, P. C. R. Turner, and T. R. Fraser, Nature 198, 576 (1963).

30. A. Dimitriadou, P. C. R. Turner, and T. R. Fraser, Nature 197, 446 (1963).

31. R. H. Tomlinson and M. W. Billinghurst, Trans. Amer. Nucl. Soc. 12, 458 (1969).

32. J. F. Balcius, D. M. Iinekin, and G. L. Brownell, Trans. Amer. Nucl. Soc. 12, 458 (1969).

33. R. McG. Harden and C. H. Bastomsky, Clin. Chem. 17, 1020 (1971). 
34. H. J. M. Bowen, Biochem. J. 13, 381 (1959).

35. L. O. Plantinard and P. O. Strandberg, Acta Reumatol. Scand. 11, 30 (1965); Chem. Abstr. 63, 15362e (1965).

36. W. Niedermeier and J. H. Giggs, J. Chron. Dis. 23, 527 (1971).

37. R. A. Levine, D. H. P. Streeten, and R. J. Doisy, Metab. Clin. Exp. 17, 114 (1968).

38. D. A. Olehy, R. A. Schmitt, and W. F. Bethard, J. Nucl. Med. I, 917 (1966).

39. W. F. Bethard, D. A. Olehy, and R. A. Schmitt, in L'Analyse par Radioactivation et ses Applications aux Sciences Blologiques (Presses Universitaries de France, 1964), p. 379; Chem. Abstr. 63, 3305g (1965).

40. W. F. Bethard, R. A, Schmitt, and D. A. Ohehy, Strahlentherapie Sonderb. 2,222 (1962); Chem. Abstr. 61, 9766c (1964).

41. N. A. Dubinsky, H. H. Mihelsons, and L. Pelekis, Neltronoaktiv. Anal., Akad. Nauk Latv. SSR, Inst. Fiz., 109 (1966).

42. D. Comar, G. Girault, and C. Kellershohn, Bull. Soc. Chim. Fr. I, 1766 (1962).

43. M. M. Molokh1a and B. Portnoy, Br. J. Dermatol. 83, 376 (1971).

44. S. Meret and R. I. Henken, Cl1n. Chem. 17, 369 (1971).

45. C. Pfelffer, Rev. Can. B1ol. 31, Suppl. 73 (1972).

46. D. M. Taylor, B1ochem. J. 91, 424 (1964).

47. THAI Office of Atomic Energy for Peace, Report THAI AEC 22, 1969.

48. R. Monacell1, H. Tanaka, and J.H. Yoe, Clin. Chim. Acta 1,577 (1956).

49. D. Comar, C. LePoec, M. Joly, and C. Kellershohn, Bull. Soc. Chim. Fr. I, 56 (1962).

50. R. P. Spencer, T. G. Mitchell, and E. R. King, Amer. J. Roentgenol. 79, 1053 (1958). 
51. S. M. Prigozhina, A. A. Kist, and E. M. Lobanov, Akt1v. Anal. Biol., Ob'ektov (1967), p. 62; Chem. Abstr. 70, $45594 \mathrm{~h}$ (1969).

52. T. F. Budinger, J. R. Farwell, A. R. Smith, and

H. B1schsel, Int. J. Appl. Radiat. Isotopes, 23, 49 (1972).

53. H. J. M. Bowen and P. A. Cawse, The Determination of Inorganic Eilements in Biological Tissue by Activation Analysis, AERE-R-4039, Atom1c Energy Research Establishment, Wantage, England (1963).

54. D. E. Nixon, Ph.D. thesis, Iowa State University, Ames, Iowa, 1976.

55. R. D. Irons, E. A. Schenk, and R. D. Giaugue, Clin. Chem. 22, 2018 (1976).

56. R. L. Kniseley, C. C. Butler, and R. G. Roxler, A. D. Report AD-A025474 (1975).

57. G. Guzzi, R. Pietra, and E. Sabbioni, J. Radioanal. Chem. 34, 35 (1976).

58. J. D. Winefordner, V. Svoboda, and L. J. Cline, Crit. Rev. Anal. Chem. 1, 233 (1970).

59.. H. L. Kahn, Trace Inorganics in Water, in Advances in Chemistry Series, No. 73, edited by R. F. Gould (American Chemical Society, Washington, D.C., 1968), p. 138 .

60. J. D. Winefordner and R. C. Elser, Anal. Chem. 43, $24 a$ (1971).

61. V. A. Fassel and D. W. Golightly, Anal. Chem. 39, 466 (197I).

62. E. E. Pickett and S. R. Kolrtyohann, Spectrochim. Acta 24b, 325 (1969).

63. E. E. Pickett and S. R. Ko1rtyohann, Spectrochim. Acta 23b, 235 (1968).

64. R. H. Tomlinson and R. C. Dickdon, in Proceedings of the 1965 International Conference on Modern Trends in Actlvation Analysis, Conlege Station, Texas, 1965, p. 66 . 
65. J. V. Dunckley, Clin. Chem. 17, 992 (1971).

66. L. de Galan, Analytical Spectroscopy (Adam H1lger, Ltd., London, 1971).

67. V. F. Fassel and R. N. Knlseley, Anal. Chem. 46, 1110a (1974).

68. M. Zief and J. W. Mitchell, Contamination Control in Trace Analysis (John Wiley \& Sons, New York, 1976).

69. B. V. L'vov, Atomic Absorption Spectrochemical Analysis (Adam Hilger, London, 1970), p. 228.

70. S. A. Clyburn, B. R. Bartschmid, and C. Veillon, Anal. Chem. 46,2201 (1974).

71. C. Velilon, in Trace Analysis: Spectroscoplc Methods for Trace Elements, edited by.J. D. Winefordner (John Wiley \& Sons, New York, 1976).

72. J. D. Winefordner, S. D. Schulman, and T. C. O'Haver, Luminescence Spectrometry in Analytical Chemistry (Intersclence, New York, 1972).

73. M. L. Parsons, Trace Analysis: Spectroscopic Methods for Elements (John Wiley \& Sons, New York, 1976):

74. H. W. Werner, in Investigations of Solids by Means of an Ion Bombardment Mass Spectrometer, edited by E. L. Grove and A. J. Perkins (Plenum Press, New York, 1969), Vol. 7a, p. 239.

75. G. H. Morrison, Trace Analys1s (Intersclence, New York, 1965), p. 10.

76. I. J. Moore and L. A. Machlan, Anal. Chem. 44, 2291 (1972).

77. N. Gochman and D. S. Young, Anal. Chem. 45, IlR (1973).

78. H. D. Schwartz, B. C. McConville, and E. F. Christopherson, Clin. Chem. Acta 31, 97 (1971).

79. S. O. Hansen and L. Theodorsen, Clin. ChIm. Acta 31 , 119 (1971).

80. P. Venkatcowarlu, L. Singer, and W. D. Armstrong, Anal. Blochem. 42, 350 (1971). 
81. J. D. Czaban and G. A. Rechnitz, Anal. Chem. 45, 471 (1973).

82. H. B. Mark, Jr., J. Pharm. Belg. 25, 367 (1967).

83. R. E. Sievers, G. Wheeler, Jr., and W. D. Ross, in Proceedings, 3rd International Symposium on Advances In Gas Chromatography, Houston, Texas, 1965.

84. H. P. Yule, Anal. Chem. 38, 818 (1966).

85. K. K. S. Pillay, C. C. Thomas, Jr., J. A. Sondel, and C. M. Hyche, Anal. Chem. 43 (il), 1419 (1971).

86. H. O. Fourie and M. Peisach, Radiochem. Radioanal. Letters 26 (4), 277 (1976).

87. S. H. Harrison, P. D. Lafleur, and W. H. Zoller, Anal. Chem. 47 (9), 1685 (1975).

88. A. P. Mackenzie, Transplantation Proceedings 8 (2), Suppl. 1, 181 (1976).

89. A. Foldzinska and W. Zmijewski, Radiochem. Radioanal. Letters 27 (3), 225 (1976).

90. R. Litman, H. L. Finston, and E. T. Williams, Anal. Chem. 47 (14), 2364 (1975).

91. P. D. Lafleur, Anal. Chem. 45 (8), 1534 (1973).

92. M. Friedman, E. Miller, and J. Tanner, Anal. Chem. 46 (2), 236 (1974).

93. National Bureau of Standards, Certificate of Analysis SRM 1577 Bovine Liver (National Bureau of Standards, Washington, D. C. 1972).

94. Z. Randa, J. Kuncir, and J. Benada, Radiochem. Radioanal. Letters 21 (6), 394 (1975).

95. J. O. Larson and E. V. Tandeski, Anal. Chem. $47(7)$, 1159 (1975).

96. R. W. Karin, J. A, Buono, and J. L. Fasching, Anal. Chem. 47 (13), 2296 (1975).

97. T. Westermark and B. Sjostrand, Int. J. Appl. Radiat. Isotopes $\underline{9}, 127(1960)$. 
98. L. C. Bate, Radiochem. Radioanal. Letters $\underline{6}, 139$ (1971).

99. R. C. McFarland, Radiochem. Radioanal. Letters 16, 47 (1973).

100. M. A. Koloniytsen, V. Yu Dundua, N. V. Puchulia, and N. V. Bagadvadze, J. Radioanal. Chem. 22, 95 (1974).

101. K. Malaby, Ames Laboratory, Iowa State University, Ames, Iowa, private communication.

102. D. L. Berry, Ames Laboratory, Iowa State University, Ames, Iowa, unpublished work.

103. D. E. Robertson, Anal. Chem. 40 (7), 106 (1968).

104. B. Sjostrand, Anal. Chem. 36, 814 (1964).

105. H. L. Rook, T. E. Gills, and P. D. LaFleur, Anal: Chem. 44 (7), 1114 (1972).

106. B. Maziere, A. Gaudry, J. Gros, and D. Comar, Radlochem. Radioanal. Letters 28 (2), 155 (1977).

107. T. T. Gorsuch, The Destruction of Organic Matter, (Pergamon Press, New York, 1970).

108. E. I. Hamilton, M. J. Minski, and J. J. Cleary, Analyst 92, 257 (1967).

109. T. T. Gorsuch, Analyst 84, 135 (1959).

110. S. R. Kolrtyohann and C. A. Hopkins, Analyst 101, 870 (1976).

111. W. Holak, J. Assoc. Off1c. Anal. Chem. 60 (1), 239 (1977).

112. P. J. LaBlanc and A. L. Jackson, J. Assoc. Offic. Anal. Chem. 56 (2), 383 (1973).

113. R. A. Isaac and W. C. Johnson, J. Assoc, Offic. Anal. Chem. 58 (3), 436 (1975).

114. E. Orvini, T. E. Gills, and P. D. LaFleur, Anal. Chem. 46 (9), 1294 (1974).

115. C. E. Gle1t and W. E. Holland, Anal. Chem. 34 (11), 1454 (1962). 
116. C. E. Mulford, Atomic Absorption Newsletter ㅁ, 135 (1966).

117. G. J. Lutz, J. S. Stemple, and H. L. Rook, J. Radioanal. Chem. 39 (1), 277 (1977).

118. E. I. Hamilton, M. J. Minski, and J. J. Cleary, Sc1. Total Environ. 1, 341 (1972/1973).

119. J. H. Wilkinson, Anal. Chem. 38 (1), 92 (1966).

120. O. E. Olson, J. Assoc. Offic. Anal. Chem. 2, 627 (1969).

121. C. Feldman, Anal. Chem. 46 (I1), 1606 (1974).

122. H. G. Brown, C. P. Hensley, and J. E. Thale, Trans. Kansas Acad. Sc1. 76 (1), 4 (1973).

123. B. Chernoff, Trans. Am. F1sh. Soc. 4, 803 (1975).

124. A. Abu-Samra, J.S. Morris, and S. R. Ko1rtyohann, Anal. Chem. 47 (8), 1475 (1975).

125. M. Malaiyand 1 and J. P. Barrette, Anal. Letters $\underline{3}$ (12), 579 (1970).

126. M. Malaiyandi and J. P. Barrette, J. Assoc. Offic. Anal. Chem. 55 (5), 951 (1972).

127. M. Malaiyandi and J. P. Barrette, Achrives of Environ. Contamination and Toxicology 2 (4) (1974).

128. J. S. McNulty, Anal. Chem. 19809 (1947):

129. L. M. Cumrnins, J. L. Martin, and D. D. Maag, Anal. Chem. 37 (3), 430 (1965).

130. A. Bouchard, Atomic Absorption Newsletter 12 (5), 115 (1973).

131. D. Polley and V. L. Miller, Anal. Chem. 27 (7), 1162 (1955).

132. J. L. Down and T. T. Gorsuch, Analyst 92, 398 (1967).

133. J. F. Uthe, F.A. J. Armstrong, and M. P. Stainton, J. Fish. Res. Board Canada 27 (4), 805 (1970).

134. F. R. Barrette, Analyst 81, 294 (1956). 
135. H. Agemian and A.S. Y. Chau, Analyst 101, 91 (1976).

136. M. M. Shemyakin and L. A. Shchukina, Quart. Rev. 10, 261 (1956).

137. J. E. Portman and J. P. Riley, Anal. Chim. Acta 31, $509(1964)$.

138. R. M. Sachs, J. L. Michael, F. B. Anastasia, and W. A. Wells, Weed Sc1. 19, 412 (1971).

139. F. A. Cotton and G. W. W1lkinson, Advanced Inorganic Chemistry (2nd Ed.) (Interscience, New York, 1967).

140. Environmental Protection Agency, Methods for Chemical Analys is of Water and Wastes 1971 (Water Quality Office, Analytical Quality Control Laboratory, Cinc1nnat1, Oh10, 1971) p. 121.

141. B, Bernas, Am. Lab., August, 1973, p. 41.

142. R. A. Nadkarn1 and G. H. Morrison, Anal. Chem. 45 (11), 1957 (1973).

143. I. M. Kolthoff, Z. Anal. Chem. 70, 397 (1927).

144. J. C. Ricq, Anal. Chim. Acta 35 (2), 265 (1966).

145. G. Torok and J.R. Diehl, Radioch1m. Acta 15, 96 (1971).

146. C. V. Banks and J. J. Richards, Talanta 2., 239 (1959).

147. W. Bock-Werthmann, in Proc., Symposlum on Nuclear Activation Techniques in the Life Sciences, 1967, p. 173 .

148. N. Spronk, Trans. Am. Nucl. Soc: $\underline{6}, 396$ (1963).

149. F. Tera, R. Ruch, and G. H. Morrison, Anal. Chem: 37 (2), 358 (1965).

150. R. Ruch, F. Tera, and G.H. Morrison, Anal. Chem. 37 (12), 1565 (1965).

151. C. Tang and C. J. Maletskos, Sclence 167, 52 (1970).

152. H. J. M. Bowen and J. A. Cook, Radiochem, Radioanal. Letters $\underline{5}$ (3), 103 (1970). 
153. F. Girardi and E. Sabbioni, J. Radioanal. Chem. 1, 169 (1968).

154. T. E. Gills, W. F. Marlow, and B. A. Thompson, Anal. Chem. 42 (14), 1831 (1970).

155. R. Caletka, C. Konecny, and M. Simkova, J. Radioanal. Chem. 10, 5 (1972).

156. S. S. Hrishnan and D. R. Crapper, Radiochem. Radioanal. Letters 20, 287 (1975).

157. H. R. Ralston and E. S. Sato, Anal. Chem. 43 (1), 129 (1971).

158. C. Konecny and I. Hartl, Z. Phys. Chemle (Leipzig) 256 (1), 17 (1975).

159. L. H. Baetsle and D. Huys, J. Inorg. Nucl. Chem. 30, 639 (1968).

160. L. G. Nagy, G. Torok, and G. Foti, in Proc. Int. Conf. Collo1d. Surf. Sci. I, 33 (1975).

161. C. Konecny and V. Kourim, Radiochem. Radioanal.

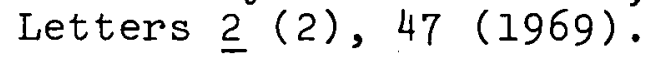

162. D. L. Massart, J. Radioanal. Chem. 4, 256 (1970).

163. T. Sipos, L. G. Nagy, G. Torok, and S. Kollar, in Proc. 1976 Int. Conf. Modern Trends in Activation Analysis, Munchen, Germany, 1976, Vol. 1, p. 240.

164. I. G. Nagy, G. Torok, G. Foti, T. Toth, and L. Feuer, J. Radioanal. Chem. 16, 245 (1973).

165. E. Sabbioni, R. Pietra, and F. Girardi, J. Radioanal. Chem. 4, 289 (1970).

166. E. S. Gladney and J. W. Owens, Anal. Chem. 48 (14), 2220 (1976).

167. F. Girardi, R. Pietra, and E. Sabbioni, J. Radioanal. Chem. 5, 141 (1970).

168. F. Kukula and M. Simkova, J. Radioanal. Chem. 4 , 271, (1970).

169. A. Elek, J. Bogancs, and E. Szabo, J. Radloanal. Chem. 4, $281(1970)$. 
170. G. Knapp, B. Schreiber, and R. W. Frei, Anal. Chim. Acta 77, 293 (1975).

171. S. S. Leitner and J. Savory, Anal. Ch1m. Acta 74,133 (1975).

172. E. Steinnes, Anal. Chem. Acta 78, 307 (19.75).

173. F. W. Wilshire, J. P. Lambert, and R. E. Butler, Anal. Chem. 47 (14), 2399 (1975).

174. J. Kucera, Radiochem. Radioanal. Letters 24 (3), 215 (1976).

175. S. Meloni, V. Caramella-Crespri, M. T. GanzerliValentini, and P. Borroni, Radiochem. Radioanal. Letters 25 (2), 117 (1976).

176. C. Testa and A. Dellesite, J. Radioanal. Chem. 34, 121 (1976).

177. V. P. Guinn, M. Dicksa, J. J. M. De Goelf, and

D. R. Young, in Proc. 1976 Int. Conf. Modern Trends in Activation Analysis, Munchen, Germany, 1976, VOI. 1, p. 24 .

178. F. Girardi and R. Pletra, Atomic Energy Review 14 (3), $521(1976)$.

179. P. S. Tyloe, J. J. M. De Goelf, and J. P. W. Houtman, J. Radioanal. Chem. 16, 153 (1973).

180. J. J. M. De Goe1f, V. P. Guinn, D. R. Young, A. J. Mearns, I. R. I. Report 133-73-09, 1973.

181. J. A, Velandia and A. K. Perkons, J. Radioanal. Chem. 20, $743(1974)$.

182. A. Gaudry, B. Maziere, D. J. Comar, and D. Nau, J. Radioanal. Chem. 29 (1), 77 (1976).

183. G. Guzzi, R. P1etra, and E. Sabbion1, Rep. EUR-5282e, 1974 .

184. K, Samsahl, Sc1. Total Environ, 1, 65 (1972).

185. G. Aubion, J. Diebolt, E. Junod, and J. Laverlochere, In Proc. Symp. Modern Trends in Actlvation Analys 1s, Texas A\&M Univers1ty, College Stat1on, Texas, 1965, p. 344 . 
186. L. O. Plantin, in Nuclear Activation Techniques in the Life Sciences, IAEA, Vienna, 1972, p. 73.

187. L. G. Nágy, G. Torok, and L. Feuer, in Proc. 1976 Int. Conf. Modern Trends in Activation Analysis, Munchen, Germany, 1976, Vol. 1, p. 626.

188. P. O. Bethge, Analytica Chim. Acta 10, 317 (1954).

189. W. Stensland, Energy and Minerals Resources Research Institute, Iowa State University, Ames, Iowa, unpublished work.

190. D. G. Scranton and E. G. Manchester, The Use of Simplotter, A High Level Plotting Sy'stem, USAEC Report IS-2305, 1971 (Available National Technical Information Service, Department A, Springfield, Virginia).

191. W. C. Schick, Jr., SKEWGAUS: A Fortran Program for Fitting Peaks in Semiconductor Detectior Spectra, USAEC Report IS-3460, 1974 (Avallable National Technical Information Service, Department A, Springfield, Virginia).

192. R. C. Weast, ed., CRC Handbook of Chemistry and Physics (The Chemical Rubber Co., Cleveland, Ohio, 1967).

193. E. DeKalb, Ames Laboratory, Iowa State University, Ames, Iowa, private communication. 


\section{ACKNOWLEDGEMENTS}

My deepest thanks. and appreciation is reserved for my parents, Ma, Momma Genia, and Pop, for instilling in me the desire to achieve and the perseverence to continue through the disillusionments and apparent setbacks which marked the progress of this work.

Special thanks must be given to my high school teacher, "Prof." Osborne, who nurtured my fledgling interest in chemistry, and to Dr. John Brauman for his encouragement to attend graduate school even though I questioned my qualifications for success.

My gratitude is extended to Dr. Marge Wechter and Dr. John Fenton for their ideas and discussions which provided the kernel from which this work developed. Sufficient appreciation cannot be expressed for the advice and guidance of Dr. Adolf Volgt throughout this endeavor.

Recognition must be given to those who contributed their special talents to the completion of this work.: My appreciation is extended to Harold S. Hall, Edgar J. Moore and Charles L. Patterson of the Chemistry Glass Shop for their advice and assistance in the design, fabrication and repair of the glasswork employed in this work; the ALRR operators for performing the irradiations; and Health Physics, particularly Paul Millis and Gary Jones, for their advice and assistance in handling radioactive materials 
and for their many "technical" discussions in the receiver room. A special note of thanks is given to Ken Malaby who as a sounding board for new ideas and a general source of information on all aspects of neutron activation opened a number of experimental approaches which might have been overlooked, and closed off numerous dead ends which could have been followed.

Finally, my thanks and appreciation to the people who helped in the preparation of this thesis: Sue Musselman for arranging and typing the manuscript; Vicki Fuller for

many laborious hours of proofreading broken with occasional perlods of uncontrolled laughter; and Kathy Burke and Dave Fay who did all of the "foot-work" while I was away. 